\title{
Hydrogen Production From Biogas Reforming: An Overview of Steam Reforming, Dry Reforming, Dual Reforming, and Tri-Reforming of Methane
}

\author{
Doan Pham Minh*, Tan Ji Siang ${ }^{\dagger}$, Dai-Viet N. $\mathrm{Vo}^{\dagger}$, Thanh Son Phan*, \\ Cyrille Ridart ${ }^{\ddagger}$, Ange Nzihou* and Didier Grouset* \\ ${ }^{*}$ Université de Toulouse, IMT Mines Albi, UMR CNRS 5302, Centre RAPSODEE, Campus Jarlard, \\ Albi, France, ${ }^{\dagger}$ Faculty of Chemical and Natural Resources Engineering, University Malaysia \\ Pahang, Lebuhraya Tun Razak, Gambang, Kuantan, Malaysia, ${ }^{\ddagger} H E R A-A L B H Y O N$, Technopole \\ Innoprod, rue Pierre Gilles de Gennes, Albi, France
}

\subsection{INTRODUCTION}

The present context of climate change, fossil resource scarcity, and environmental issues imposes the development of renewable energy, such as solar, wind, geothermal, and biomass. In France, 24.5 million metric tons of oil equivalent of renewable energy were produced in 2013, which corresponds to $17.6 \%$ of the total energy amount produced this year (ADEME, 2014a). According to the last report of ADEME (agence de l'environnement et de la maittrise de l'énergie, France) on the "lightened environmental footprint" scenario, the objective is to reduce by $17 \%$ the carbon footprint in France by 2030 (ADEME, 2014b). This energy transition dynamic is also being conducted in many other countries, such as Germany, the United Kingdom, the United States, Sweden, Norway, Switzerland, and China (IEA, 2017).

In the transport domain, much effort has been devoted to the development of electric vehicles. In parallel, the development of hydrogen vehicles is also very attractive. Up-to-date, hydrogen vehicles present some major advantages compared to electric vehicles, namely, a shorter charging time and a higher autonomy. The use of hydrogen as a clean fuel starts now, and hydrogen can become a strategic energy vector in the near future. 
Nowadays, around $96 \%$ of hydrogen is produced from fossil resources, and particularly from natural gas, oil and derivatives, and coal. Chemicals synthesized from these fossil resources are usually obtained via synthetic gas, which is produced by steam reforming of natural gas. Details about steam reforming will be discussed later. Scheme 4.1 below illustrates the most common products that can be obtained from syngas, including hydrogen, methanol, liquid fuels, synthetic natural gas (SNG), ammonia, and heat and power.

Hydrogen from water electrolysis accounts only for about $4 \%$ of total hydrogen production. Naturally, water electrolysis using electricity from renewable resources, such as solar, wind, or hydro is a promising way for green hydrogen production. However, the process still needs to be improved in order to reach the competitive cost required by the hydrogen market.

Another way to produce green hydrogen is the valorization of bioresources, such as biogas. This last one is obtained from biomass, residues, or wastes by anaerobic digestion. In general, two types of biogas are distinguished: (1) digested gas from anaerobic digester, which is commonly called biogas, and (2) landfill gas from landfill sites (IEA, 2009).

The production of hydrogen from biogas and landfill gas can be achieved via a syngas route as shown in Scheme 4.2 below. Syngas is obtained from biogas or landfill gas by different reforming processes, which will be detailed later. Then a mixture of $\mathrm{H}_{2}$ and $\mathrm{CO}_{2}$ can be obtained from syngas by the watergas-shift (WGS) reaction. Finally, hydrogen can be separated from the mixture with $\mathrm{CO}_{2}$ by using a pressure swing adsorption (PSA) or an equivalent process.

Both biogas/landfill gas reforming and WGS are catalytic processes. The reforming step can be achieved with catalytic steam reforming process, which is already commercialized for natural gas. However, the energy balance of the steam reforming is not optimized because of a large excess of water vapor, which is required with current catalysts. Because the composition of

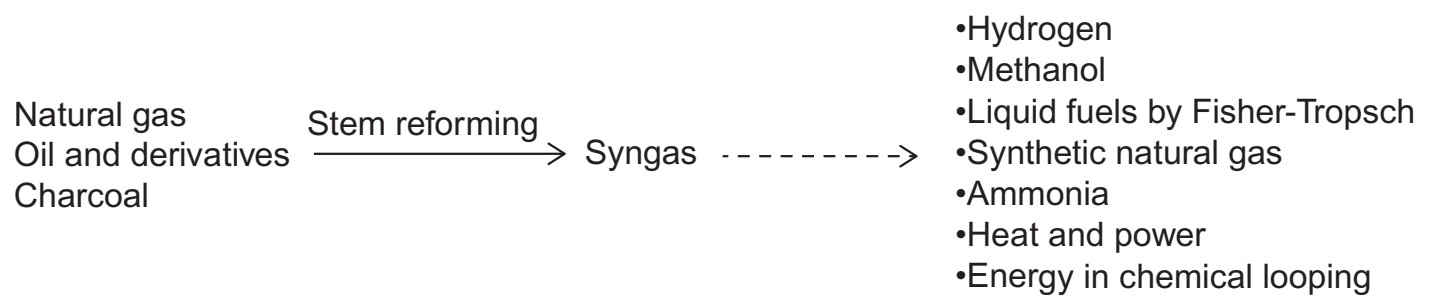

SCHEME 4.1 Chemicals and energy from fossil resources via steam reforming.

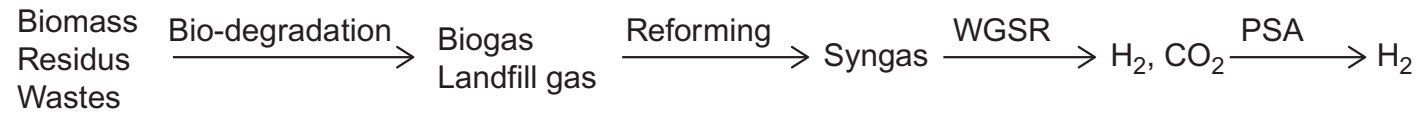

SCHEME 4.2 Main steps for the production of hydrogen from biogas or landfill gas via syngas route. 
biogas/landfill gas varies as shown in Table 4.1, other reforming processes can be considered, as listed below:

- Dry reforming of methane (DRM) with $\mathrm{CO}_{2}$.

- Dual reforming of methane with a mixture of $\mathrm{CO}_{2}$ and $\mathrm{H}_{2} \mathrm{O}$.

- Tri-reforming of methane (TRM) with a mixture of $\mathrm{CO}_{2}, \mathrm{H}_{2} \mathrm{O}$ and $\mathrm{O}_{2}$.

For a given mixture of $\mathrm{CH}_{4}$ with at least one of the three oxidants $\left(\mathrm{CO}_{2}, \mathrm{H}_{2} \mathrm{O}\right.$, and $\mathrm{O}_{2}$ ), different chemical equilibriums can take place. Table 4.2 summarizes the most important chemical reactions usually found in methane reforming processes. The dependence of the Gibbs free energy change per mole of reaction $\left(\Delta_{r} G\right)$ on the reaction temperature has been previously reported in the literature, and some of them have been calculated from the handbook of chemistry data. FactSage software (Factsage, n.d.) (6.3.1 version) is used for the thermodynamic equilibrium calculation of a given mixture at well-defined conditions of temperature and pressure. The calculation is based on the principle of the Gibbs free energy minimization. Standard enthalpies of reaction $\left(\Delta_{r} H_{298}^{\circ}\right)$ are calculated from the handbook of chemistry (Lide, 2003-2004).

TABLE 4.1 Main Characteristics of Digested Gas and Landfill Gas in Comparison With Some Natural Gases

\begin{tabular}{|c|c|c|c|c|}
\hline Compounds & Biogas & $\begin{array}{l}\text { Landfill } \\
\text { gas }\end{array}$ & $\begin{array}{l}\text { Natural Gas } \\
\text { (Danish) }\end{array}$ & $\begin{array}{l}\text { Natural } \\
\text { Gas } \\
\text { (Dutch) }\end{array}$ \\
\hline Methane (vol\%) & $60-70$ & $35-65$ & 89 & 81 \\
\hline $\begin{array}{l}\text { Other hydrocarbons } \\
\text { (vol\%) }\end{array}$ & 0 & 0 & 9.4 & 3.5 \\
\hline Hydrogen (vol\%) & 0 & $0-3$ & 0 & - \\
\hline $\begin{array}{l}\text { Carbon dioxide } \\
(\text { vol\%) }\end{array}$ & $30-40$ & $15-50$ & 0.67 & 1 \\
\hline Nitrogen (vol\%) & $\approx 0.2$ & $5-40$ & 0.28 & 14 \\
\hline Oxygen (vol\%) & 0 & $0-5$ & 0 & 0 \\
\hline $\begin{array}{l}\text { Hydrogen sulfide } \\
\text { (ppm) }\end{array}$ & $0-4000$ & $0-100$ & 2.9 & - \\
\hline Ammonia (ppm) & $\approx 100$ & $\approx 5$ & 0 & - \\
\hline $\begin{array}{l}\text { Lower heating value } \\
\left(\mathrm{kWh} / \mathrm{Nm}^{3}\right)\end{array}$ & 6.5 & 4.4 & 11.0 & 8.8 \\
\hline
\end{tabular}

Adapted from IEA, 2009. IEA bioenergy, Task 37-Energy from biogas and landfill gas. 
TABLE 4.2 The Main Chemical Reactions That Occur During the Reforming of Methane With At Least One of the Following Oxidants: $\mathrm{CO}_{2}, \mathrm{H}_{2} \mathrm{O}$, and $\mathrm{O}_{2}$

\begin{tabular}{|c|c|c|c|}
\hline Reaction & $\begin{array}{l}\Delta_{r} G \text { function }(P=1 \text { bar }) \\
(\mathrm{kJ} / \mathrm{mol})\end{array}$ & $\begin{array}{l}\Delta_{r} H_{298}^{\circ} \\
(\mathrm{kJ} / \mathrm{mol})\end{array}$ & Equations \\
\hline $\mathrm{CH}_{4}+\mathrm{CO}_{2} \rightarrow 2 \mathrm{CO}+2 \mathrm{H}_{2}$ & $\Delta_{r} G=61,770-67.3 \times T$ & +247 & $(4.1)$ \\
\hline $2 \mathrm{CO} \rightarrow \mathrm{C}+\mathrm{CO}_{2}$ & $\begin{array}{l}\Delta_{r} G=-39,810+40.9 \times \\
T\end{array}$ & -172 & $(4.2)$ \\
\hline $\mathrm{CO}+\mathrm{H}_{2} \mathrm{O} \rightarrow \mathrm{CO}_{2}+\mathrm{H}_{2}$ & $\begin{array}{l}\Delta_{r} G=-39,802+37.673 \\
\times T\end{array}$ & -41 & (4.3) \\
\hline $\mathrm{CH}_{4} \rightarrow \mathrm{C}+2 \mathrm{H}_{2}$ & $\Delta_{r} G=21,960-26.5 \times T$ & +75 & (4.4) \\
\hline $\mathrm{CH}_{4}+\mathrm{H}_{2} \mathrm{O} \rightarrow \mathrm{CO}+3 \mathrm{H}_{2}$ & $\begin{array}{l}\Delta_{r} G=210,359-233.9 \times \\
T\end{array}$ & +206 & (4.5) \\
\hline $\mathrm{C}_{\mathrm{s}}+\mathrm{H}_{2} \mathrm{O} \rightarrow \mathrm{CO}+\mathrm{H}_{2}$ & $\begin{array}{l}\Delta_{r} G=132,184-138.8 \times \\
T\end{array}$ & +131 & (4.6) \\
\hline $2 \mathrm{CH}_{4}+\mathrm{O}_{2} \rightarrow 2 \mathrm{CO}+4 \mathrm{H}_{2}$ & $\Delta_{r} G=-653.9-369 \times T$ & -71 & $(4.7)$ \\
\hline $\mathrm{CH}_{4}+2 \mathrm{O}_{2} \rightarrow \mathrm{CO}_{2}+2 \mathrm{H}_{2} \mathrm{O}$ & $\begin{array}{l}\Delta_{r} G=-803,508+13 \times \\
T-0.018 \times T^{2}+8 \times 10^{-6} \\
\times T^{3}\end{array}$ & -802.5 & (4.8) \\
\hline $\mathrm{C}+\mathrm{O}_{2} \rightarrow \mathrm{CO}$ & $\begin{array}{l}\Delta_{r} G= \\
-110,872-89.4 \times T\end{array}$ & -110.5 & (4.9) \\
\hline $\mathrm{C}+\mathrm{O}_{2} \rightarrow \mathrm{CO}_{2}$ & $\begin{array}{l}\Delta_{r} G=-393,647-2.5 \\
\times T\end{array}$ & -393.5 & $(4.10)$ \\
\hline $\mathrm{CH}_{4}+2 \mathrm{H}_{2} \mathrm{O} \rightarrow \mathrm{CO}_{2}+4 \mathrm{H}_{2}$ & $\begin{array}{l}\Delta_{r} G=170,557-196.29 \\
\times T\end{array}$ & +165 & $(4.11)$ \\
\hline
\end{tabular}

(4.1) Dry reforming of methane (DRM); (4.2) Boudouard reaction; (4.3) water-gas-shift (WGS) reaction; (4.4) methane cracking; (4.5) steam reforming of methane; (4.6) steam reforming of carbon; (4.7) partial oxidation of methane; (4.8) methane combustion; (4.9) partial oxidation of carbon; (4.10) carbon combustion; and (4.11) Methane reforming with large excess of steam. All molecules are in the gas state except carbon (C), which is in the solid state.

\subsection{METHANE REFORMING WITH STEAM (SMR) AND WITH A MIXTURE OF STEAM/CARBON DIOXIDE (DUAL-MR)}

\subsubsection{Thermodynamic Equilibrium of Steam Methane Reforming}

The ideal reaction of steam methane reforming (SMR) to syngas is given in Eq. (4.5) (Table 4.2). One mole of $\mathrm{H}_{2} \mathrm{O}$ is needed to transform 1 mol of $\mathrm{CH}_{4}$. In reality, SMR is usually carried out with a large excess of steam (molar steam/carbon ratio or $\mathrm{S} / \mathrm{C}$ close to 3 ). Fig. 4.1 shows the thermodynamic equilibrium of a $\mathrm{CH}_{4}-\mathrm{H}_{2} \mathrm{O}$ mixture with two different molar ratios of $\mathrm{H}_{2} \mathrm{O} / \mathrm{CH}_{4}$. Only products present at significant amounts are presented. They are all in 

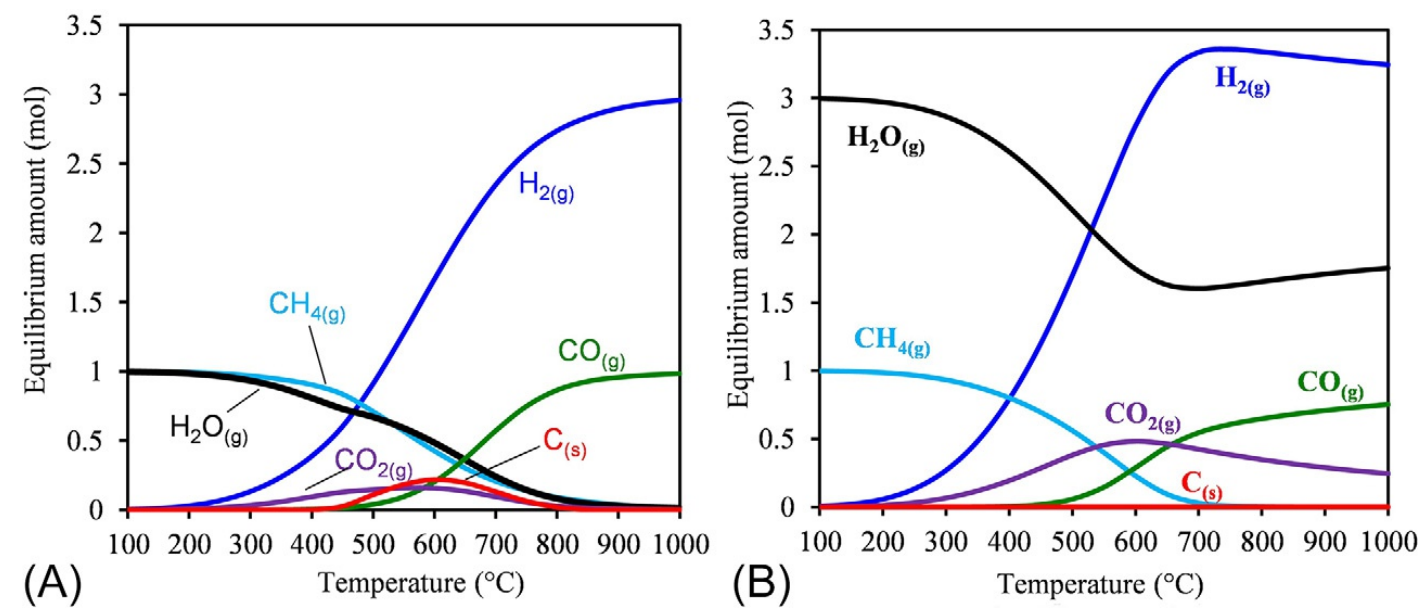

FIG. 4.1 Thermodynamic equilibrium as a function of the temperature at atmospheric pressure of the mixture containing (A) $1 \mathrm{~mol} \mathrm{CH}_{4}$ and $1 \mathrm{~mol} \mathrm{H}_{2} \mathrm{O}$ and (B) $1 \mathrm{~mol} \mathrm{CH}_{4}$ and $3 \mathrm{~mol} \mathrm{H}_{2} \mathrm{O}$.

the gas state except for solid carbon $\left(\mathrm{C}_{(\mathrm{s})}\right)$. Other hydrocarbons, such as ethylene, ethane, methanol, and acetone, can be formed in very small quantities (approximately $10^{-6}$ to $10^{-14} \mathrm{~mol}$ ) and are not presented.

With the equimolar ratio of $\mathrm{H}_{2} \mathrm{O} / \mathrm{CH}_{4}$ (Fig. 4.1 A), hydrogen is formed above $180^{\circ} \mathrm{C}$ and its content increases with the temperature. Carbon dioxide and solid carbon are formed in the temperature ranges of around $250-800^{\circ} \mathrm{C}$ and $450-800^{\circ} \mathrm{C}$, respectively. This makes the process difficult because solid carbon formation causes catalyst deactivation, and carbon dioxide is an undesirable byproduct. Under these conditions, syngas formation is really favorable above $800^{\circ} \mathrm{C}$ from the thermodynamic point of view.

For the molar ratio of $\mathrm{H}_{2} \mathrm{O} / \mathrm{CH}_{4}$ equal to $3 / 1$ (Fig. 4.1B), solid carbon is potentially eliminated and methane can be completely consumed above around $720^{\circ} \mathrm{C}$. This is the main advantage of using a large molar ratio of $\mathrm{H}_{2} \mathrm{O} / \mathrm{CH}_{4}$. However, a large excess of water ( $>50 \%$ ) strongly burdens the energy balance of the process. Also, carbon dioxide is omnipresent above $200^{\circ} \mathrm{C}$ because of the WGS reaction (Eq. 4.3 in Table 4.2).

Fig. 4.2 shows $\mathrm{CH}_{4}$ conversion and coke selectivity as a function of the molar ratio of $\mathrm{H}_{2} \mathrm{O} / \mathrm{CH}_{4}$ (or $\mathrm{S} / \mathrm{C}$ ) and reaction temperature. Increasing the molar ratio of $\mathrm{H}_{2} \mathrm{O} / \mathrm{CH}_{4}$ leads to the increase of the $\mathrm{CH}_{4}$ conversion at a given reaction temperature, and to the decrease of the reaction temperature at a given $\mathrm{CH}_{4}$ conversion (Fig. 4.2A). Solid carbon can be formed at a low molar ratio of $\mathrm{H}_{2} \mathrm{O} / \mathrm{CH}_{4}$ of $1 / 1$ and $1.2 / 1$ and can be avoided above 1.5/1 (Fig. 4.2B).

In Fig. 4.3A, as previously observed for $\mathrm{CH}_{4}$ conversion, at a given reaction temperature, the amount of hydrogen increases with the molar ratio of $\mathrm{H}_{2} \mathrm{O}$ / $\mathrm{CH}_{4}$. At a high molar ratio of $\mathrm{H}_{2} \mathrm{O} / \mathrm{CH}_{4}$ (2/1 to 3/1), the amount of hydrogen reaches a maximum due to the presence of WGS. On Fig. 4.3B, $\mathrm{CO}$ can be obtained above $400^{\circ} \mathrm{C}$, and its amount increases with the reaction temperature. The molar ratio of $\mathrm{H}_{2} \mathrm{O} / \mathrm{CH}_{4}$ slightly influences the $\mathrm{CO}$ amount up to around $600^{\circ} \mathrm{C}$. Then, above this temperature, WGS is favored by increasing the molar ratio of $\mathrm{H}_{2} \mathrm{O} / \mathrm{CH}_{4}$, and thus the amount of $\mathrm{CO}$ decreases. WGS explains also the 

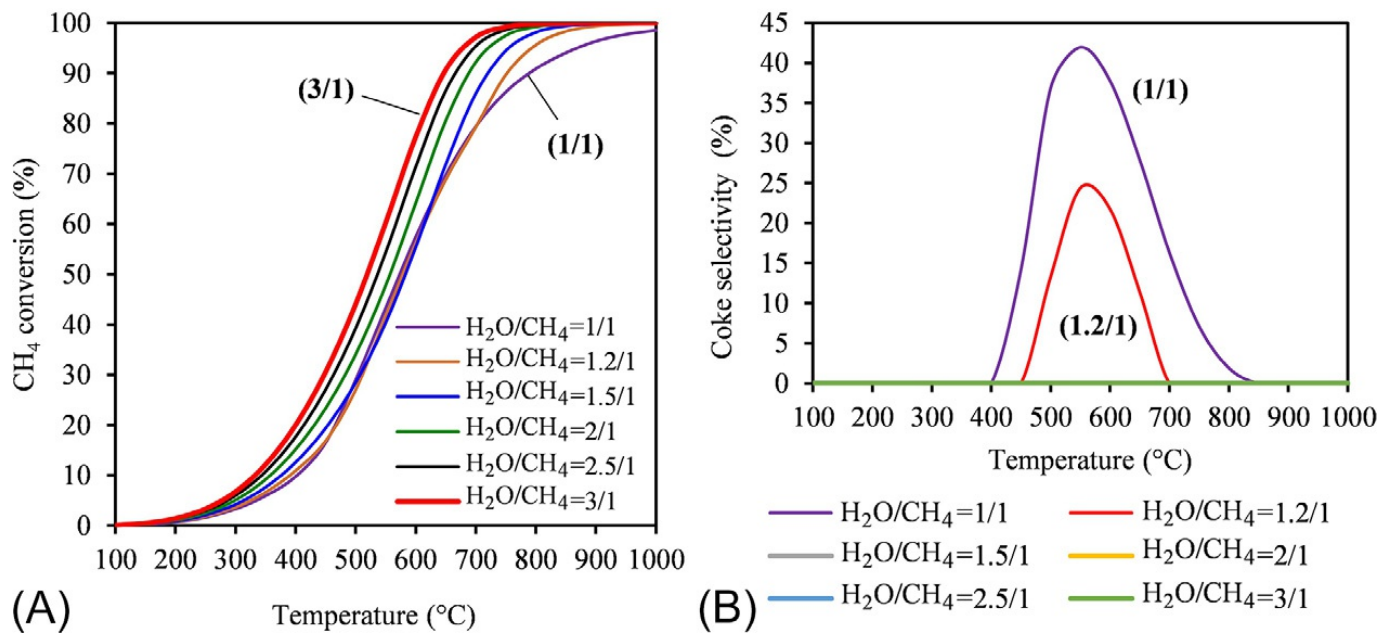

FIG. 4.2 Influence of the molar ratio of $\mathrm{H}_{2} \mathrm{O} / \mathrm{CH}_{4}$ and the temperature on (A) $\mathrm{CH}_{4}$ conversion and (B) coke selectivity at the thermodynamic equilibrium; Initial mixture: $1 \mathrm{~mol}^{\circ} \mathrm{CH}_{4}$ and 1 to $3 \mathrm{~mol}$ of $\mathrm{H}_{2} \mathrm{O}$.
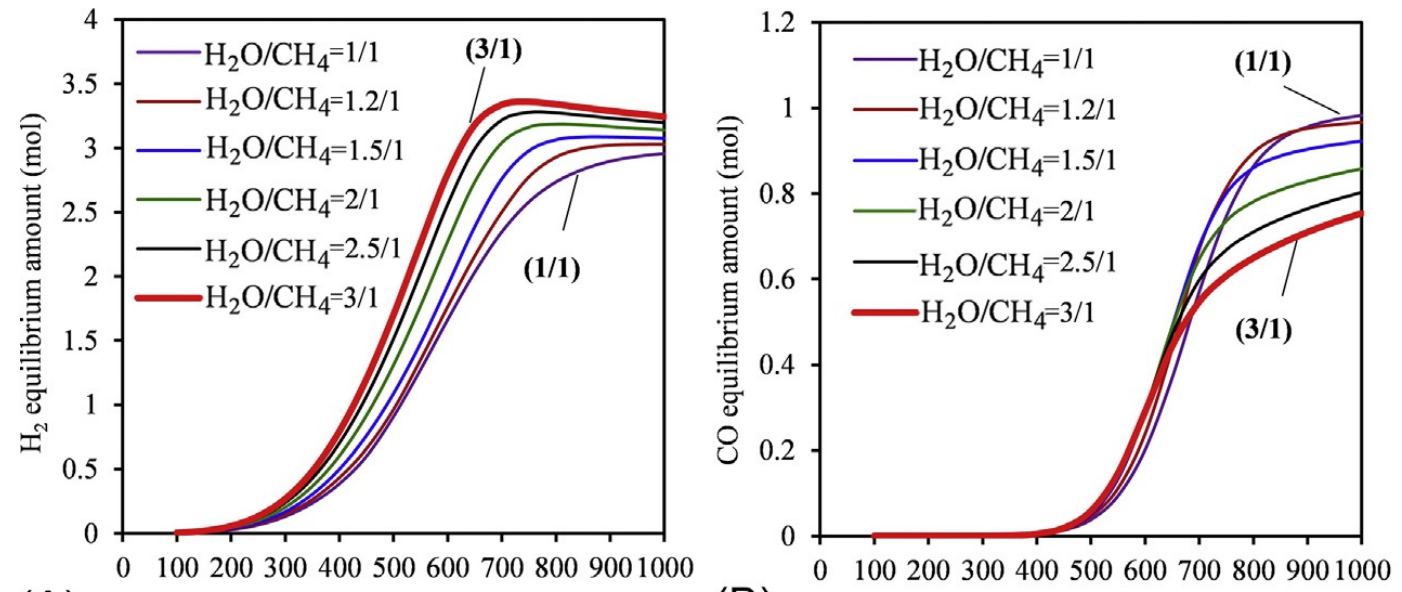

(A)

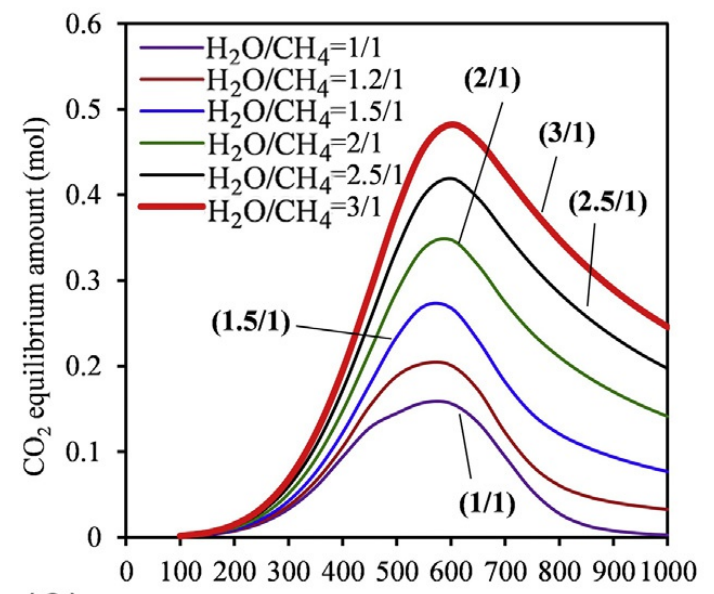

(C)
Temperature $\left({ }^{\circ} \mathrm{C}\right)$
(B)

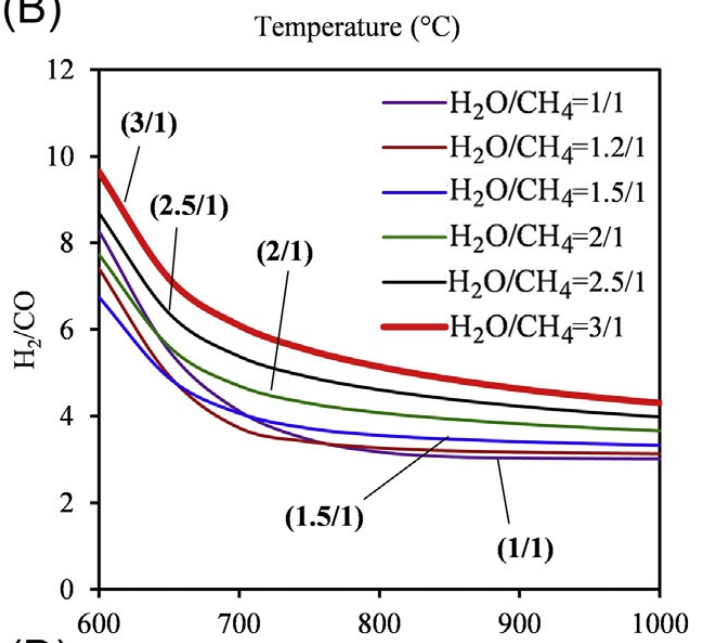

(D)

FIG. 4.3 Influence of the molar ratio of $\mathrm{H}_{2} \mathrm{O} / \mathrm{CH}_{4}$ and the temperature on (A) $\mathrm{H}_{2}$ amount, (B) CO amount, (C) $\mathrm{CO}_{2}$ amount, and (D) molar ratio of $\mathrm{H}_{2} / \mathrm{CO}$ at the thermodynamic equilibrium; Initial mixture: $1 \mathrm{~mol}$ of $\mathrm{CH}_{4}$ and 1 to $3 \mathrm{~mol}$ of $\mathrm{H}_{2} \mathrm{O}$. 
evolution of the amount of $\mathrm{CO}_{2}$ in Fig. 4.3C. At a given reaction temperature, the amount of $\mathrm{CO}_{2}$ increases with an increase in the molar ratio of $\mathrm{H}_{2} \mathrm{O} / \mathrm{CH}_{4}$. Also, for each molar ratio of $\mathrm{H}_{2} \mathrm{O} / \mathrm{CH}_{4}$, the amount of $\mathrm{CO}_{2}$ reaches a maximum around $600^{\circ} \mathrm{C}$. The molar ratio of $\mathrm{H}_{2} / \mathrm{CO}$ is always higher than 3 and is favorable for all downstream uses as listed in Scheme 4.1, with an eventual regulation of this ratio by WGS.

From these results, it appears that, at atmospheric pressure, SMR is highly favored above $700^{\circ} \mathrm{C}$ using a molar ratio of $\mathrm{H}_{2} \mathrm{O} / \mathrm{CH}_{4} \geq 1.5 / 1$.

SMR is not favored at high pressure. However, for different reasons, it can be carried out at 30 bar pressure or even higher in large units. Fig. 4.4 shows the influence of the pressure on the amounts of the main species in SMR at 700, 800, and $900^{\circ} \mathrm{C}$ using a mixture of $1 \mathrm{~mol} \mathrm{CH}_{4}$ and $3 \mathrm{~mol} \mathrm{H}_{2} \mathrm{O}$. Under these conditions, the behavior of the system seems to be similar from each other. As expected, increasing the pressure of the reaction strongly burdens the transformation of methane. At each reaction temperature, the amount of $\mathrm{CH}_{4}$ increases with an increase of the reaction pressure, which is evidenced in Fig. 4.4D. This leads to a strong decrease in the amount of hydrogen with an increase of the
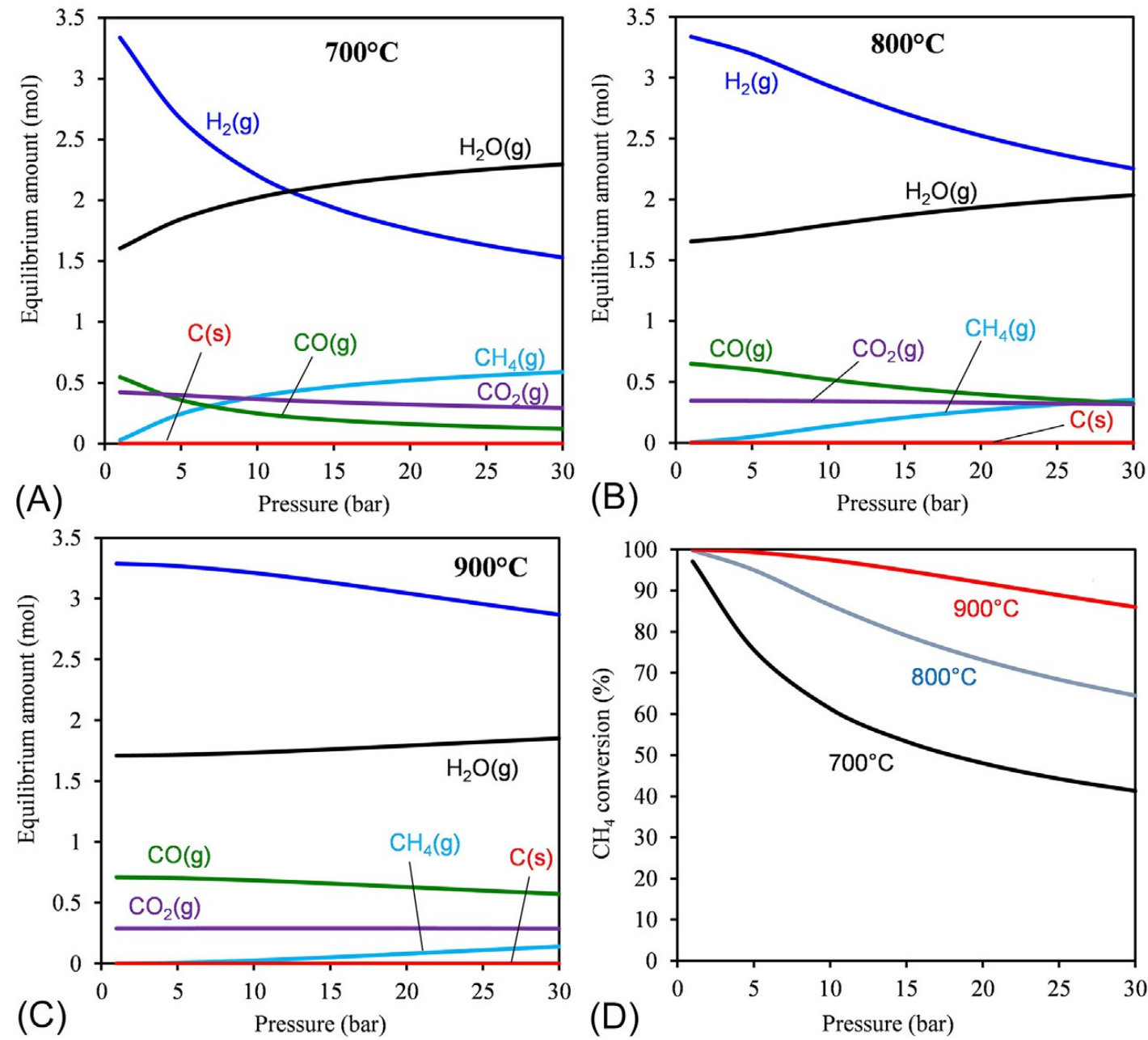

FIG. 4.4 Influence of the reaction pressure in steam methane reforming in the temperature range of $700-900^{\circ} \mathrm{C}$ for a mixture containing $1 \mathrm{~mol}$ of $\mathrm{CH}_{4}$ and $3 \mathrm{~mol}$ of $\mathrm{H}_{2} \mathrm{O}$ : (A) $700^{\circ} \mathrm{C}$, (B) $800^{\circ} \mathrm{C}$, (C) $900^{\circ} \mathrm{C}$, and (D) $\mathrm{CH}_{4}$ conversion at different temperatures. 
reaction pressure. Increasing the reaction temperature to $900^{\circ} \mathrm{C}$ does not allow the complete transformation of $\mathrm{CH}_{4}$ above 5 bar (Fig. 4.4D. No solid carbon is observed under these reaction conditions, as explained previously by a large excess of steam. Because of the WGS, $\mathrm{CO}_{2}$ is omnipresent in large quantities in the temperature range of $700-900^{\circ} \mathrm{C}$.

\subsubsection{Thermodynamic Equilibrium of Dual Methane Reforming (Dual-MR)}

Dual methane reforming (DMR) refers to the transformation of a $\mathrm{CH}_{4}-\mathrm{CO}_{2}$ $\mathrm{H}_{2} \mathrm{O}$ mixture into syngas. This system is particularly interesting for different configurations, such as steam reforming of biogas and also carbon dioxide valorization by its incorporation into the reforming of methane or natural gas. Thus, both $\mathrm{CO}_{2}$ and $\mathrm{H}_{2} \mathrm{O}$ play the role of oxidants. The simultaneous presence of $\mathrm{CO}_{2}$ and $\mathrm{H}_{2} \mathrm{O}$ influences also the WGS equilibrium. Hereafter, we consider two cases: (1) an initial mixture of $\mathrm{CH}_{4}$ and $\mathrm{CO}_{2}$ is kept constant, then $\mathrm{H}_{2} \mathrm{O}$ is added in various amounts; and (2) an initial mixture of $\mathrm{CH}_{4}$ and $\mathrm{H}_{2} \mathrm{O}$ is kept constant, then $\mathrm{CO}_{2}$ is added in various amounts.

Fig. 4.5 shows the thermodynamic equilibrium of mixtures containing $1 \mathrm{~mol}$ of $\mathrm{CH}_{4}, 1 \mathrm{~mol}$ of $\mathrm{CO}_{2}$ and 0.5 to $2.0 \mathrm{~mol}$ of $\mathrm{H}_{2} \mathrm{O}$ at 1 bar. The equimolar mixture of $\mathrm{CH}_{4}$ and $\mathrm{CO}_{2}$ can represent the composition of a purified landfill gas. Adding water to this mixture is not beneficial for methane conversion under $700^{\circ} \mathrm{C}$. In fact, as shown in Fig. 4.5A, the addition of water decreases the methane conversion below $600^{\circ} \mathrm{C}$ because of the formation of water from the $\mathrm{CO}_{2}$ and $\mathrm{CH}_{4}$ mixture by the WGS reaction. Then, above $700^{\circ} \mathrm{C}$, the increase in the amount of water leads to a slight increase in $\mathrm{CH}_{4}$ conversion. Thus, it is possible to reach $100 \% \mathrm{CH}_{4}$ conversion. Also, $\mathrm{CO}_{2}$ conversion decreases with an increase in the amount of water added to the system. This may be explained by the WGS. On the other hand, the amount of water added to the system strongly influences the amounts of solid carbon, hydrogen, and CO. In Fig. 4.5C, the coke selectivity curve is displaced on the left-hand side, which signifies that coke can be efficiently limited by the addition of water. For hydrogen formation, the addition of water is favorable because of the gasification of the coke. The CO amounts are different from each other above $700^{\circ} \mathrm{C}$, as explained by the equilibrium of the WGS. Finally, the molar ratio of $\mathrm{H}_{2} / \mathrm{CO}$ is only slightly affected by the amount of water above $700^{\circ} \mathrm{C}$, as highlighted by the insert in Fig. 4.5F.

Fig. 4.6 shows the thermodynamic equilibrium of mixtures containing $2 \mathrm{~mol}$ of $\mathrm{CH}_{4}, 1 \mathrm{~mol}$ of $\mathrm{H}_{2} \mathrm{O}$, and 0.5 to $2.0 \mathrm{~mol}$ of $\mathrm{CO}_{2}$ at 1 bar. In this case, the initial amounts of $\mathrm{CH}_{4}$ and $\mathrm{H}_{2} \mathrm{O}$ are fixed while the amount of $\mathrm{CO}_{2}$ varies. In Fig. 4.6A, increasing $\mathrm{CO}_{2}$ helps to notably increase the $\mathrm{CH}_{4}$ conversion below about $700^{\circ} \mathrm{C}$, but this is much less important above this temperature. In Fig. 4.6B and $\mathrm{D}$, the initial amount of $\mathrm{CO}_{2}$ slightly influences the $\mathrm{CO}_{2}$ conversion and the amount of $\mathrm{H}_{2}$. However, the initial amount of $\mathrm{CO}_{2}$ has a strong impact on the formation of coke (Fig. 4.6C) and $\mathrm{CO}$ (Fig. 4.6E) and the molar ratio of 

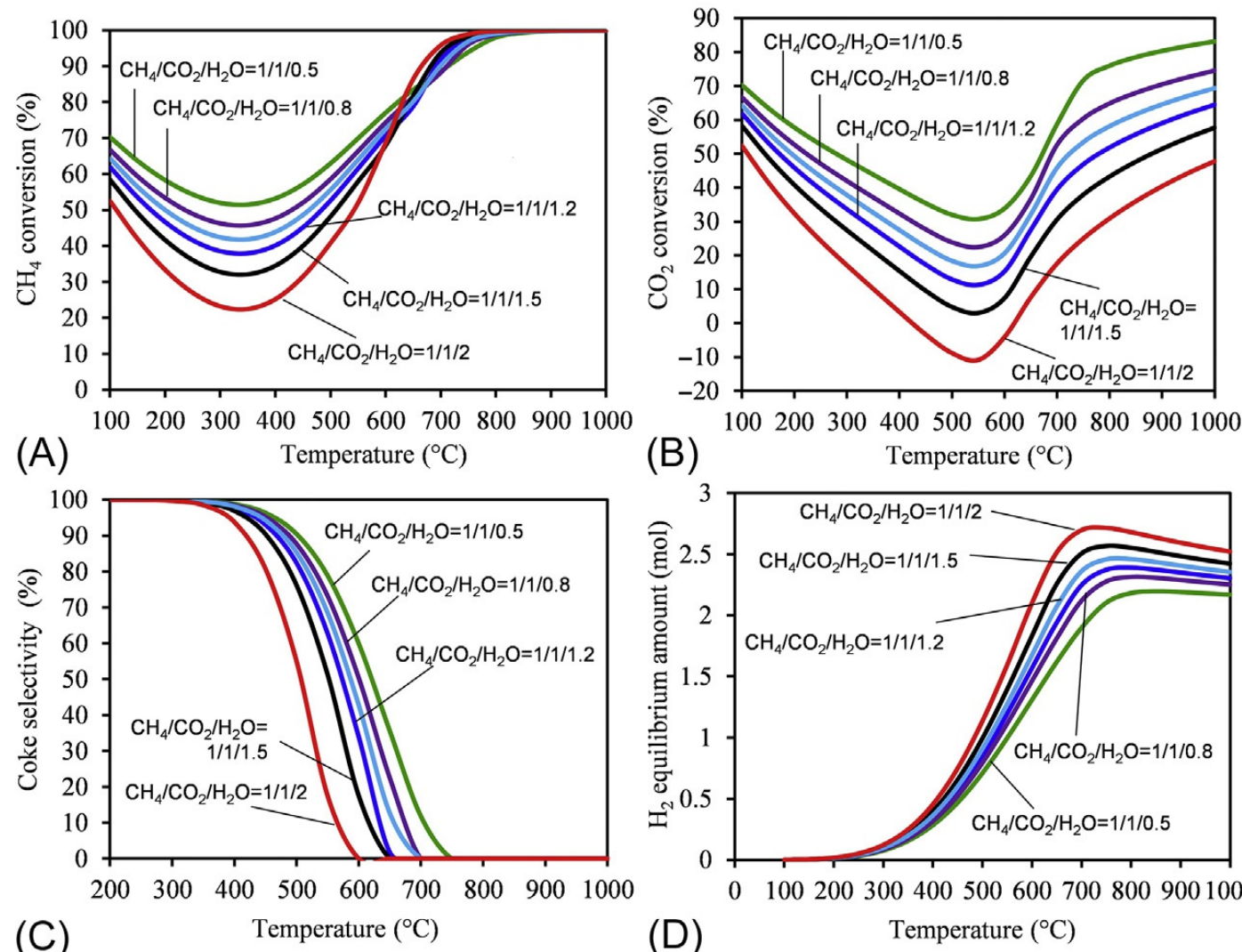

(B) Temperature $\left({ }^{\circ} \mathrm{C}\right)$
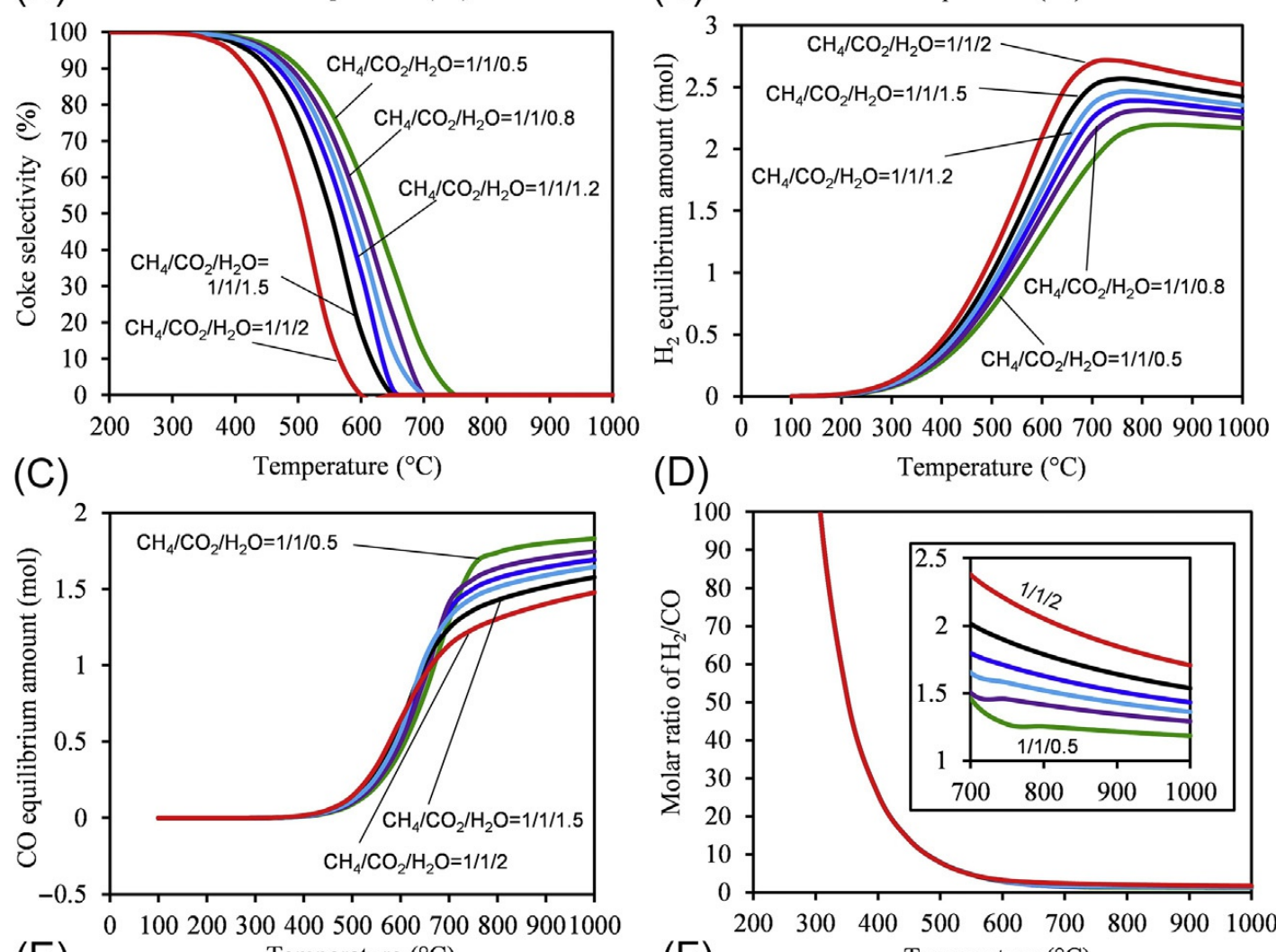

(E) Temperature $\left({ }^{\circ} \mathrm{C}\right)$

$(\mathrm{F})$

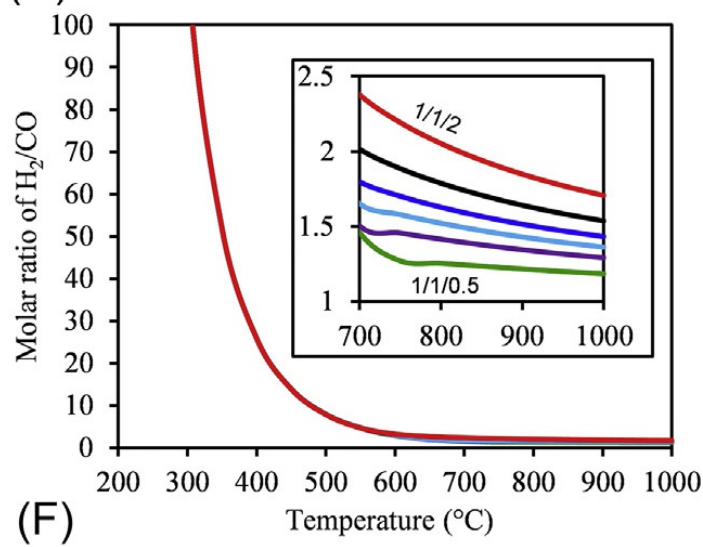

$-\mathrm{CH}_{4} / \mathrm{CO}_{2} / \mathrm{H}_{2} \mathrm{O}=1 / 1 / 0.5-\mathrm{CH}_{4} / \mathrm{CO}_{2} / \mathrm{H}_{2} \mathrm{O}=1 / 1 / 1$

$\mathrm{CH}_{4} / \mathrm{CO}_{2} / \mathrm{H}_{2} \mathrm{O}=1 / 1 / 1.2-\mathrm{CH}_{4} / \mathrm{CO}_{2} / \mathrm{H}_{2} \mathrm{O}=1 / 1 / 2$

FIG. 4.5 Thermodynamic equilibrium of mixtures containing $1 \mathrm{~mol}$ of $\mathrm{CH}_{4}, 1 \mathrm{~mol}$ of $\mathrm{CO}_{2}$, and 0.5 to 2.0 mol of $\mathrm{H}_{2} \mathrm{O}$ at 1 bar: (A) $\mathrm{CH}_{4}$ conversion, (B) $\mathrm{CO}_{2}$ conversion, (C) coke selectivity, (D) $\mathrm{H}_{2}$ amount, (E) $\mathrm{CO}$ amount, (F) molar ratio of $\mathrm{H}_{2} / \mathrm{CO}$.

$\mathrm{H}_{2} / \mathrm{CO}$ (Fig. 4.6F). Above $500^{\circ} \mathrm{C}$, coke selectivity is highly limited by an increasing amount of $\mathrm{CO}_{2}$, and this is explained by the gasification of coke by $\mathrm{CO}_{2}$ to form $\mathrm{CO}$. This helps to explain also the positive effect of the initial amount of $\mathrm{CO}_{2}$ on $\mathrm{CO}$ formation (Fig. 4.6E). Finally, the $\mathrm{H}_{2} / \mathrm{CO}$ molar ratio decreases with the increase of the initial amount of $\mathrm{CO}_{2}$ (Fig. 4.6F), explained by the fact that $\mathrm{H}_{2}$ formation is less influenced, while $\mathrm{CO}$ formation is strongly affected, by the initial amount of $\mathrm{CO}_{2}$. 

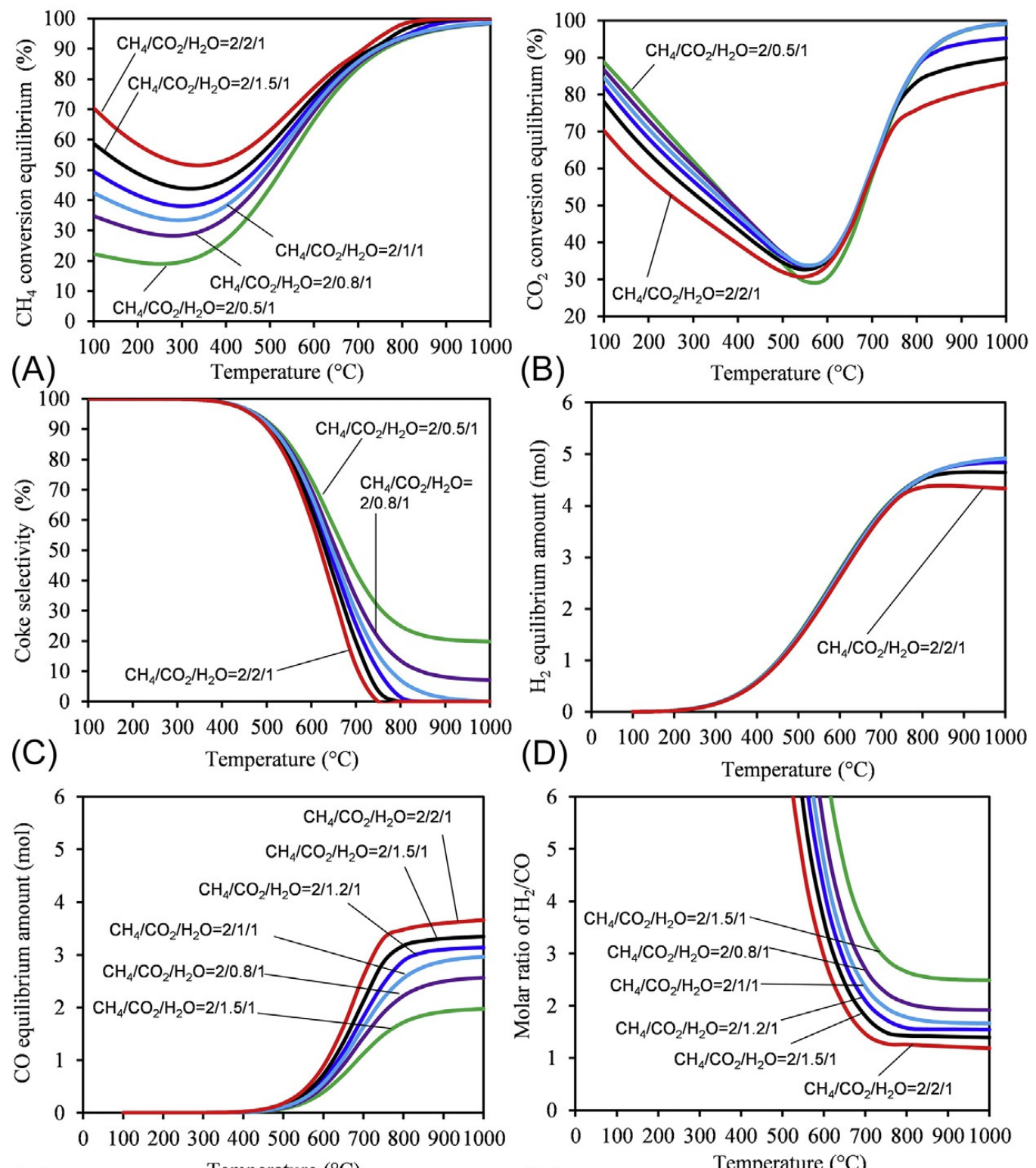

(E)

Temperature $\left({ }^{\circ} \mathrm{C}\right)$

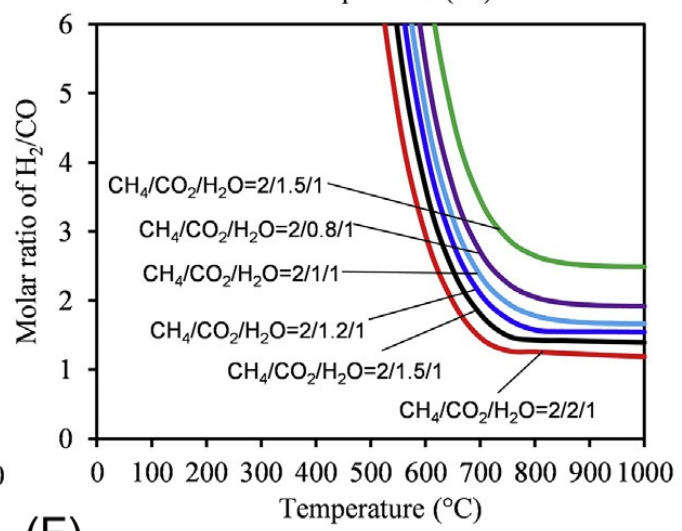

$(\mathrm{F})$

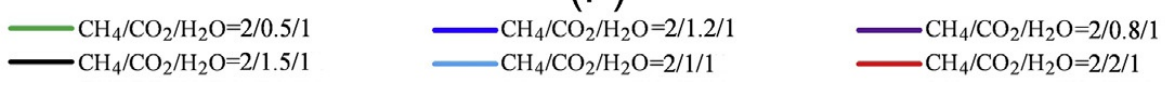

FIG. 4.6 Thermodynamic equilibrium of mixtures containing $2 \mathrm{~mol}$ of $\mathrm{CH}_{4}, 1 \mathrm{~mol}$ of $\mathrm{H}_{2} \mathrm{O}$, and 0.5 to $2.0 \mathrm{~mol}$ of $\mathrm{CO}_{2}$ at 1 bar: (A) $\mathrm{CH}_{4}$ conversion, (B) $\mathrm{CO}_{2}$ conversion, (C) coke selectivity, (D) $\mathrm{H}_{2}$ amount, (E) $\mathrm{CO}$ amount, (F) molar ratio of $\mathrm{H}_{2} / \mathrm{CO}$.

\subsubsection{Steam Methane Reforming: The SMR Process}

As previously mentioned, hydrogen is mostly produced from fossil resources, including natural gas. Using natural gas as feedstock, the hydrogen production process is composed of the following steps:

- Natural gas pretreatment: removal of $\mathrm{H}_{2} \mathrm{~S}$ and sulfur-containing compounds using a zinc oxide bed, which has high affinity for these pollutants.

- Generation of steam: production of steam from demineralization water. Natural gas can be used as fuel, together with waste heat recovered from the reforming reactor and waste combustible gases from $\mathrm{H}_{2}$ separation. 
- Steam reforming (Eq. 4.5 in Table 4.2): reaction of $\mathrm{CH}_{4}$ with $\mathrm{H}_{2} \mathrm{O}$ to give principally $\mathrm{CO}$ and $\mathrm{H}_{2}$. Other byproducts are also formed, such as $\mathrm{CO}_{2}$ and solid carbon. This is a catalytic process that generally needs a heterogeneous catalyst. As shown in Table 4.2, this reaction is highly endothermal $\left(\Delta_{r} H_{298}^{\circ}=+206 \mathrm{~kJ} / \mathrm{mol}\right)$. The thermodynamic study in Section 4.2 .1 shows that the reaction is favorable at high temperature (typically $500-900^{\circ} \mathrm{C}$ ) and high steam-to-carbon $(\mathrm{S} / \mathrm{C})$ ratio (typically 2.5-3). According to Fig. $4.2 \mathrm{~A}$, a high temperature is needed to get high $\mathrm{CH}_{4}$ conversion and high chemical kinetic, while a high S/C ratio allows limiting the catalyst deactivation by coke deposition. The reactor for the SMR process is composed of several vertical tubes filled with solid catalysts. These tubes are placed inside a furnace that is heated (using a gas burner for example) to the desired temperature for the SMR reaction (Linde, n.d.).

- WGS: Syngas from the SMR reactor is cooled down to around $300-500^{\circ} \mathrm{C}$ and then fed into the WGS reactors. Waste heat from this step is recovered and used for steam production. A WGS reactor is classified as either a hightemperature shift reactor (HTSR) or a low-temperature shift reactor (LTSR). Because of the exothermicity of the WGS (Eq. 4.3 in Table 4.2), a LTSR allows a high $\mathrm{CO}$ conversion to be obtained. However, its kinetic is slow. On the other hand, a HTSR allows reaching high kinetic, but low CO conversion. In general, the combination of both a HTSR and a LTSR leads to higher performance than using only one shift reactor (Chen et al., 2008).

- $\mathrm{H}_{2}$ separation: Hydrogen of high purity can be separated from a $\mathrm{H}_{2} / \mathrm{CO}_{2}$ mixture left from a WGS reactor by using the PSA technique (Pressure Swing Adsorption). This technique involves the difference in adsorption capacity of $\mathrm{H}_{2}$ compared to other molecules, as well as the fact that adsorption and desorption can be controlled by the increase or decrease of the process pressure.

Concerning the energy balance of hydrogen production from natural gas at an industrial scale, Table 4.3 shows the typical performance figures for a steam reforming-based hydrogen plant of $50,000 \mathrm{Nm}^{3} / \mathrm{h}$, according to Linde- a world leader in the hydrogen production field (Linde, n.d.). A fuel consumption of $744.4 \mathrm{GJ} / \mathrm{h}$ for a production $50 \mathrm{kNm}^{3} / \mathrm{h}$ represents a specific consumption of $14.88 \mathrm{MJ} / \mathrm{Nm}^{3} \mathrm{H}_{2}$ and as $1 \mathrm{Nm}^{3} \mathrm{H}_{2}$ contains $10.82 \mathrm{MJ} / \mathrm{Nm}^{3}$, the hydrogen production efficiency is $72.7 \%$; but $31 \mathrm{t} / \mathrm{h}$ extra steam are exported, so it is a specific steam production of $0.62 \mathrm{~kg} / \mathrm{Nm}^{3} \mathrm{H}_{2}$ with a heat content of $3.2 \mathrm{MJ} / \mathrm{kg}$ at $390^{\circ} \mathrm{C}$ and an extra $2.03 \mathrm{MJ} / \mathrm{Nm}^{3} \mathrm{H}_{2}$, leading finally to an overall efficiency of $86.2 \%$., including the steam credit. For comparison, hydrogen plants by Air Liquide Engineering \& Construction have an energy consumption of 12.3 to $13.2 \mathrm{MJ} / \mathrm{Nm}^{3} \mathrm{H}_{2}$, which is comparable to Linde plants (Air Liquide, n.d.).

The utilization of a reforming catalyst is mandatory for the transformation of methane and oxidants to syngas. Nickel-based catalysts appear as the best choice for both SMR and Dual-MR processes, taking into account their catalytic 


\begin{tabular}{|c|c|c|c|}
\hline \multirow[b]{3}{*}{ Product hydrogen } & Flow Rate & $\mathrm{Nm}^{3} / \mathrm{h}$ & 50,000 \\
\hline & Pressure & bar & 25 \\
\hline & Purity & mol.\% & 99.9 \\
\hline \multirow[t]{3}{*}{ Export steam } & Flow rate & $\mathrm{T} / \mathrm{h}$ & 31 \\
\hline & $\begin{array}{l}\text { Steam } \\
\text { temperature }\end{array}$ & ${ }^{\circ} \mathrm{C}$ & 390 \\
\hline & Steam pressure & bar & 40 \\
\hline Feed and fuel consumption & & $\mathrm{GJ} / \mathrm{h}$ & 744.4 \\
\hline $\begin{array}{l}\text { Energy consumption (including } \\
\text { steam credit) }\end{array}$ & & $\begin{array}{l}\mathrm{GJ} / \\
1000 \mathrm{Nm}^{3} \\
\mathrm{H}_{2}\end{array}$ & 12.853 \\
\hline \multirow[t]{3}{*}{ Utilities } & $\begin{array}{l}\text { Demineralized } \\
\text { water }\end{array}$ & $\mathrm{T} / \mathrm{h}$ & 55.6 \\
\hline & Cooling water & $\mathrm{T} / \mathrm{h}$ & 160 \\
\hline & Electrical energy & kW & 850 \\
\hline \multirow[t]{2}{*}{ Design flexibility } & $\begin{array}{l}\text { Export steam } \\
\text { production }\end{array}$ & $\begin{array}{l}\mathrm{T} / \\
1000 \mathrm{Nm}^{3} \\
\mathrm{H}_{2}\end{array}$ & $0.5-1.2$ \\
\hline & $\begin{array}{l}\text { Fuel } \\
\text { consumption }\end{array}$ & $\begin{array}{l}\mathrm{GJ} / \\
1000 \mathrm{Nm}^{3} \\
\mathrm{H}_{2}\end{array}$ & $0.9-3.5$ \\
\hline
\end{tabular}

performance and their low cost compared to noble metals, such as $\mathrm{Ru}, \mathrm{Pt}$, and Rh (LeValley et al., 2014; Baysal et al., 2017; Ferreira-Aparicio and Benito, 2005). Alumina is also the most appropriate support for these processes (Baysal et al., 2017; Ferreira-Aparicio and Benito, 2005). Alumina-supported nickel catalysts are generally well shaped for use under industrial conditions. The recent review on catalysts for the SMR process by Angeli et al., 2014 confirmed this observation again. The lifetime of a given alumina-supported nickel catalyst is required to be about 5 years under continuous operation (Liu et al., 2010). SMR catalysts can be supplied by different companies, such as Johnson Matthey, BASF, Haldo Topsoe, Thermo Fisher GMBH, and Süd-Chemie (Ferreira-Aparicio and Benito, 2005; Liu et al., 2010). 
There are several producers of hydrogen via the SMR process at a large industrial scale: Linde, Haldo Topsoe, Howe-Baker, Foster Wheeler, Sanyo Electric, Osaka Gas Co, Air Liquide, Thyssenkrupp, and others (Linde, n.d.; Ferreira-Aparicio and Benito, 2005; Liu et al., 2010; Shah, 2017). As an example, Linde has built more than 200 plants for hydrogen production with capacities from 1000 to over $100,000 \mathrm{Nm}^{3} / \mathrm{h}$ (Linde, n.d.). Air Liquide Engineering \& Construction provides solutions for hydrogen plants with capacities in the range of $10,000-200,000 \mathrm{Nm}^{3} / \mathrm{h}$ of hydrogen (Air Liquide, n.d.).

\subsubsection{Steam Biogas Reforming: The SBR Process}

Most of the features of the SMR process presented in the previous section are still valid for the steam biogas reforming (SBR) process. One of the most important differences is the capacity of the units: biogas production plants have a capacity ranging from $100 \mathrm{Nm}^{3} / \mathrm{h}$ for small agricultural or agro-food waste digesters to a few $1000 \mathrm{Nm}^{3} / \mathrm{h}$ for large municipal waste landfills; moreover, in some cases all of the biogas is not converted to hydrogen and other biogas valorization can coexist on the site. Thus, biogas steam reforming processes have to be designed for capacities ranging from 50 to $1000 \mathrm{Nm}^{3} \mathrm{H}_{2} / \mathrm{h}$. The example presented in this section is relative to a $50 \mathrm{Nm}^{3} \mathrm{H}_{2} / \mathrm{h}$ production unit to be realized in 2018 by ALBHYON HERA's office under the VABHYOGAZ project on the site of TRIFYL's bioreactor, which produces about $1500 \mathrm{Nm}^{3} / \mathrm{h}$ of biogas, $40 \mathrm{~km}$ from the city of Albi (Occitanie region, France). This unit has a capacity about 1000 times smaller than the industrial SMR process presented in the previous section. Yet it produces more than $100 \mathrm{~kg} \mathrm{H}_{2} /$ day, enough to travel $10,000 \mathrm{~km} /$ day on hydrogen. It is adapted to supply several tens of cars per day, refueling each with a few $\mathrm{kg} \mathrm{H}_{2}$, and this is the size of fuel cell car fleets for the next few years. As biogas sources are located in many places all over the territory, this underlines an important feature of biogas steam reforming: it concerns distributed hydrogen production.

A second difference with respect to large SMR processes is the integration of the SBR process on the site, which is radically different in that there is no need for steam on biogas production sites: in most cases, SBR has to be a standalone process and so efficiency optimization is more difficult. When another biogas valorization process coexists on the biogas production site, some interaction between the two processes can be implemented in order to improve efficiency or simplify the process and lower the investment cost; an example is shown here.

Then, of course, an important difference comes from the nature of the feedstock in that biogas contains more $\mathrm{CO}_{2}$ than natural gas. The typical composition of the biogas feeding the SBR process at the TRIFYL bioreactor is given in Table 4.4.

Until now, the choice of designers for biogas reforming has been mainly to add a preliminary step in the process in order to extract the $\mathrm{CO}_{2}$ from the 


$\begin{aligned} & \text { TABLE 4.4 Composition of the Biogas Feeding the Steam Biogas Reform } \\
& \text { Process }\end{aligned}$
\begin{tabular}{l|l|l}
\hline Biogas Composition & Molar Fraction & Mass Fraction \\
\hline $\mathrm{CH}_{4}$ & $59.75 \%$ & $35.05 \%$ \\
\hline $\mathrm{CO}_{2}$ & $40.0 \%$ & $64.60 \%$ \\
\hline $\mathrm{N}_{2}$ & $0.20 \%$ & $0.20 \%$ \\
\hline $\mathrm{O}_{2}$ & $0.04 \%$ & $0.05 \%$ \\
\hline $\mathrm{H}_{2} \mathrm{~S}$ & $725 \mathrm{ppmv}$ & $900 \mathrm{ppm}$ \\
\hline
\end{tabular}

mixture and then to reform the methane in a classical SMR. This preliminary step for $\mathrm{CO}_{2}$ separation, also called enrichment of the biogas, can be done through PSA, or amines absorption, or membrane permeation. This case in which SBR is Enrichment + SMR has the disadvantage of increasing the complexity and the investment cost of the overall process. "Direct SBR" is considered here, without preliminary enrichment and with steam injected into the reforming reactor. Thus, it is a form of DMR, and is, in fact, not new as a commercial process for DMR, in that SPARG was developed 30 years ago by HaldoTopsoe (Rostrup-Nielsen, 2002). Here the feeding ratio $\mathrm{CH}_{4} / \mathrm{CO}_{2}$ is $1 / 0.67$, in the range explored in Section 4.2.2. Yet, for a given $\mathrm{CH}_{4}$ flow rate feeding the process, the total volume flow rate is increased by a factor of 1.67 and the total mass flow rate is increased by a factor of 2.85 due to the presence of $\mathrm{CO}_{2}$. Thus, the aerodynamic, thermal, and chemical behaviors of the mixture are considerably modified in the equipment used for the SBR process as compared to the SMR process. The process developed under the VABHYOGAZ project has been designed so that, through its control system, it can deal with these different behaviors and manage mixtures with $\mathrm{CH}_{4} / \mathrm{CO}_{2}$ ratios ranging from $1 / 0$ to $1 / 1$. The nature of the $\mathrm{CO}_{2}$ must be emphasized: SMR, when applied to natural gas, produces large amounts of $\mathrm{CO}_{2}$ with a fossil origin. On the other hand, SBR also produces $\mathrm{CO}_{2}$, but this $\mathrm{CO}_{2}$ comes from the biodegradation of green waste or of agro-food waste; it has no fossil origin as it was previously captured by plants from the atmosphere. Thus, the SBR process does not add any fossil $\mathrm{CO}_{2}$ or greenhouse gas to the atmosphere and produces renewable hydrogen.

The successive steps of the SBR process are similar to those of the SMR process, with the necessary adaptations to accommodate the different features, as explained above. These steps are sketched in Fig. 4.7 and presented here, together the main operating parameters:

- Biogas cleaning: $\mathrm{H}_{2} \mathrm{~S}$ and other sulfur compounds are removed by adsorption on an active carbon-fixed bed.

- Compression of the biogas: the PSA requires pressure to be efficient and it costs less energy to compress the biogas and liquid water before reforming 


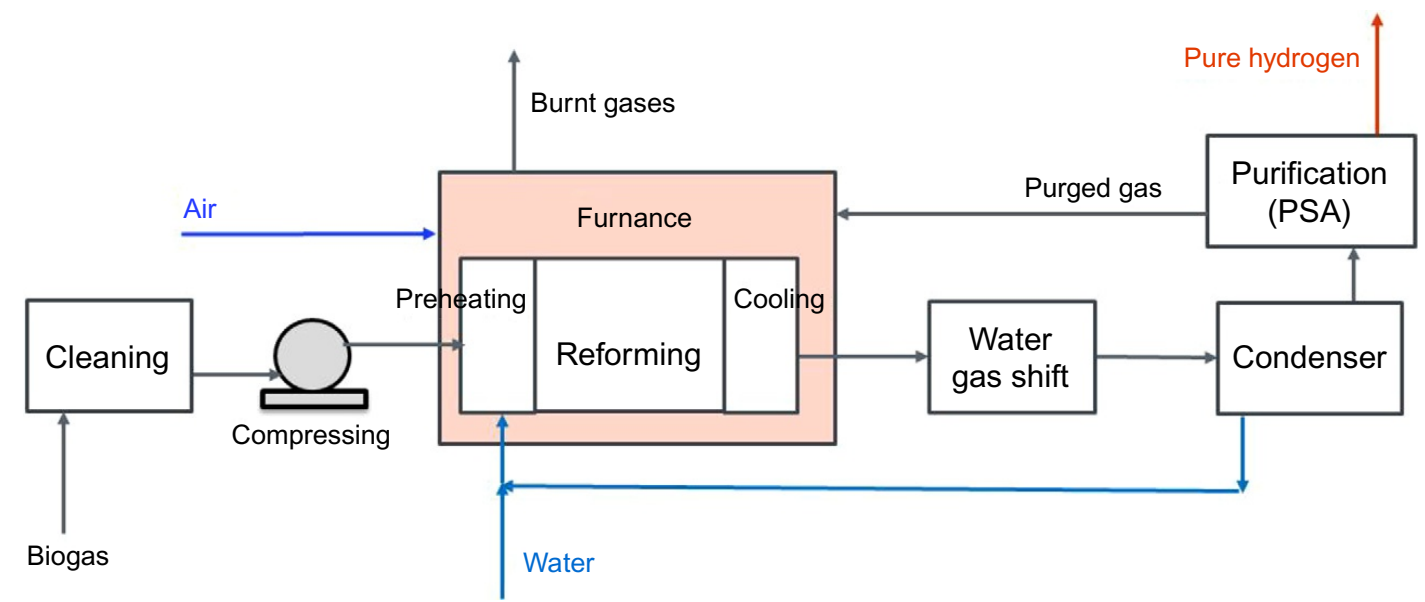

FIG. 4.7 Block diagram of the SBR process in the VABHYOGAZ project.

than compressing the gas mixture after reforming. The pressure level here is 15 bar. As seen in the previous section, increasing the pressure has a negative effect on $\mathrm{CH}_{4}$ conversion, but at this level, the residual $\mathrm{CH}_{4}$ is low.

- Heating of biogas, vaporization and overheating of water: this is mainly realized in a specific zone inside the reforming tubes through heat recovery from the reformate gas before it leaves the tubes and through exchange with the combustion gases.

- $\operatorname{SBR}$ (Eq. 4.5) on a catalytic fixed bed inside the reforming tubes. The heat for this highly endothermal reaction $\left(\Delta_{r} H_{298}^{\circ}=+206 \mathrm{~kJ} / \mathrm{mol}\right)$ is provided through exchange with the combustion gases inside the furnace where the tubes are placed. The reaction temperature is $860^{\circ} \mathrm{C}$ and the $\mathrm{S} / \mathrm{C}$ ratio is 3; for a production of $50 \mathrm{Nm}^{3} \mathrm{H}_{2} / \mathrm{h}$, the reformed biogas flow rate is $31.7 \mathrm{Nm}^{3} / \mathrm{h}$ and the water flow rate is $45.6 \mathrm{~kg} / \mathrm{h}$. With these operating parameters, a chemical equilibrium calculation shows no carbon formation and a $100 \% \mathrm{CH}_{4}$ conversion. Nevertheless, as indicated in Table 4.5, some residual $\mathrm{CH}_{4}$ is assumed, corresponding to an imperfect catalytic effect.

- Cooling of the reformate gas mixture down to $300^{\circ} \mathrm{C}$ before leaving the tubes.

- WGS catalytic reactor to convert $\mathrm{CO}$ and water into $\mathrm{H}_{2}$ and $\mathrm{CO}_{2}$ (Eq. 4.3). The heat from this exothermal reaction $\left(\Delta_{r} H_{298}^{\circ}=-41 \mathrm{~kJ} / \mathrm{mol}\right)$ is valorized for preheating and partial vaporization of water. WGS is conducted in 2 steps: first, $\mathrm{HTSR}$ around $300^{\circ} \mathrm{C}$, and then LTSR around $200^{\circ} \mathrm{C}$. The $\mathrm{CO}$ level is decreased to $1.5 \%$.

- Cooling the reformate mixture down to $10^{\circ} \mathrm{C}$ through exchange with cold water. Most of the water contained in the reformate mixture condenses and can be recycled as reforming water.

- $\mathrm{H}_{2}$ separation using a PSA. The purity achieved for hydrogen is $99.995 \%$. At 15 bar, the PSA efficiency is $79 \%$, which means that $21 \%$ of the produced hydrogen leaves the PSA with the purged gases, which also contain $\mathrm{CO}_{2}$ and residual $\mathrm{CO}$ and $\mathrm{CH}_{4}$.

- The pure hydrogen can then be compressed and stored at high pressure. 


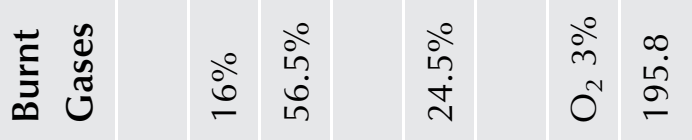

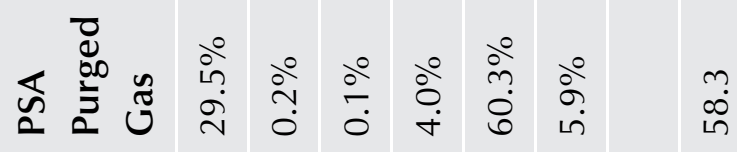

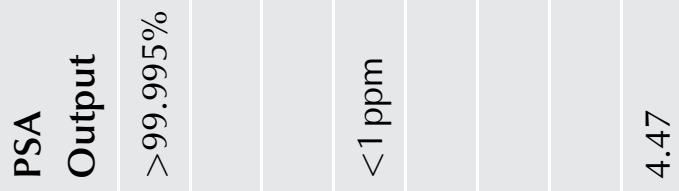

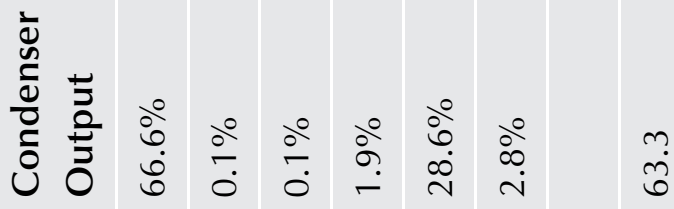

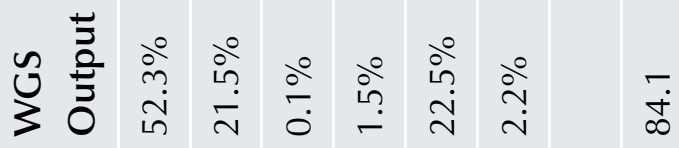

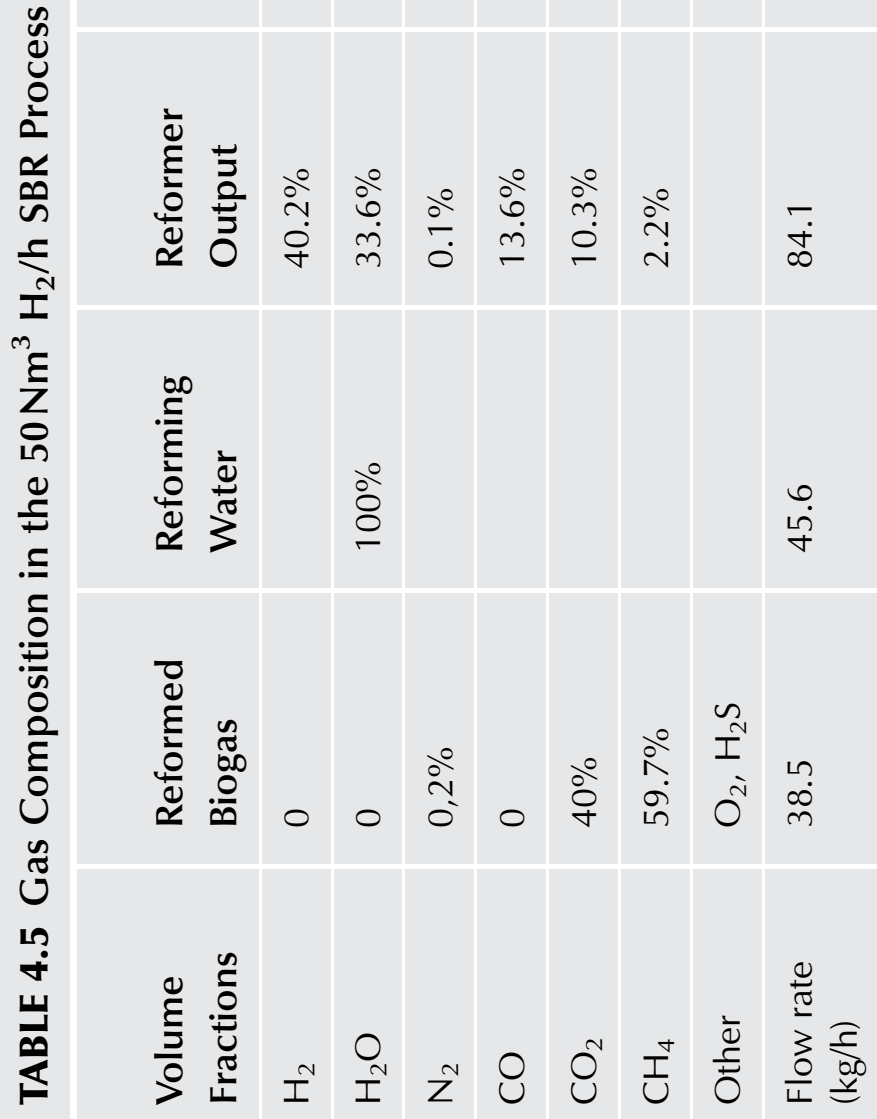


- Heat production in the furnace surrounding the reforming tubes comes from the combustion of the purged gases. The energy needed is $72.3 \mathrm{~kW}$ to balance the SMR endothermicity and to complete the vaporizing and overheating of water and biogas. The energy available in the purged gases is $74 \mathrm{~kW}$ and taking into account the energy losses in the exhaust gases, a complement must be provided by some biogas injected into the furnace; $3.7 \mathrm{Nm}^{3} / \mathrm{h}$ of biogas are added to supply $22 \mathrm{~kW}$. It can be noticed here that as long as the energy contained in the purged gas is lower than the energy to be burnt in the furnace, there is no need to improve the PSA efficiency, nor the $\mathrm{CH}_{4}$ conversion in the reforming tube, nor the $\mathrm{CO}$ conversion in the WGS reactor as any decrease in the $\mathrm{H}_{2}, \mathrm{CH}_{4}$ or $\mathrm{CO}$ content of the purged gas should be balanced by an extra injection of biogas in the furnace.

A better way to valorize the purged gases may be considered when another valorization process coexists on site (electricity production in gas engines for example), especially when the flow of reformed biogas is small with respect to the total available biogas flow, as in the present case. Then, the purged gases can be returned and mixed with the flow of biogas feeding the other process for electricity production. Heat production in the furnace is then realized with biogas only: $14 \mathrm{Nm}^{3} / \mathrm{h}$ of biogas supply $84 \mathrm{~kW}$ to the furnace. With this integration, thanks to the interaction between the two processes, the global efficiency, including the purged gas credit, is increased from $71 \%$ to $82 \%$, as presented in Table 4.6.

It must be pointed out that the SBR process, similar to SMR process, is an energy-intensive process, and high-temperature thermal integration is the key to reach good efficiency. For a $150 \mathrm{~kW}$ hydrogen output, the reforming reaction heat $\left(206 \mathrm{~kJ} / \mathrm{mol} \mathrm{CH}_{4}\right)$ is $48.3 \mathrm{~kW}$ (32.2\% of the hydrogen energy content) and this heat

TABLE 4.6 Energy Efficiency of a $50 \mathrm{Nm}^{3} \mathrm{H}_{2} / \mathrm{h}$ SBR Process With Two Options, a Standalone Process or an Integrated Process With Purged Gas Credit

\begin{tabular}{|c|c|c|}
\hline Parameter & $\begin{array}{l}\text { Stand-Alone } \\
\text { Process }\end{array}$ & $\begin{array}{l}\text { Integrated } \\
\text { Process }\end{array}$ \\
\hline Reformed biogas flow rate $\left(\mathrm{Nm}^{3} / \mathrm{h}\right)$ & 31.7 & 31.7 \\
\hline Combustion biogas flow rate $\left(\mathrm{Nm}^{3} / \mathrm{h}\right)$ & 3.7 & 14 \\
\hline $\begin{array}{l}\text { Purged gas energy returned to the main } \\
\text { biogas flow }(\mathrm{kW})\end{array}$ & 0 & 74 \\
\hline Energy in the produced hydrogen (kW) & 150 & 150 \\
\hline Hydrogen energy efficiency (\% LHV) & 71.3 & 55.7 \\
\hline $\begin{array}{l}\text { Energy efficiency with purged gas credit (\% } \\
\text { LHV) }\end{array}$ & 71.3 & 82.4 \\
\hline
\end{tabular}




\begin{tabular}{l} 
TABLE 4.7 Energy Repartition of the \\
SBR Process With $150 \mathrm{~kW}$ Hydrogen \\
Output \\
\begin{tabular}{|c|c|}
\hline Energy needs & Energy sources \\
\hline $\begin{array}{c}\text { Reaction heat: } \\
48.3 \mathrm{~kW} \\
(32.2 \%)\end{array}$ & $\begin{array}{c}\text { Combustion of } \\
\text { purges gas and } \\
\text { extra biogas } \\
72.3 \mathrm{~kW}\end{array}$ \\
$\begin{array}{c}\text { Preheating of the } \\
\text { reactants } \\
\text { (water and biogas): } \\
71.3 \mathrm{~kW} \\
(47.5 \%)\end{array}$ & $\begin{array}{c}\text { Cooling of } \\
\text { reformate mixture } \\
33.5 \mathrm{~kW}\end{array}$ \\
\cline { 2 - 2 } $\begin{array}{c}\text { Cooling WGS } \\
\text { reactor: } 13.8 \mathrm{~kW}\end{array}$ \\
\hline \multicolumn{2}{|c|}{ Total : $119.6 \mathrm{~kW}$} \\
(79.7\% of hydrogen energy content)
\end{tabular} \\
\hline
\end{tabular}

has to be brought through an external exchange at very high temperature to reach the $860^{\circ} \mathrm{C}$ reacting temperature. Together with preheating, vaporizing, and overheating of water and biogas, it is $119.6 \mathrm{~kW}$ (79.7\% of the hydrogen energy content) to be brought to the reactants, among which $13.8 \mathrm{~kW}$ come from the WGS reactors $(11.6 \%), 33.5 \mathrm{~kW}$ come from the cooling of the reformate mixture (28\%), and the remaining $72.3 \mathrm{~kW}$ come from the furnace (60.4\%) (Table 4.7).

For this small-capacity unit, the electric consumption of the auxiliaries is estimated to be $12.6 \mathrm{~kW}$ and the main parts are for biogas compression $(5.7 \mathrm{~kW})$ and for refrigeration $(3.6 \mathrm{~kW})$. This can be compared to the $750 \mathrm{~kW}$ for the 1000 times larger SMR process, in which natural gas compression is not included, as natural gas is delivered at a sufficient pressure from the pipe. It appears the small-scale effect is sensible: excluding compression, auxiliary consumption is divided by 100 (from 750 to $7.5 \mathrm{~kW}$ ) when capacity is divided by 1000 (from 50,000 to $50 \mathrm{Nm}^{3} \mathrm{H}_{2} / \mathrm{h}$ ).

\subsubsection{Kinetic of Steam Methane Reforming}

Kinetic data on the SMR process are rich after several decades of research and development. Because the process is complex, with numerous intermediate steps, and because of the nature of kinetic parameters, which strongly depend on experimental conditions, it is difficult to achieve a general agreement on kinetic models. Discrepancies, even contradictions, exist as reported in the literature (Liu et al., 2010; Nguyen et al., 2014). The most common kinetic laws considered for the SMR process are: Langmuir-Hinshelwood, Temkin, Eley-Rideal, power law, and microkinetic analysis (Soria et al., 2012; Temkin, 1979). Table 4.8 summarizes some selected models and results reported in the literature. 


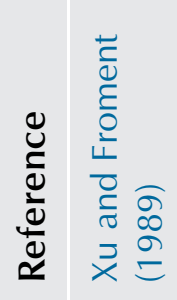

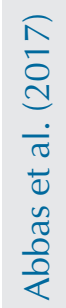

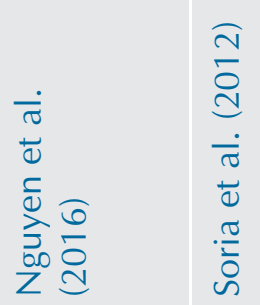

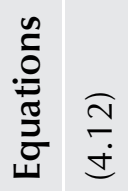

$\stackrel{\overparen{v}}{ \pm}$

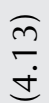

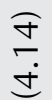

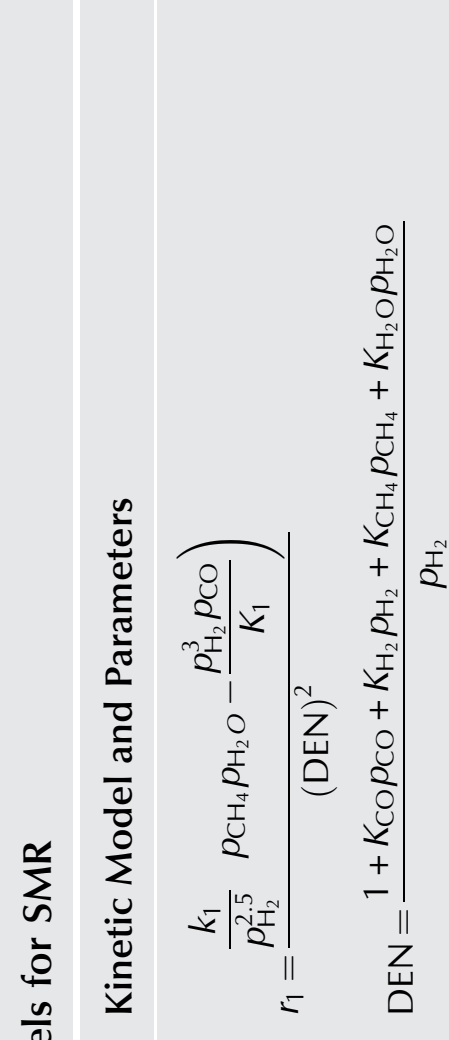

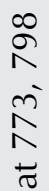

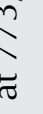

ב

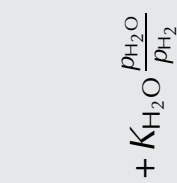

in
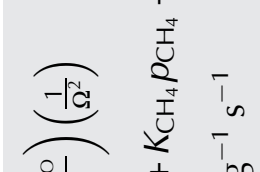

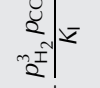

I

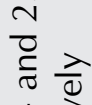

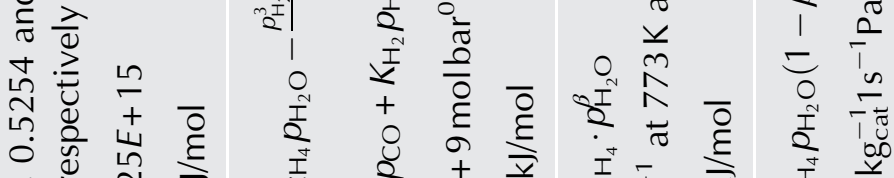

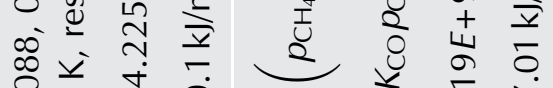

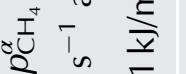

壳

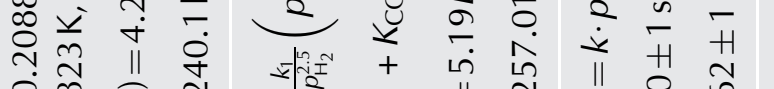

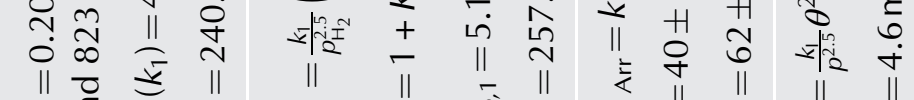

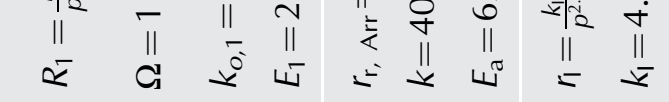

$\frac{\frac{1}{0}}{0}$

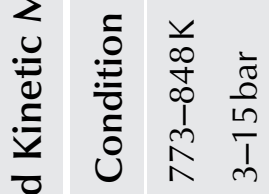

$\frac{v}{m}$
$\hat{a}$
ñ
ก

$\frac{v}{m}$
$\frac{1}{0}$
$\frac{\pi}{1}$

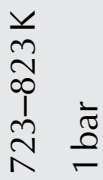

$\frac{0}{0}$

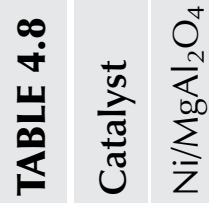

$\frac{\bigcap_{n}^{m}}{\frac{0}{Z}}$

$\stackrel{N}{\Sigma}$

$\frac{\sqrt{n}}{\sqrt[n]{n}}$ 


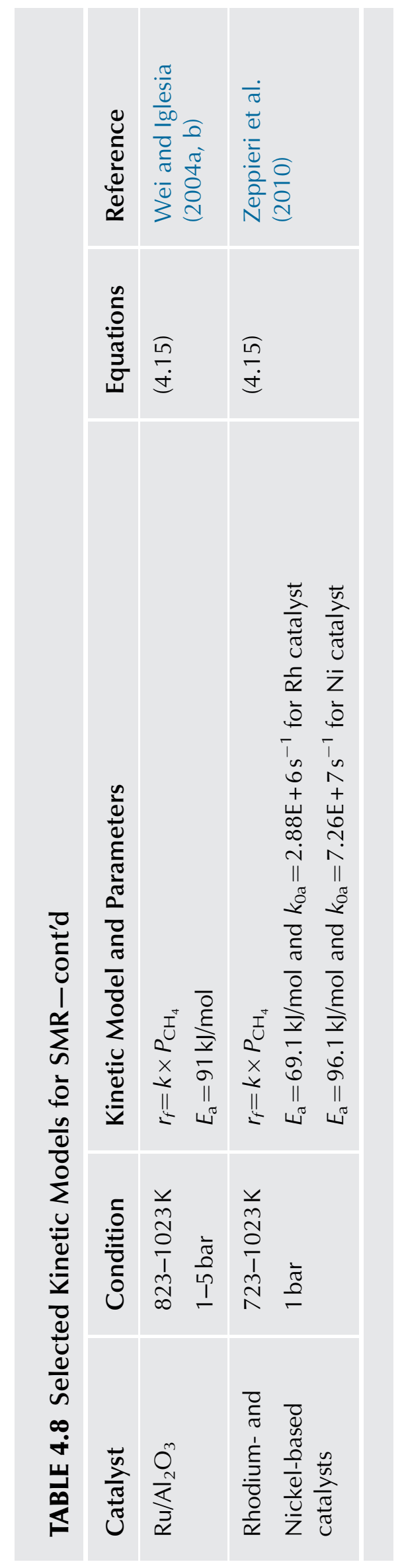


The model proposed by Xu and Froment (1989) is based on LangmuirHinshelwood methodology and is usually considered as the most widely used model for the SMR process. In this model, various chemical reactions were considered in order to explain the formation of different products, including $\mathrm{H}_{2}$, $\mathrm{CO}, \mathrm{CO}_{2}, \mathrm{H}_{2} \mathrm{O}$, and solid carbon (C). The following assumptions were made to build reaction schemes of the SMR process (Xu and Froment, 1989):

- Water reacts with surface nickel atoms, yielding adsorbed oxygen and gaseous hydrogen.

- Methane is adsorbed on surface nickel atoms. The adsorbed methane either reacts with the adsorbed oxygen or is dissociated to form chemisorbed radicals.

- The concentrations of the carbon-containing radicals are much lower than the total concentration of the active sites.

- The adsorbed oxygen and the carbon-containing radicals react to form oxygen-containing radicals.

- The hydrogen formed is directly released into the gas phase and/or the gaseous hydrogen is in equilibrium with adsorbed atomic or molecular hydrogen.

- All reaction schemes have a rate-determining step among the following reactions: SMR, WGS, and the direct formation of $\mathrm{CO}_{2}$ and $\mathrm{H}_{2}$ from $\mathrm{CH}_{4}$ and $\mathrm{H}_{2} \mathrm{O}$ (reactions 4.3, 4.5, 4.11 in Table 4.2).

After the work reported by Xu and Froment (1989), other research confirmed the validity of this model for the SMR process, such as the recent work of Abbas et al. (2017).

Nguyen et al. (2016) studied the kinetic of the SMR process by expressing the reaction rate as a function of the exponential of methane and steam pressure (power law). They highlighted also that the reaction order (for methane and steam) varies significantly, as reported by several studies. The value of $\alpha$ (reaction order with respect to partial pressure of methane) was typically found in the range of $0.85-1.4$, while the value of $\beta$ (reaction order with respect to partial pressure of steam) can be negative, zero, or positive depending strongly on the ratio of steam/carbon (S/C). Small S/C ratios yield positive $\beta, \mathrm{S} / \mathrm{C}$ ratios on the order of 2 yield $\beta$ close to zero, and high $\mathrm{S} / \mathrm{C}$ ratios yield negative $\beta$. In their study, Nguyen et al. (2016) found the value of $\alpha$ and $\beta$ to be equal to 2 and 1, respectively, for S/C ratios of 2-3, and an activation energy, $E_{\mathrm{a}}$, equal to $62 \pm 1 \mathrm{~kJ} / \mathrm{mol}$.

As previously assumed by Xu and Froment (1989) and other researchers and based on a thermodynamic analysis of the SMR process under the studied conditions, three reactions build the kinetic mechanism of the process, which are the reactions (4.3), (4.5), (4.11) in Table 4.2. Thus, methane is dissociated on nickel sites. In the study of Soria et al. (2012), the SMR process was carried out at $723-823 \mathrm{~K}$ and 1 bar over a $\mathrm{Ru} / \mathrm{SiO}_{2}$ catalyst. Their kinetic models were 
built by supposing that both methane and steam react as adsorbed species. Thus, steam can be adsorbed on the catalyst surface with or without dissociation, while methane presents more possibilities for dissociation, forming $\mathrm{C}$ or the intermediate specie $\mathrm{CH}_{2}$. The combination of these possibilities yields a total of six kinetic mechanisms. Among these, the best kinetic model was found by fitting with the experimental data, and the reaction rate equation is shown in Table 4.8 (Eq. 4.14). For this kinetic model, the following assumptions were made:

- Steam is dissociated into gaseous $\mathrm{H}_{2}$ and adsorbed $\mathrm{O}$ when it is adsorbed on the catalyst surface.

- Methane is adsorbed to form the intermediate $\mathrm{CH}_{2(\text { ads) }}$, which later reacts with oxygen to form $\mathrm{CHO}_{(\text {ads) }}$.

- $\mathrm{CHO}_{(\mathrm{ads})}$ species react in parallel to form $\mathrm{CO}$ and $\mathrm{CO}_{2}$. These surface reactions that produce $\mathrm{CO}$ and $\mathrm{CO}_{2}$ are considered to be the rate controlling steps.

- Also, WGS takes place.

- Desorption of adsorbed $\mathrm{CO}, \mathrm{CO}_{2}$ species, and a combination of adsorbed $\mathrm{H}$ species to form gaseous $\mathrm{CO}, \mathrm{CO}_{2}$ and $\mathrm{H}_{2}$.

The activation energy was found to be $140 \mathrm{~kJ} / \mathrm{mol}$ for the SMR reaction over a $\mathrm{Ru} / \mathrm{SiO}_{2}$ catalyst (Soria et al., 2012).

In their earlier study, Wei and Iglesia (2004a, b) experimentally studied the SMR process using a $\mathrm{Ru} / \mathrm{Al}_{2} \mathrm{O}_{3}$ catalyst at $823-1023 \mathrm{~K}$ and $1-5$ bar. They found that the reaction rate depends only on the partial pressure of methane and not on the partial pressure of steam. Thus, the global kinetic equation is simple, as shown in Eq. (4.15) in Table 4.8. They also obtained a similar result for the $\mathrm{CO}_{2}$ reforming of methane in this study. This kinetic mechanism was later confirmed by Zeppieri et al. (2010), using rhodium- and nickel-based catalysts. Note that in these two papers, both research groups used a very small quantity of catalyst. Wei and Iglesia (2004a, b) used $5 \mathrm{mg}$ of catalyst $(250-425 \mu \mathrm{m})$ diluted in $500 \mathrm{mg}$ of acid-washed quartz powder $(250-425 \mu \mathrm{m})$ to fill a quartz or steel tube ( $8 \mathrm{~mm}$ inner diameter). Zeppieri et al. (2010) used 5-30 $\mathrm{mg}$ of catalyst samples diluted with 500-1500 mg of acid-washed silicon dioxide to fill a quartz tube reactor of $8 \mathrm{~mm}$ inner diameter. The absence of preferential passage of reactants through the catalytic bed should be confirmed, considering the small quantities of catalysts versus the reactor inner diameter of $8 \mathrm{~mm}$.

As a partial conclusion, there have been several kinetic studies of the SMR process. Because the process is complex, with the implication of different chemical equilibriums, different kinetic models have been built and discussed. The validation of a given model is generally done by fitting with the experimental data. Thus, it is only meaningful to retain a kinetic mechanism taking into account the experimental conditions. More effort is still needed to determine the intrinsic kinetic of the SMR process. 


\subsection{DRY REFORMING OF METHANE}

\subsubsection{Thermodynamic Equilibrium Aspect}

DRM relates to the reaction between $\mathrm{CH}_{4}$ and $\mathrm{CO}_{2}$ to form $\mathrm{CO}$ and $\mathrm{H}_{2}$ (Eq. 4.1 in Table 4.2). According to Eq. (4.1), $1 \mathrm{~mol}$ of $\mathrm{CO}_{2}$ is needed to reform $1 \mathrm{~mol}$ of $\mathrm{CH}_{4}$. Fig. 4.8 shows the thermodynamic equilibrium of an equimolar mixture of $\mathrm{CH}_{4}$ and $\mathrm{CO}_{2}$ at atmospheric pressure. Only the main species are presented. Methane conversion increases above $350^{\circ} \mathrm{C}$ and reaches more than $98 \%$ at $900^{\circ} \mathrm{C}$. Solid carbon and water are highly selected below $600^{\circ} \mathrm{C}$. Above this temperature, $\mathrm{CO}$ and $\mathrm{H}_{2}$ become the main products. Taking into account the conversion of $\mathrm{CH}_{4}$ and $\mathrm{CO}_{2}$, and the selectivity of the reaction, this process should be carried out at $850^{\circ} \mathrm{C}$ or above.

Fig. 4.9 shows the influence of the molar ratio of $\mathrm{CO}_{2} / \mathrm{CH}_{4}$ on the thermodynamic equilibrium of a $\mathrm{CO}_{2}$ and $\mathrm{CH}_{4}$ mixture. Increasing this ratio increases
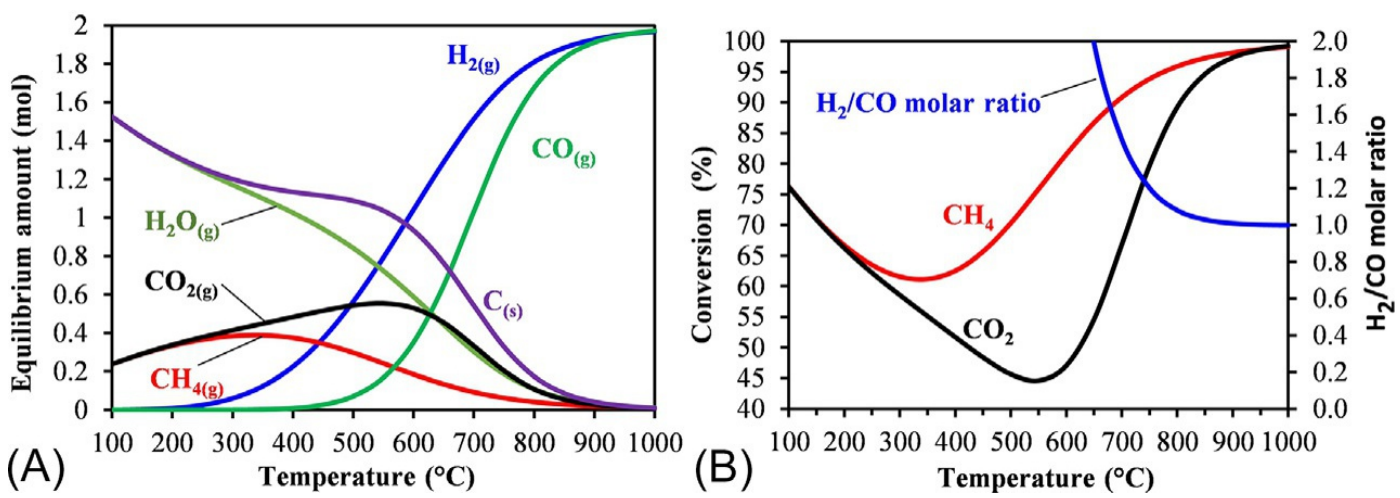

FIG. 4.8 Thermodynamic equilibrium at 1 bar of the equimolar mixture of $\mathrm{CH}_{4}$ and $\mathrm{CO}_{2}(\mathrm{~A})$ and the corresponding $\mathrm{CH}_{4}$ and $\mathrm{CO}_{2}$ conversion and molar ratio of $\mathrm{H}_{2} / \mathrm{CO}(\mathrm{B})$.
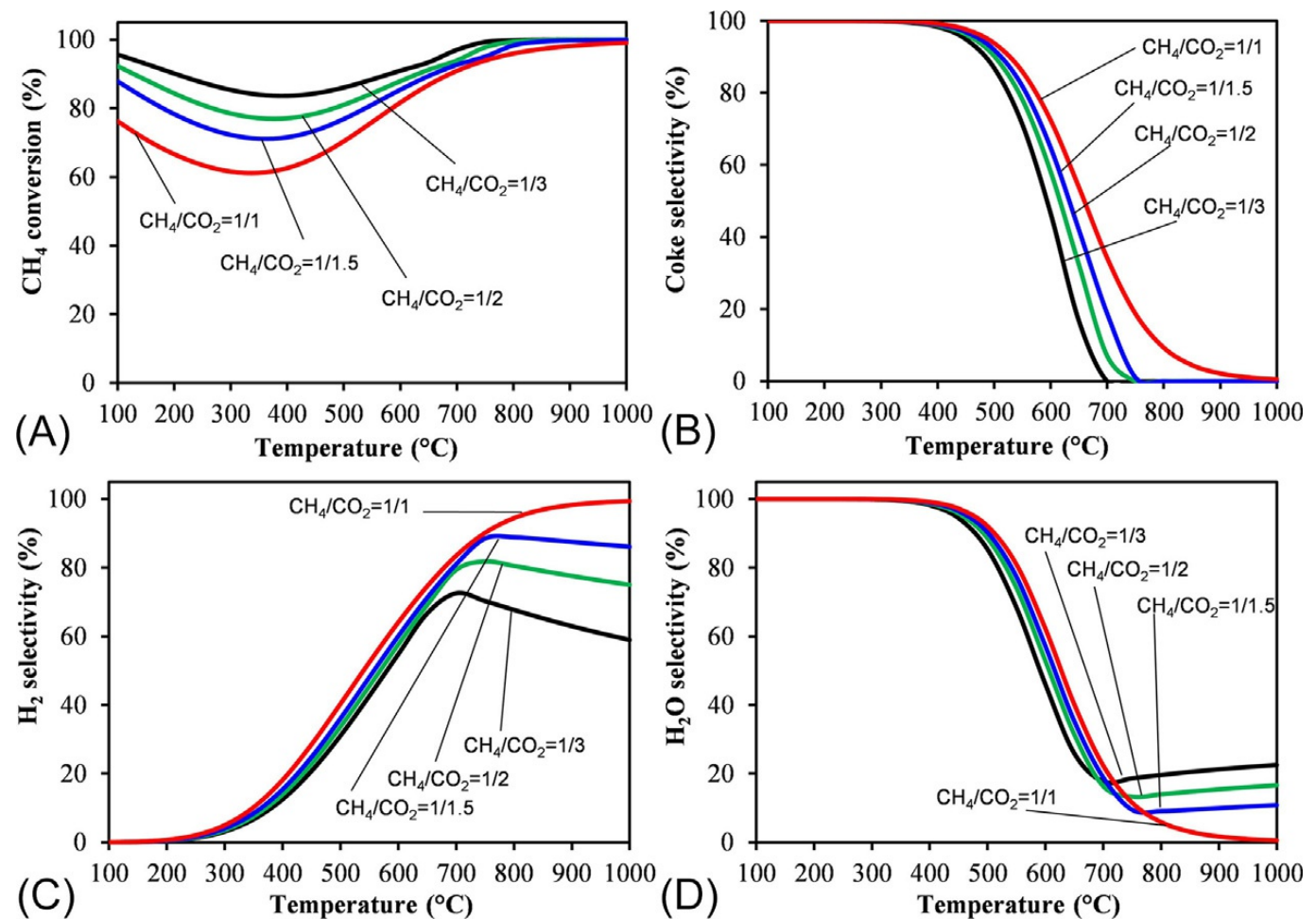

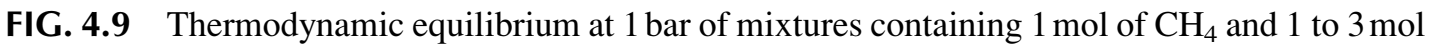
of $\mathrm{CO}_{2}$ : (A) $\mathrm{CH}_{4}$ conversion, (B) coke selectivity, (C) $\mathrm{H}_{2}$ selectivity, and (D) $\mathrm{H}_{2} \mathrm{O}$ selectivity. 

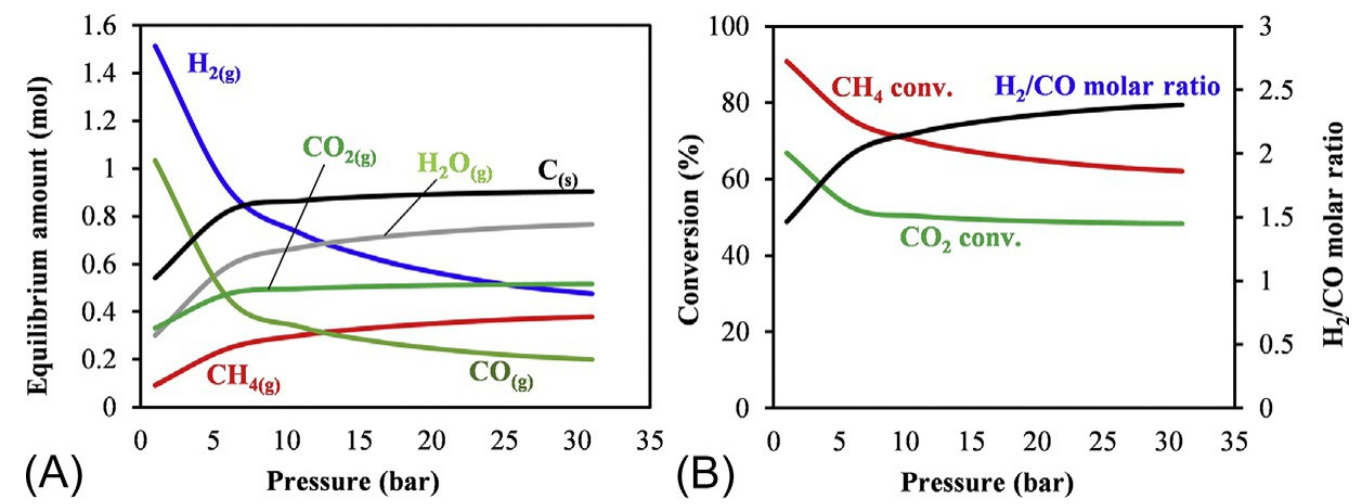

FIG. 4.10 Influence of the reaction pressure on the equilibrium of an equimolar mixture of $\mathrm{CH}_{4}$ and $\mathrm{CO}_{2}$ at $700^{\circ} \mathrm{C}$.

methane conversion at a given temperature and decreases coke selectivity. At a ratio of $\mathrm{CO}_{2} / \mathrm{CH}_{4}$ equal to 3 , coke can be avoided above $700^{\circ} \mathrm{C}$. However, adding more $\mathrm{CO}_{2}$ influences also WGS (Eq. 4.3 in Table 4.2). Consequently, the amount of $\mathrm{H}_{2}$ decreases and the amount of $\mathrm{H}_{2} \mathrm{O}$ increases. Thus, the choice of $\mathrm{CO}_{2} / \mathrm{CH}_{4}$ molar ratio must integrate all the factors, i.e., reaction conversion, reaction selectivity, and energy consumption, in order to optimize the DRM process, in particular for $\mathrm{H}_{2}$ production.

High pressure is generally not favorable for the DRM process. Fig. 4.10 presents the influence of the reaction pressure on the thermodynamic equilibrium of an equimolar mixture of $\mathrm{CH}_{4}$ and $\mathrm{CO}_{2}$ at $700^{\circ} \mathrm{C}$. Methane conversion decreases quickly from 91 to $62 \%$ when the pressure increases from 1 to 30 bar. In parallel, the amounts of $\mathrm{CO}$ and $\mathrm{H}_{2}$ drastically decrease while the amounts of $\mathrm{H}_{2} \mathrm{O}$ and solid carbon strongly increase with the increase of the reaction pressure. Thus, DRM at high pressure is not recommended.

\subsubsection{Catalysts for Methane Dry Reforming}

Because DRM is an extremely endothermic reaction, one of the main challenges in the heterogeneous catalytic DRM process is the considerable loss of catalytic activity with time-on-stream (TOS) due to the formation of carbonaceous species on the catalyst surface from $\mathrm{CH}_{4}$ cracking and metal sintering (Argyle and Bartholomew, 2015; Usman et al., 2015). Thus, numerous studies have been conducted to seek for ideal and cost-effective solutions to overcome the limitations in catalytic stability during DRM. In general, the employment of noble metal catalysts (namely, $\mathrm{Pt}, \mathrm{Ru}$, and $\mathrm{Rh}$ ) could solve the above-mentioned problems with high catalytic activity and coke resistance (Jones et al., 2008; Pakhare and Spivey, 2014). However, the high cost and limited availability of noble metals have limited their use in industrial applications. For these reasons, catalyst development has tended to shift toward the design of metal catalysts other than noble metals, such as $\mathrm{Ni}$ - and Co-based catalysts, which are globally available and more economical. In order to achieve catalyst activity and stability comparable to those of precious metals, tuning catalytic properties by 
modification of supports and addition of promoters has become a main focus area in many studies (Wang et al., 2017; Qian et al., 2014; Zarei et al., 2016; Djinović and Pintar, 2017). The recent efforts in designing promoted and supported nonnoble metal catalysts for DRM are comprehensively discussed in this section.

\subsubsection{Catalyst Supports}

The active metals (including noble metals, $\mathrm{Ni}$, and $\mathrm{Co}$ ) for DRM are normally dispersed on various single-metal oxides possessing basic $\left(\mathrm{CeO}_{2}\right.$ and $\mathrm{La}_{2} \mathrm{O}_{3}$ according to Barroso-Quiroga and Castro-Luna, 2010), acidic ( $\mathrm{SiO}_{2}$, amphoteric $\gamma-\mathrm{Al}_{2} \mathrm{O}_{3}$ (Barroso-Quiroga and Castro-Luna, 2010; Selvarajah et al., 2016), and $\mathrm{ZrO}_{2}$ (Rong-jun et al., 2015; Lou et al., 2017)) attributes. Metal oxide supports play an important role in catalytic DRM performance. Apart from providing mechanical strength, they increase specific surface area of the catalyst and act as a host for facilitating metal dispersion, thus increasing active metal dispersion (Wang et al., 2018; Abdullah et al., 2017).

Barroso-Quiroga and Castro-Luna (2010) investigated the effect of different ceramic oxide supports, such as $\mathrm{Al}_{2} \mathrm{O}_{3}, \mathrm{CeO}_{2}, \mathrm{La}_{2} \mathrm{O}_{3}$, and $\mathrm{ZrO}_{2}$, on the catalytic activity of $\mathrm{Ni}$ metal using the incipient wetness impregnation technique for catalytic synthesis. Among supported $\mathrm{Ni}$ catalysts, $10 \% \mathrm{Ni} / \mathrm{CeO}_{2}$ exhibited the highest $\mathrm{CH}_{4}$ conversion followed by $\mathrm{Ni} / \mathrm{ZrO}_{2}$ catalyst. However, $\mathrm{Ni} / \mathrm{ZrO} \mathrm{O}_{2}$ catalyst was the best catalyst in terms of catalytic stability, with negligible deactivation observed. Lou et al. (2017) also designed a stable $\mathrm{ZrO}_{2}$-supported $\mathrm{Ni}$ nanocatalyst system with metal loading of $1-5 \mathrm{wt} \%$ using air-stable Ni colloids. $\mathrm{Ni} / \mathrm{ZrO}_{2}$ catalyst having a $1.1 \mathrm{~nm}$ particle dimension reportedly exhibited excellent catalytic stability with TOS and maintained up to $90 \%$ initial activity beyond $60 \mathrm{~h}$ on-stream. The location of nearly all of the $\mathrm{Ni}$ atoms at the interface and perimeter of the $\mathrm{ZrO}_{2}$ support could result in easier access to the oxygen generated from activated $\mathrm{CO}_{2}$ at the $\mathrm{Ni}-\mathrm{ZrO}_{2}$ interface. Thus, the labile oxygen could facilitate the gasification of surface carbon to $\mathrm{CO}$ and prevent $\mathrm{Ni} / \mathrm{ZrO}_{2}$ catalyst deactivation. The interaction between $\mathrm{NiO}$ and various semiconductor metal oxide supports, including $\mathrm{SiO}_{2}, \mathrm{Al}_{2} \mathrm{O}_{3}, \mathrm{MgO}, \mathrm{TiO}_{2}$, and $\mathrm{ZrO}_{2}$, was the focus in the DRM study by Rong-jun et al. (2015). $\mathrm{SiO}_{2}, \mathrm{TiO}_{2}$, and $\mathrm{ZrO}_{2}$ weakly interact with $\mathrm{NiO}$ and hence ease $\mathrm{NiO}$ reduction. However, the weak metal support interaction induced quick catalytic deactivation owing to metal agglomeration. $\mathrm{TiO}_{2}$-supported $\mathrm{Ni}$ catalyst had the lowest reactant conversions of $<5 \%$ during $20 \mathrm{~h}$ on-stream because of low surface area and weak interaction with $\mathrm{NiO}$, whereas the basic nature of the $\mathrm{MgO}$ support attracted acidic $\mathrm{CO}_{2}$ adsorption, which in turn gasified surface carbon. Thus, a gradual decrease in the activity of the $\mathrm{Ni} / \mathrm{MgO}$ catalyst was observed within $50 \mathrm{~h}$ and then the catalyst appeared to be stable for $100 \mathrm{~h}$ on-stream (Rong-jun et al., 2015).

Ordered mesoporous silica (such as SBA-16 (Zhang et al., 2013), MCM-41 (Xie et al., 2015), and SBA-15 (Omoregbe et al., 2017)) has attracted significant attention from academics and appears to be a promising support because its 
large specific surface area, thick framework walls, high thermal stability, and well-ordered hexagonal structure with a narrow pore size distribution yields a supported catalyst with a uniform particle size and high metal dispersion (Zhang et al., 2013; Xie et al., 2015; Omoregbe et al., 2017). Wang et al. (2013) compared different types of silica-based supports on the DRM performance of $\mathrm{LaNiO}_{3}$ perovskite catalysts, including $\mathrm{SiO}_{2}$, mesoporous SBA-15, and MCM-41 materials. Supported catalysts showed higher catalytic activity and stability than those of bare $\mathrm{LaNiO}_{3}$ catalyst due to a strong metal-support interaction and greater metal dispersion. The initial $\mathrm{CH}_{4}$ conversion decreased in the following order: $\mathrm{LaNiO}_{3} / \mathrm{MCM}-41>\mathrm{LaNiO}_{3} / \mathrm{SBA}-15>\mathrm{LaNiO}_{3} / \mathrm{SiO}_{2}>$ $\mathrm{LaNiO}_{3}$ catalysts. However, the longevity test revealed that the SBA-15 supported $\mathrm{LaNiO}_{3}$ catalyst was free from graphitic carbon and possessed the highest catalytic stability within $60 \mathrm{~h}$ at $973 \mathrm{~K}$ owing to the greater anchoring effect of the SBA-15 mesostructure, resulting in well-dispersed active Ni species. Additionally, the mesoporous structure SBA-15 support was largely undamaged after $60 \mathrm{~h}$ on-stream, while structural collapse was observed for the MCM-41 support. Cai et al. (2014) also reported that the anchoring effect of mesoporous silica not only contributed to great Ni particle dispersion, inducing remarkable catalytic activity, but also significantly stabilized metallic Ni nanoparticles inside mesoporous channels and prevented them from agglomerating.

Owing to the outstanding oxygen storage capacities and distinctive redox properties of rare earth metal oxides, namely, $\mathrm{CeO}_{2}$ and $\mathrm{La}_{2} \mathrm{O}_{3}$, these metal oxides have been utilized as supports for reducing carbon deposition (Barroso-Quiroga and Castro-Luna, 2010; Ayodele et al., 2016). Ay and Üner (2015) synthesized Ce-supported $\mathrm{Ni}$, monometallic $\mathrm{Co}$, and bimetallic $\mathrm{Ni}-\mathrm{Co}$ catalysts using the incipient wetness impregnation approach for DRM evaluation. Both $\mathrm{Ni} / \mathrm{CeO}_{2}$ and $\mathrm{Ni}-\mathrm{Co} / \mathrm{CeO}_{2}$ catalysts had excellent interaction between the $\mathrm{Ni}$ metal and the $\mathrm{CeO}_{2}$ support as evidenced in HRTEM analysis, and hence they had higher catalytic activities compared to the $\mathrm{Co} / \mathrm{CeO}_{2}$ catalyst. In the assessment of DRM over $\mathrm{Ni} / \mathrm{La}_{2} \mathrm{O}_{3}$ catalyst, $\mathrm{Li}$ et al. (2017) found that $\mathrm{Ni} / \mathrm{La}_{2} \mathrm{O}_{3}$ catalyst exhibited outstanding catalytic stability with comparable $\mathrm{CH}_{4}$ and $\mathrm{CO}_{2}$ conversions of about $75 \%$ at $973 \mathrm{~K}$ and atmospheric pressure for $50 \mathrm{~h}$ on-stream. This noteworthy observation was attributed to improved Ni dispersion due to strong metal-support interaction, which thus inhibited $\mathrm{Ni}$ sintering and suppressed carbon deposition on the catalyst surface. Additionally, they reported that a complete transformation cycle between the $\mathrm{La}_{2} \mathrm{O}_{3}$ and $\mathrm{La}_{2} \mathrm{O}_{2} \mathrm{CO}_{3}$ phases that occurred during DRM was responsible for deposited carbon removal. In particular, $\mathrm{CO}_{2}$ could adsorb on $\mathrm{La}_{2} \mathrm{O}_{3}$ form to generate the intermediate $\mathrm{La}_{2} \mathrm{O}_{2} \mathrm{CO}_{3}$ phase, which in turn reacted with neighboring active surface carbon species to produce $\mathrm{CO}$ product and $\mathrm{La}_{2} \mathrm{O}_{3}$ form.

Besides single metal oxide supports, mixed metal oxides, such as $\mathrm{CeO}_{2-}$ $\mathrm{Al}_{2} \mathrm{O}_{3}, \mathrm{La}_{2} \mathrm{O}_{3}-\mathrm{Al}_{2} \mathrm{O}_{3}$ (Charisiou et al., 2016), and $\mathrm{MgO}-\mathrm{Al}_{2} \mathrm{O}_{3}$ (Zhang et al., 2016), have been recently utilized as a support in DRM catalysts in order to receive synergistic benefits from these compounds. In a study of the DRM 
reaction over $\mathrm{Ni}$ supported on mixed metal oxides between $\mathrm{Al}_{2} \mathrm{O}_{3}$ and $\mathrm{CeO}_{2}$ or $\mathrm{La}_{2} \mathrm{O}_{3}$, Charisiou et al. (2016) noticed that Ni/CeAl, Ni/LaAl, and Ni/CeLaAl catalysts appreciably improved reactant conversions compared with an unmodified $\mathrm{Ni} / \mathrm{Al}$ catalyst owing to the high oxygen storage capacity of $\mathrm{CeO}_{2}$ and $\mathrm{La}_{2} \mathrm{O}_{3}$ alleviating surface carbon oxidation. Additionally, a longevity test revealed that modified alumina catalysts could constantly retain their catalytic activity over $20 \mathrm{~h}$ on-stream while the unmodified $\mathrm{Ni} / \mathrm{Al}$ catalyst experienced catalytic deterioration within $5 \mathrm{~h}$.

Zhang et al. (2016) examined a series of $\mathrm{Ni} / \mathrm{MgO}-\mathrm{Al}_{2} \mathrm{O}_{3}$ catalysts (with varying $\mathrm{Al}_{2} \mathrm{O}_{3}$ content from 0 to $45 \mathrm{wt} \%$ ) synthesized by a two-step hydrothermal approach. $\mathrm{NiO}$ reportedly dissolved into the $\mathrm{MgO}$ support to form a solid solution, which was difficult to reduce to the active $\mathrm{Ni}^{\circ}$ metallic phase. They found that the addition of $\mathrm{Al}_{2} \mathrm{O}_{3}$ to the $\mathrm{MgO}$ support could weaken the formation of $\mathrm{Mg}$-Ni-O solid solution and hence alleviate the $\mathrm{H}_{2}$ reaction. Nevertheless, the generation of a more spinel-like $\mathrm{NiAl}_{2} \mathrm{O}_{4}$ form at high $\mathrm{Al}_{2} \mathrm{O}_{3}$ loading beyond $15 \mathrm{wt} \%$ required a greater reduction temperature than for $\mathrm{Ni} / \mathrm{MgO}$ catalyst. Additionally, basic site concentration improved with increasing $\mathrm{Al}_{2} \mathrm{O}_{3}$ content in the support mixture and attained an optimum at $15 \mathrm{wt} \%$, which was also the best $\mathrm{Al}_{2} \mathrm{O}_{3}$ loading for the DRM reaction in terms of $\mathrm{CH}_{4}$ conversion $(52 \%)$ and stability due to the formation of a stable and basic $\mathrm{MgAl}_{2} \mathrm{O}_{4}$ phase instead of the undesirable $\mathrm{MgNiO}_{2}$ and $\mathrm{NiAl}_{2} \mathrm{O}_{4}$ forms. In the study of $\mathrm{Ni} / \mathrm{MgAl}_{2} \mathrm{O}_{4}$ spinel catalysts with various $\mathrm{Ni}$ contents from 2.5 to $10 \%$ for DRM, Habibi et al. (2016) also found that $5 \% \mathrm{Ni} / \mathrm{MgAl}_{2} \mathrm{O}_{4}$ exhibited the highest catalytic activity because of high $\mathrm{Ni}$ dispersion on the mesoporous $\mathrm{MgAl}_{2} \mathrm{O}_{4}$ support, large BET surface area, low-temperature reducibility, and the strong interaction between the $\mathrm{Ni}$ and $\mathrm{MgAl}_{2} \mathrm{O}_{4}$ spinel support.

\subsubsection{Promoters}

Apart from adjusting operational conditions or modifying the structure or composition of catalyst supports, adding small amounts of promoters is an effective way to suppress catalyst deactivation from carbon deposition and metal sintering. Although precious metals exhibit excellent catalytic performance and stability, these metals are preferably employed as promoters due to their high cost and low availability (Pakhare and Spivey, 2014; Abdullah et al., 2017). In a comparative study of noble metal effect on catalytic activity and carbon deposition for DRM, Arandiyan et al. (2014) prepared various precious metal-doped LaAlNi catalysts (including Pt, Pd, Ru, Rh, and Ir) via the sol-gel method. The addition of noble metal promoters eased the $\mathrm{H}_{2}$ reduction of cationic nickel owing to the $\mathrm{H}_{2}$-spillover effect in agreement with the findings from Jabbour et al. (2014). Arandiyan et al. (2014) reported the order of $\mathrm{CH}_{4}$ conversion as: $\mathrm{La}_{0.4} \mathrm{Rh}_{0.6} \mathrm{Al}_{0.2} \mathrm{Ni}_{0.8} \mathrm{O}_{3}>\mathrm{La}_{0.4} \mathrm{Ru}_{0.6} \mathrm{Al}_{0.2} \mathrm{Ni}_{0.8} \mathrm{O}_{3}>\mathrm{LaAl}_{0.2} \mathrm{Ni}_{0.8} \mathrm{O}_{3}>\mathrm{La}_{0.4} \mathrm{Ir}_{0.6}$ $\mathrm{Al}_{0.2} \mathrm{Ni}_{0.8} \mathrm{O}_{3} \geq \mathrm{La}_{0.4} \mathrm{Pt}_{0.6} \mathrm{Al}_{0.2} \mathrm{Ni}_{0.8} \mathrm{O}_{3}>\mathrm{La}_{0.4} \mathrm{Pd}_{0.6} \mathrm{Al}_{0.2} \mathrm{Ni}_{0.8} \mathrm{O}_{3}$. The enhancement of the catalytic performance and stability was ascribed to the low 
reduction temperature and the high content of oxygen adspecies on noble metal promoters accelerating surface carbon gasification.

Mahoney et al. (2014) examined the promotional effect of $\mathrm{Pt}(0.2 \mathrm{wt} \%)$ on $15 \% \mathrm{Ni} / \mathrm{Al}_{2} \mathrm{O}_{3}$ and $15 \% \mathrm{Ni} / \mathrm{CeZrO}_{2}$ catalysts in a fixed-bed reactor at a stoichiometric $\mathrm{CH}_{4}: \mathrm{CO}_{2}$ ratio $=1: 1$ and $1073 \mathrm{~K}$. The addition of Pt did not significantly affect $\mathrm{CH}_{4}$ and $\mathrm{CO}_{2}$ conversions of $15 \% \mathrm{Ni} / \mathrm{Al}_{2} \mathrm{O}_{3}$ catalyst. However, the superior catalytic activity and stability of $0.2 \% \mathrm{Pt}-15 \% \mathrm{Ni} / \mathrm{CeZrO}_{2}$ catalyst were attributed to the facilitated oxygen spillover from Pt atoms to the oxygen vacancies in the ceria-zirconia support. Based on density functional theory (DFT) calculations, Gould et al. (2015) found that Pt-promoted Ni catalyst possessed a great resistance to carbon because the presence of Pt atoms weakened the carbon adsorption energy at step edges and increased the carbon diffusion barrier on terraces.

Besides noble metals, rare earth metal oxides (such as $\mathrm{CeO}_{2}$ and $\mathrm{La}_{2} \mathrm{O}_{3}$ ) have been widely employed as promoters for Ni-based catalysts due to their basic property and high oxygen storage capacity, which hinders carbonaceous deposition on the catalyst surface and enhances catalytic activity (Usman et al., 2015; Omoregbe et al., 2016). Shamskar et al. (2017) scrutinized the influence of $\mathrm{CeO}_{2}$ and $\mathrm{La}_{2} \mathrm{O}_{3}$ dopants on $25 \% \mathrm{Ni} / \mathrm{Al}_{2} \mathrm{O}_{3}$ catalyst prepared by the ultrasonic-assisted coprecipitation approach. Temperature-programmed oxidation analysis shows that the addition of promoter reduced the amount of accumulated carbon and the $5 \% \mathrm{CeO}_{2}-25 \% \mathrm{Ni} / \mathrm{Al}_{2} \mathrm{O}_{3}$ catalyst was stable during $15 \mathrm{~h}$ on-stream. The promotional effect of a series of rare-earth elements, namely, $\mathrm{Sc}, \mathrm{Y}, \mathrm{Ce}$, and Pr on NiMgAl catalysts produced from layered double hydroxides for the DRM reaction was also investigated by Cao et al. (2016). The addition of promoter increased the $\mathrm{CH}_{4}$ conversion in the order: Ce-promoted > Pr-promoted $>$ Y-promoted $>$ Sc-promoted $>$ unpromoted catalysts. The amount of carbon deposition decreased from $47.22 \%$ (unpromoted catalyst) to $33.76 \%$ (Ce-doped catalyst). The increased reactant conversion and coke resistance with the addition of a rare-earth promoter were attributed to enhanced surface basicity, the great redox properties, and well-dispersed Ni particles on the catalyst surface. Notably, Ce- and Pr-modified catalysts had higher catalytic activity and carbon resilience compared with other promoted and unpromoted catalysts owing to their fast redox cycling that involved the reversible formation of $\mathrm{Ce}^{3+} / \mathrm{Ce}^{4+}$ and $\operatorname{Pr}^{3+} / \mathrm{Pr}^{4+}$ redox pairs.

Sarkar et al. (2016) investigated the addition of $0.2 \mathrm{wt} \% \mathrm{Gd}$ dopant to $5 \% \mathrm{Ni} /$ ZSM-5 catalyst and found that Gd promotion improved the oxygen atom supply to the adjacent $\mathrm{Ni}$ sites and hence oxidized accumulated coke on the catalyst surface. As a result, Gd-doped Ni/ZSM-5 catalyst exhibited a high $\mathrm{CH}_{4}$ conversion of $83 \%$ without noticeable carbon deposition and sintering at $1023 \mathrm{~K}$ after $100 \mathrm{~h}$ on-stream. Al-Fatesh (2017) also examined the influence of Gd loading from 1 to $5 \mathrm{wt} \% \mathrm{Gd}$ on the catalytic performance of $10 \% \mathrm{Ni} / \mathrm{Y}_{2} \mathrm{O}_{3}$ catalyst for the DRM reaction. Both $\mathrm{CH}_{4}$ and $\mathrm{CO}_{2}$ conversions reportedly increased with increasing Gd loading from 1 to $3 \mathrm{wt} \%$ owing to the synergetic effect between 
Gd and Ni metals. Metal dispersion was also improved with Gd addition, and the optimal value was obtained at $3 \mathrm{wt} \% \mathrm{Gd}$ because $\mathrm{Gd}$ metal incorporated itself into the pores of the catalyst and inhibited Ni agglomeration. Thus, 3\% $\mathrm{Gd}-10 \% \mathrm{Ni} / \mathrm{Y}_{2} \mathrm{O}_{3}$ catalyst appeared to be the best catalyst in terms of reactant conversions, $\mathrm{H}_{2}$ yield, and carbon resistance. Boron promoter has recently gained considerable attention for coke resistance in the DRM reaction because, according to DFT calculations from Xu and Saeys (2007), boron atoms effectively suppress surface carbon diffusion into the Ni lattice by preoccupying the octahedral sites of the initial $\mathrm{Ni}$ (111) subsurface layer. In the study of boronpromoted $\mathrm{Ni} / \mathrm{Al}_{2} \mathrm{O}_{3}$ catalyst, Fouskas et al. (2014) found that low boron content (0.6-5.6 wt\%) improved $\mathrm{Ni}$ dispersion in an $\mathrm{Al}_{2} \mathrm{O}_{3}$ support without any changes in textural attributes. Additionally, the total amount of carbonaceous deposits on a B-promoted catalyst was about $74 \%-86 \%$ lower than on unpromoted catalyst.

Table 4.9 summarizes the catalytic performance of various nonnoble metalbased catalysts employing various support and promoter types. In order to facilitate the comparison among the catalysts used, the experimental conditions, including feed composition, reaction temperature, and gas hourly space velocity (GHSV), are also listed. In addition, the initial and final reactant conversions are given to justify catalytic stability. In fact, the estimated degree of catalyst deactivation based on $\mathrm{CH}_{4}$ conversion is also summarized, together with the $\mathrm{H}_{2} / \mathrm{CO}$ ratio.

\subsubsection{DRM Kinetic Models}

Fundamentally understanding the intrinsic mechanistic DRM pathways and determining the kinetic parameters based on the best-fit kinetic model are essential for optimizing catalyst synthesis and subsequent reactor design for commercialized applications in industry. The typical kinetic models commonly implemented in the DRM reaction are the power law, Eley Rideal (ER), and Langmuir Hinshelwood-Hougen Watson (LHHW) models. Among these main kinetic models, the empirical power law model is regarded as the simplest one capable of generating approximately estimated values for associated reaction parameters. The empirical power law model for the DRM reaction is given in Eq. (4.16).

$$
-r_{\mathrm{CH}_{4}}=k P_{\mathrm{CH}_{4}}^{\alpha} P_{\mathrm{CO}_{2}}^{\beta}
$$

where $P_{i}$ is the partial pressure of component $i\left(i: \mathrm{CH}_{4}\right.$ or $\left.\mathrm{CO}_{2}\right)$ and $k$ is the apparent rate constant. Additionally, $\alpha$ and $\beta$ are reaction orders varying with the type of catalyst while $-r_{\mathrm{CH}_{4}}$ is the reaction rate of $\mathrm{CH}_{4}$.

Although the power law model has been widely employed in many studies (Pakhare and Spivey, 2014; Kathiraser et al., 2015) for roughly computing the kinetic parameters because of its simplicity and because there is no requirement to understand the mechanistic reaction pathways (see summary in Table 4.10), 


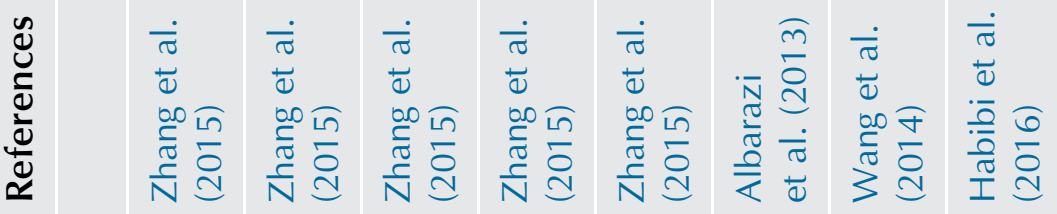

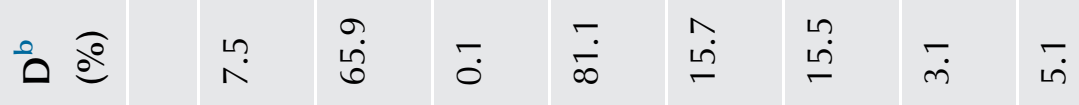

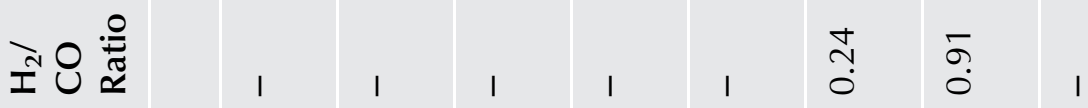

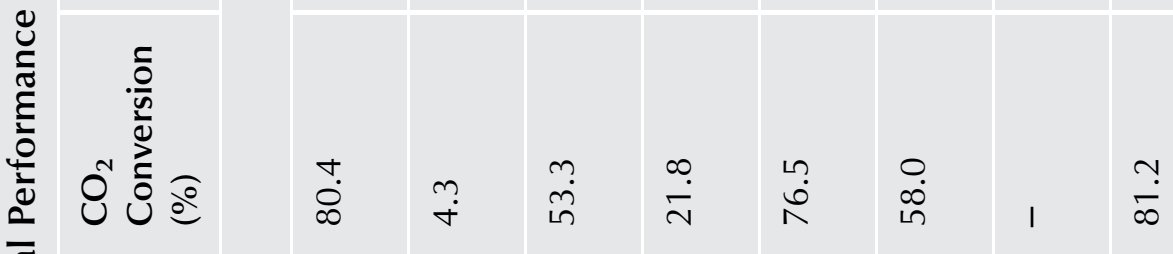

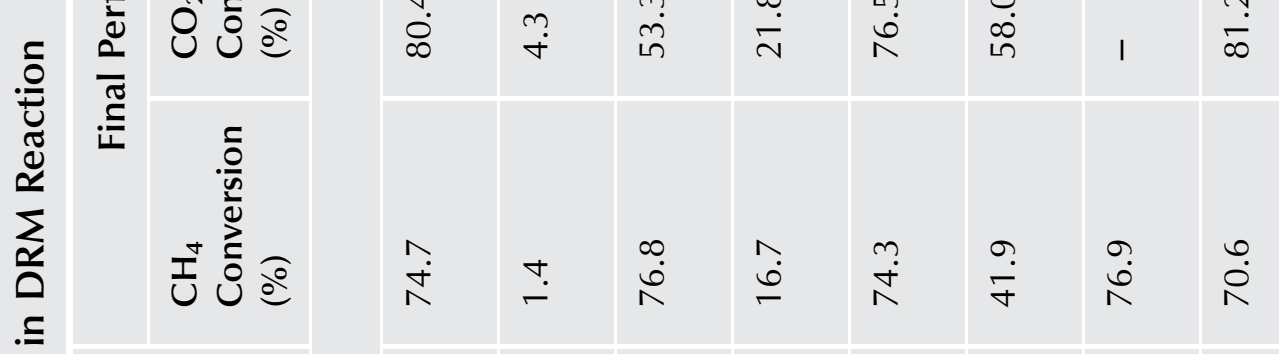

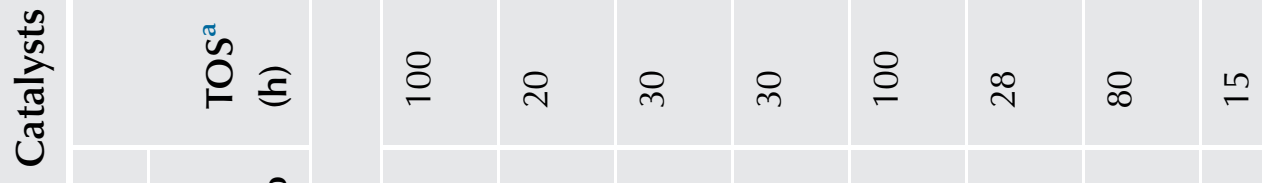

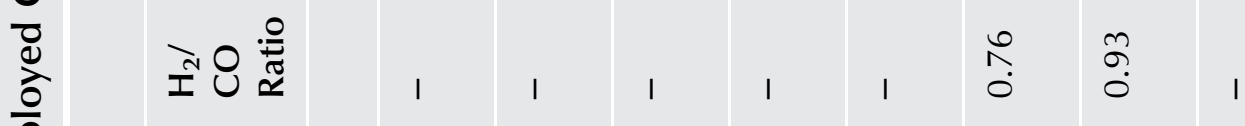

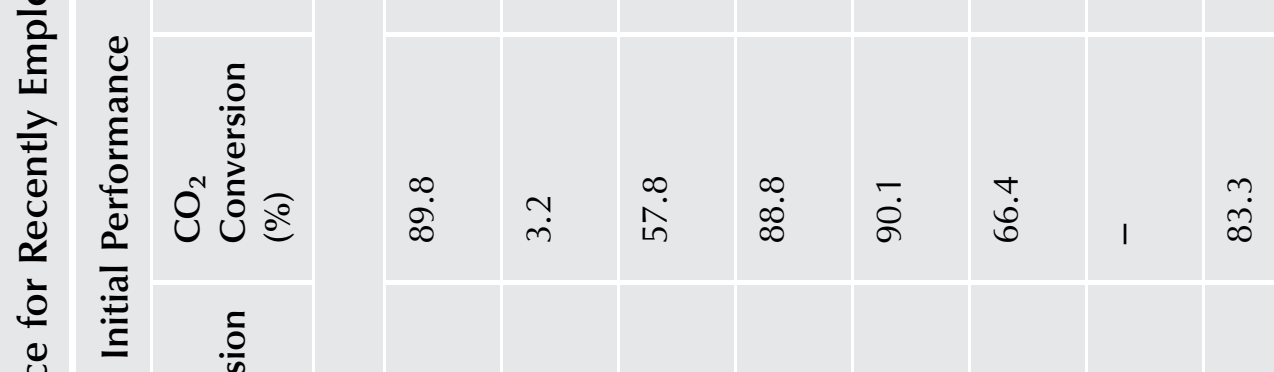

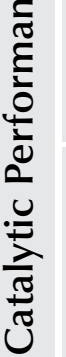

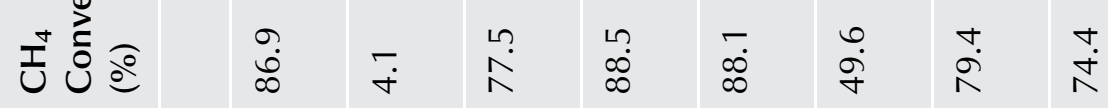

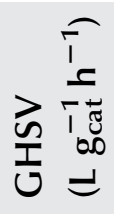

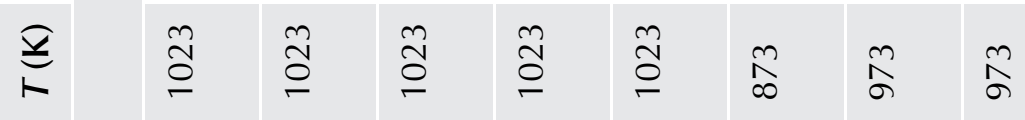

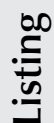

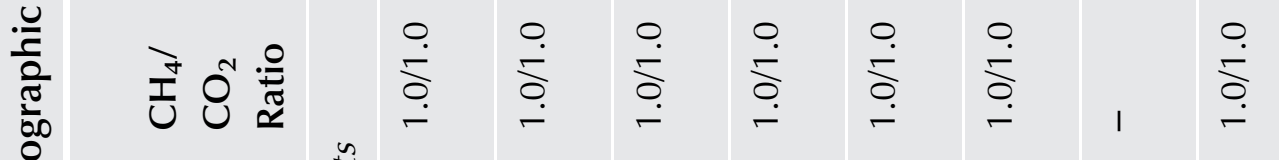

产

要

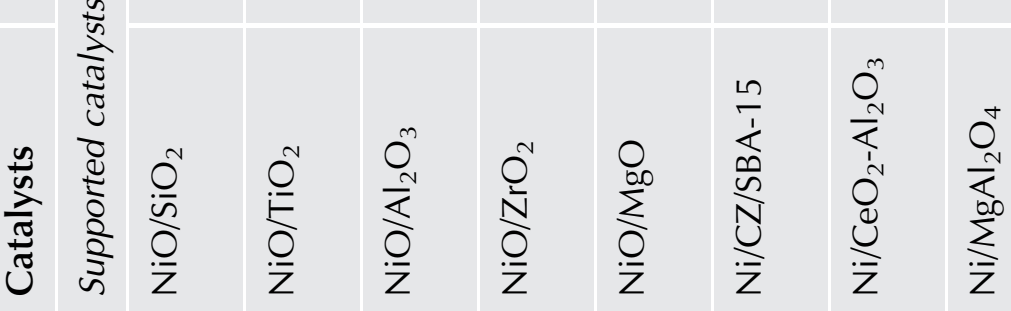




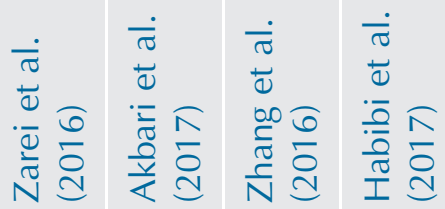

मे वู ฮิ

कू

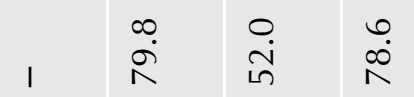

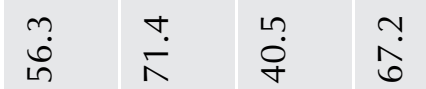

ก $\frac{1}{2}$

\begin{tabular}{lll}
0 & \multirow{2}{*}{} & 0 \\
0 & 0 & 0
\end{tabular}

1)

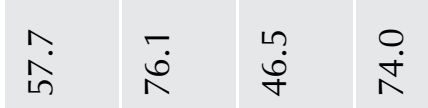

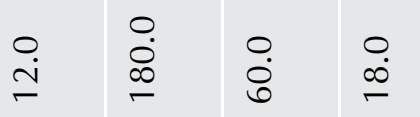

罂

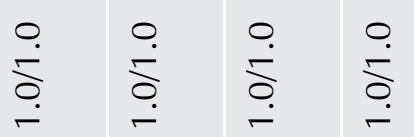

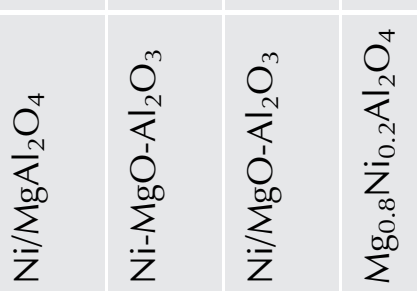

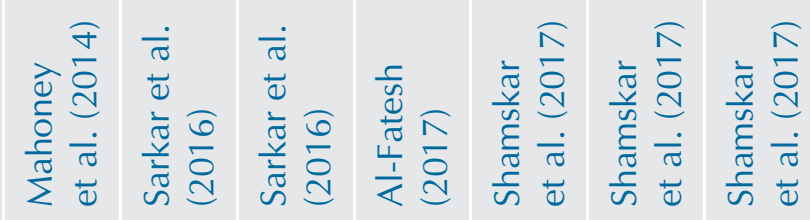

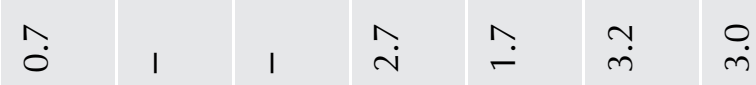

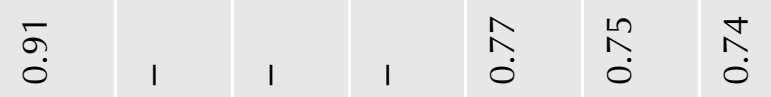

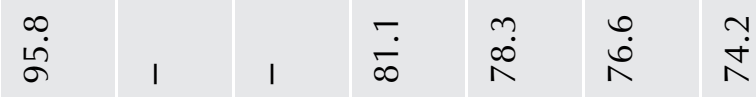

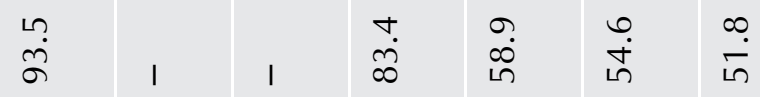

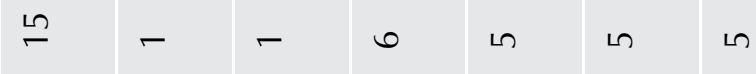

总 总

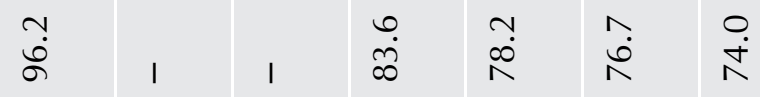

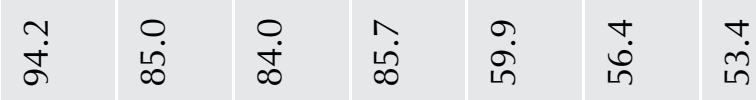

离

菓

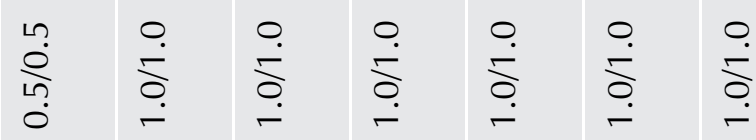

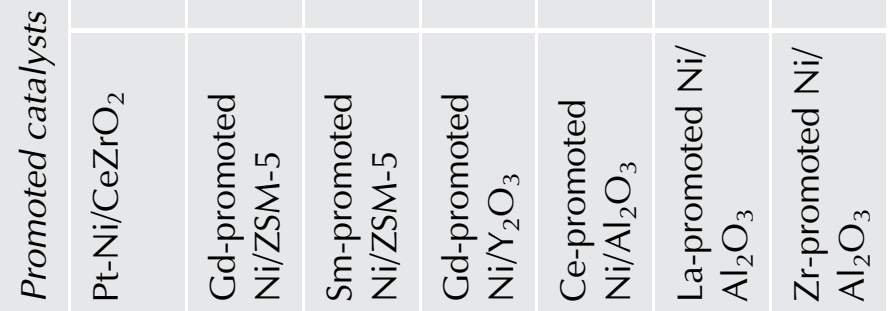




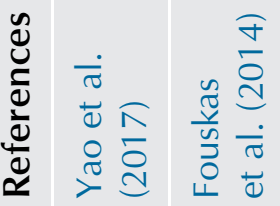

0 व

సิㅇำ

일

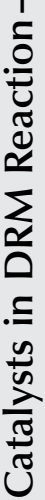

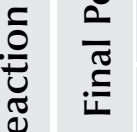

ชี ㅎ

施

İ

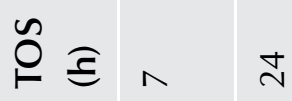

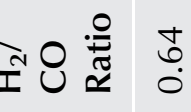

竞

$\frac{5}{\frac{0}{5}}$

8 ป

$\frac{5}{\frac{0}{n+m}}$

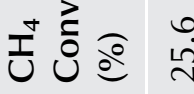

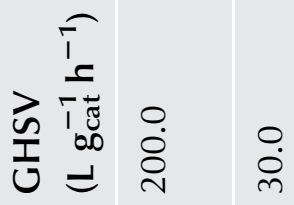

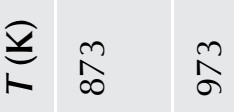

$\stackrel{\infty}{.0}$

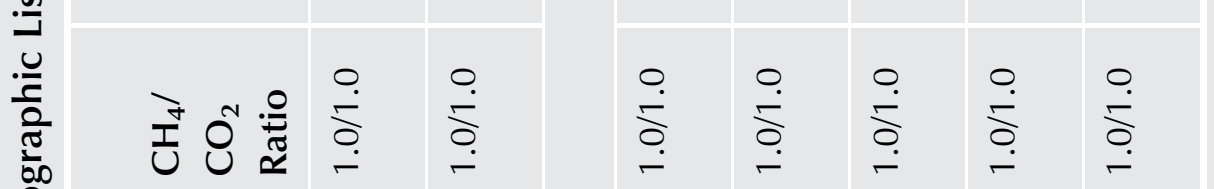

음

苞

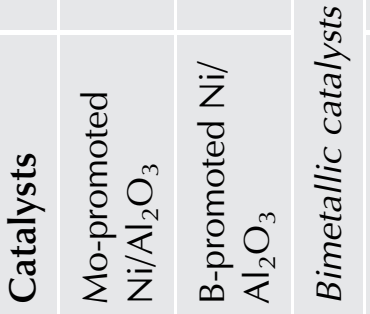

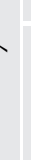

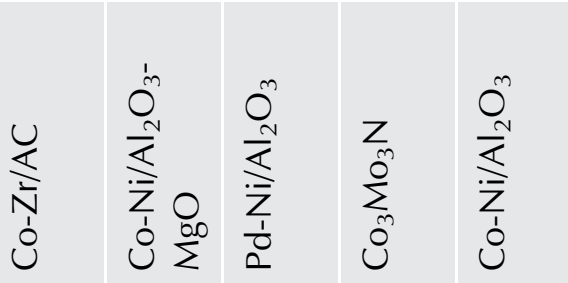




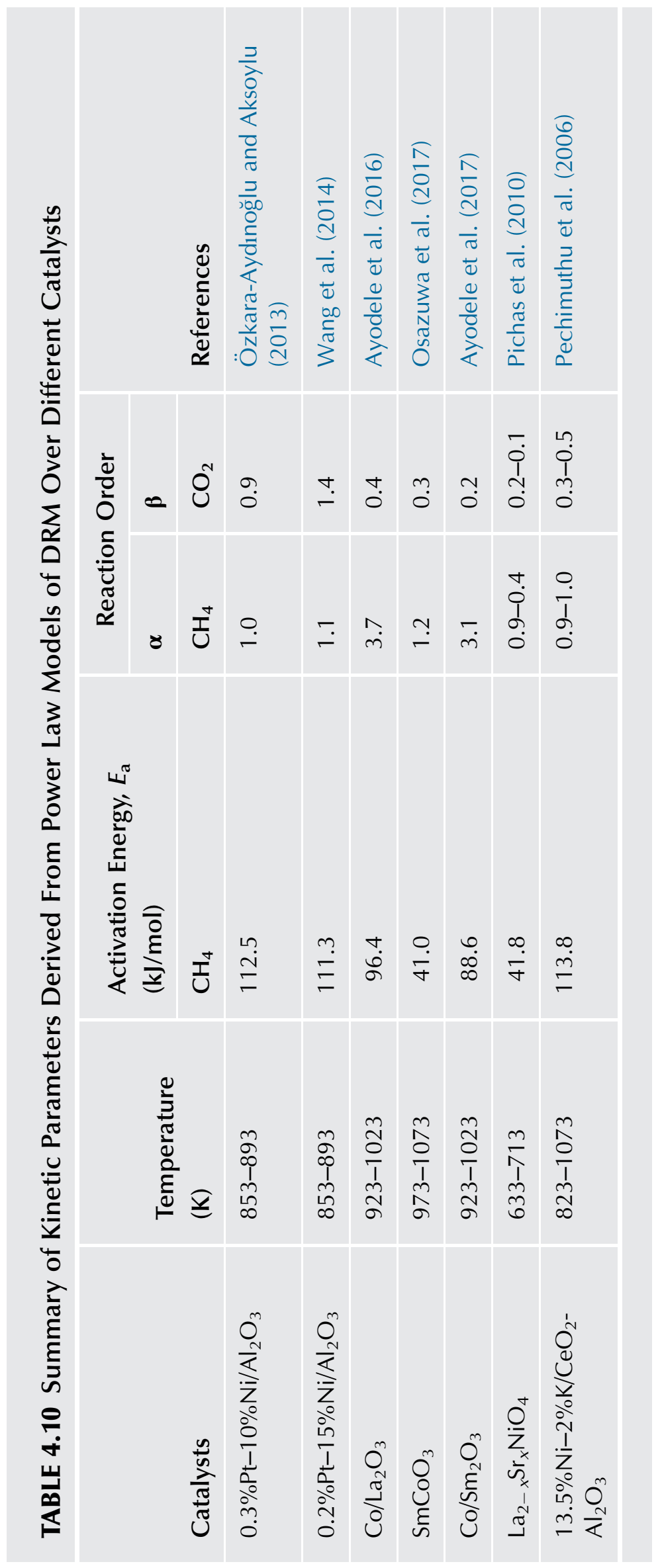


the power law model may not be applicable and accurate for a wide range of reactant partial pressure (Pakhare and Spivey, 2014; Kathiraser et al., 2015). Nevertheless, this empirical model can be effectively used for initially guessing the overall activation energy and power constants of each reactant for comparison among catalysts used in the literature.

Table 4.10 summarizes the estimated $\mathrm{CH}_{4}$ activation energy and reaction orders obtained from power law models recently reported in the literature for several catalysts. Özkara-Aydınoğlu and Aksoylu (2013) fitted the experimental data for DRM on Pt-Ni/ $\mathrm{Al}_{2} \mathrm{O}_{3}$ catalysts to a power law model and found that the reaction orders of $\mathrm{CH}_{4}$ and $\mathrm{CO}_{2}$ varied from 1.0 to 1.1 and 0.9 to 1.4 in this order depending on the $\mathrm{Pt}$ and $\mathrm{Ni}$ loading. For $0.2 \% \mathrm{Pt}-15 \% \mathrm{Ni} / \mathrm{Al}_{2} \mathrm{O}_{3}$ catalyst, the higher reaction order for $\mathrm{CO}_{2}$ than for $\mathrm{CH}_{4}$ suggests a greater reliance on the $\mathrm{CO}_{2}$ partial pressure for surface carbon gasification. However, at higher Pt content $\left(0.3 \%\right.$ Pt- $\left.10 \% \mathrm{Ni} / \mathrm{Al}_{2} \mathrm{O}_{3}\right)$, the $\mathrm{CO}_{2}$ dependency was reduced and $\mathrm{CH}_{4}$ appeared to be the dominant component affecting the reaction rate, because higher Pt content enhanced the oxygen utilization for removing deposited carbon. As seen in Table 4.10, the $\mathrm{CH}_{4}$ reaction order was superior to that of $\mathrm{CO}_{2}$ for most catalysts, suggesting that $\mathrm{CH}_{4}$ adsorption on the catalyst surface dominated the DRM reaction.

As discussed above, the power law models do not reflect the intrinsic DRM reaction steps occurring on the catalyst surface. Thus, in order to thoroughly understand various complex mechanistic DRM schemes, ER and LHHW models are normally employed, together with statistical criteria and thermodynamic consistency (Abdullah et al., 2017), for assessing the adequacy of the fitting of experimental data to the mechanistic-based kinetic models. ÖzkaraAydınoğlu and Aksoylu (2013) investigated Pt-Ni/ $/ \mathrm{Al}_{2} \mathrm{O}_{3}$ catalyst for the DRM reaction and fitted their experimental data on the $\mathrm{CH}_{4}$ consumption rate into eight ER and LHHW kinetic models derived from various mechanistic pathways with different rate-determining steps (RDS). Based on the squared error from nonlinear regression, they deduced that the ER model (see Eq. 4.17 in Table 4.11) in which the reaction between molecularly adsorbed $\mathrm{CO}_{2}$ and $\mathrm{CH}_{4}$ in the gas phase is the RDS, was the model that provided the best fit.

In kinetic studies of Pt- and Ru-doped $\mathrm{TiO}_{2}$ catalysts, Singh and Madras (2016) performed an in situ FTIR analysis during the DRM reaction and found that $\mathrm{CH}_{4}$ adsorbed on the catalyst surface while the absence of adsorbed $\mathrm{CO}_{2}$ species on the metal or support surfaces was evident. Hence, an ER model (see Eq. 4.18 in Table 4.11) in which $\mathrm{CH}_{4}$ adsorbs molecularly, followed by $\mathrm{CH}_{4}$ dissociative adsorption as RDS (rate-determining step) while $\mathrm{CO}_{2}$ exists in the gas phase, was proposed to forecast the experimental reaction rate.

Ayodele et al. (2017) examined the $\mathrm{CH}_{4}$ reaction rate over $\mathrm{Co} / \mathrm{La}_{2} \mathrm{O}_{3}$ catalyst in six different LHHW models derived from both single-site (adsorption of $\mathrm{CH}_{4}$ and $\mathrm{CO}_{2}$ reactants on the same active site) and dual-site $\left(\mathrm{CH}_{4}\right.$ and $\mathrm{CO}_{2}$ favorably adsorbed on two nonidentical sites on active metal and support) mechanisms. They discovered that the experimental data on the $\mathrm{CH}_{4}$ 


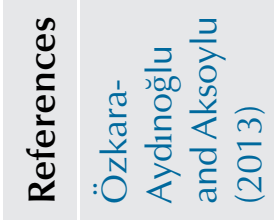

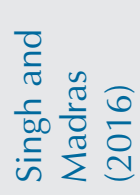

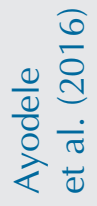

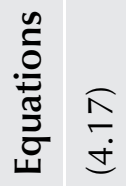

$\stackrel{\infty}{\stackrel{\infty}{ \pm}}$

$\underset{\sigma}{\stackrel{a}{ \pm}}$
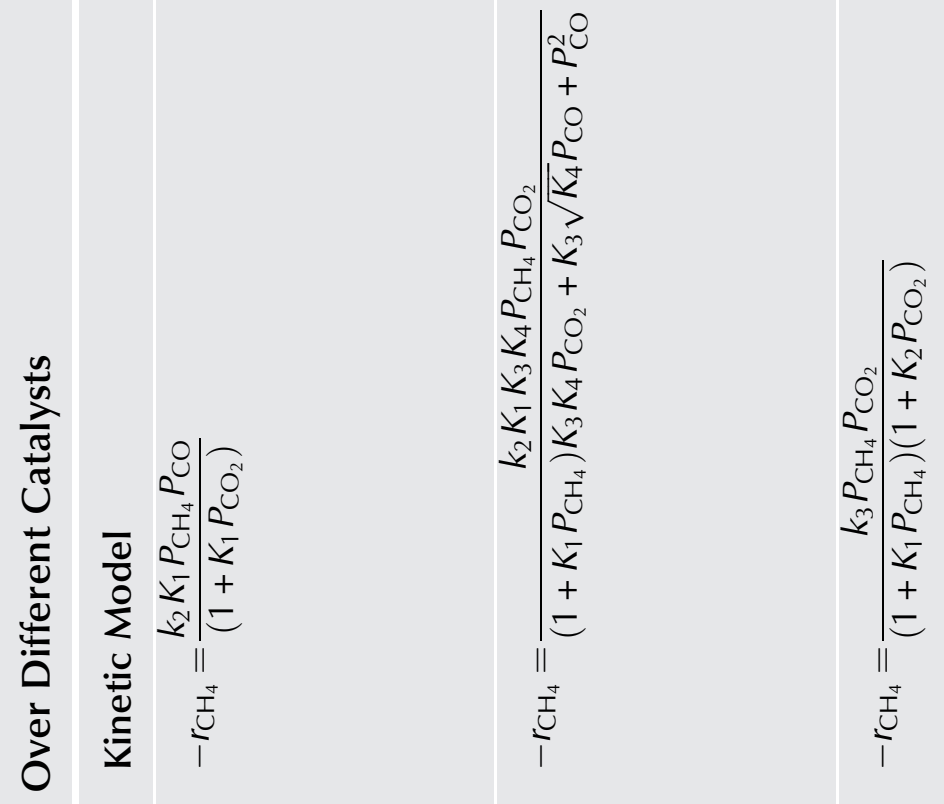

$\sum_{\substack{0 \\ 0}}$

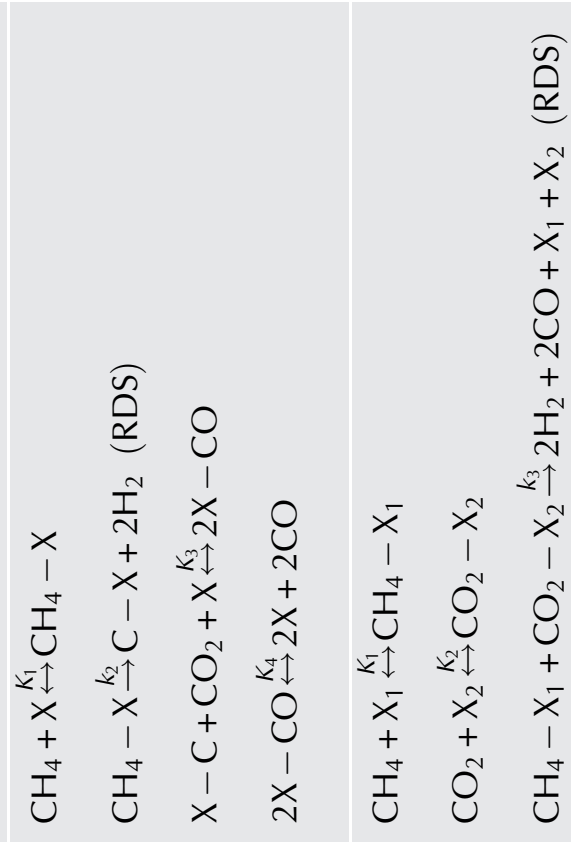

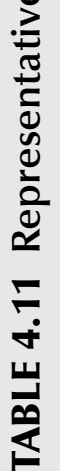

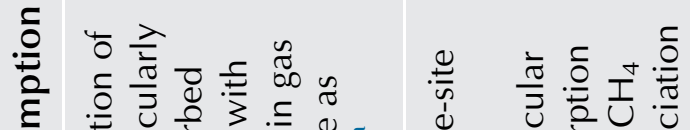

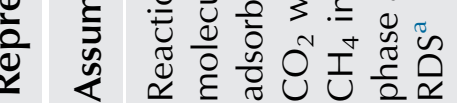

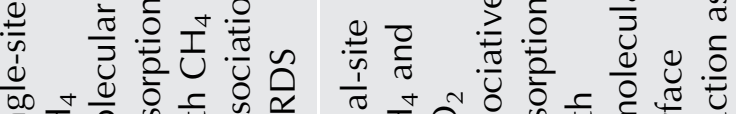

$\stackrel{0}{0}$

$\underline{\underline{\alpha}}$

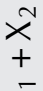

$\stackrel{\text { थิ }}{\underline{2}}$

8

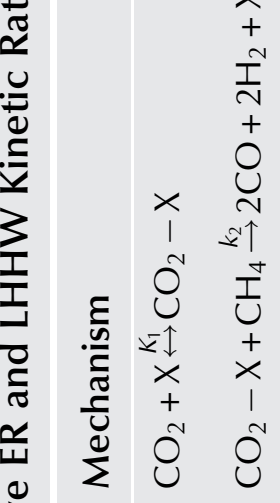

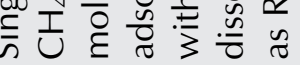

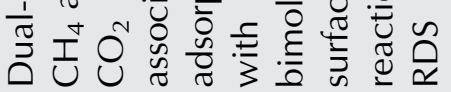

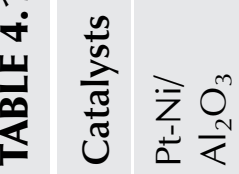

$\frac{0}{0^{2}}$

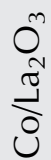




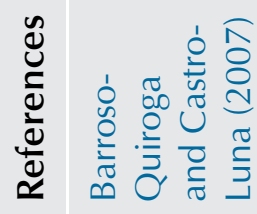

高諳

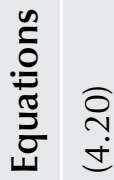

$\stackrel{\overline{\grave{I}}}{\stackrel{ \pm}{ \pm}}$

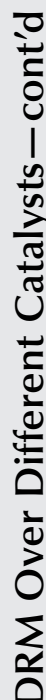

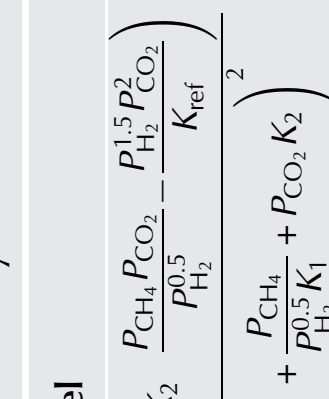

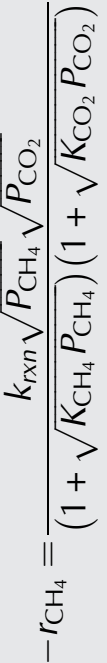

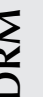

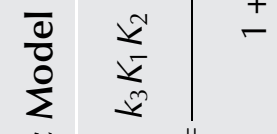

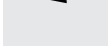

i

$\overline{\text { ¿̇ }}$

$\frac{\frac{1}{0}}{\frac{0}{0}}$

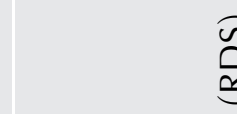

華

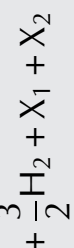

$\underset{\substack{\mathrm{V} \\ \mathrm{V} I}}{\mathrm{\lambda}}$

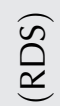

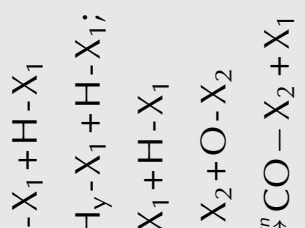

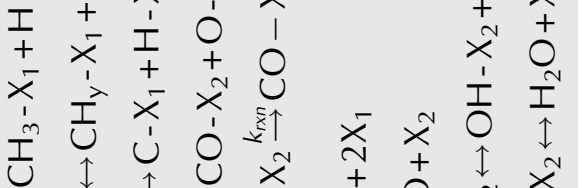

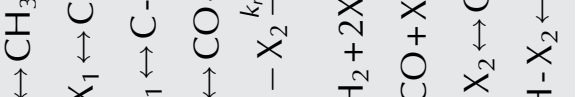

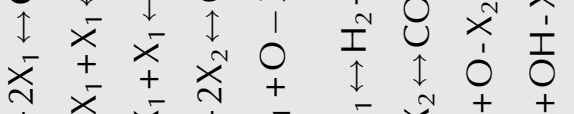

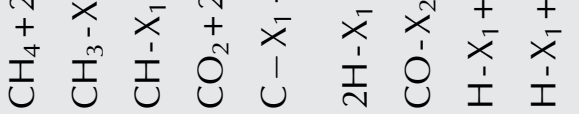

$\stackrel{x}{2}$

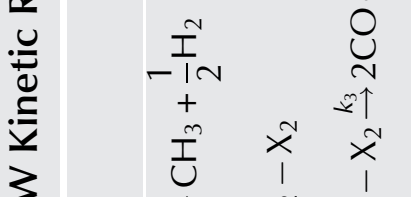

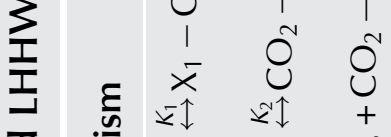

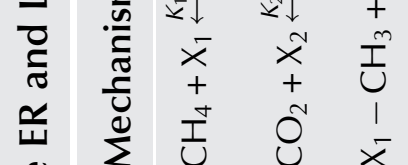



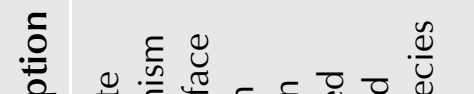

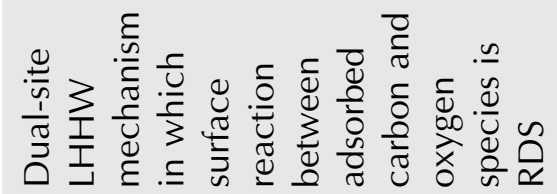

F

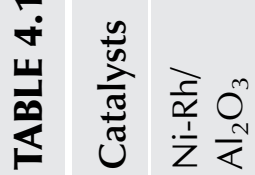

$\bar{z}_{i} \frac{N}{O^{m}}$ 
consumption rate at different reactant partial pressures from 5 to $50 \mathrm{kPa}$, and different reaction temperatures from 923 to $1023 \mathrm{~K}$, were sufficiently captured by a dual-site LHHW model (see Eq. 4.19 in Table 4.11) with surface reaction between molecularly adsorbed $\mathrm{CH}_{4}$ and $\mathrm{CO}_{2}$ species as RDS. This model satisfied both statistical and thermodynamic criteria with a high correlation coefficient $(>0.95)$. Other dual-site LHHW models with detailed mechanistic steps are also summarized in Table 4.11.

\subsubsection{Conclusions and Outlook}

DRM is a promising green technology to produce a syngas mixture appropriate for downstream production of synthetic long-chained hydrocarbons via FischerTropsch synthesis. However, the DRM technology is still impractical for implementation at an industrial scale because the highly endothermic nature of DRM requires excessive energy consumption, leading to high operating and investment costs. In addition, the inevitably severe catalyst deactivation induced by carbon deposition and metal sintering at high reaction temperature is other limitation of DRM. The synergistic effect of promoters and supports on catalytic attributes, including metal dispersion, extent of metal-support interaction, and crystallite size, has been extensively studied to improve catalytic performance and stability. The use of appropriate supports or promoters possessing a mesoporous structure and basic or redox properties help prevent the catalyst from deteriorating by carbonaceous deposition and sintering.

Power law, ER, and LHHW models are the three standard DRM kinetic models. The empirical power law models do not explain the complex and multistep pathways of the DRM reaction, but the reaction orders could indicate the dominance or important role of reactant partial pressure on overall catalytic activity. A large number of mechanistic-based ER and LHHW models derived from single-site or dual-site mechanisms with various RDS have been proposed for capturing the $\mathrm{CH}_{4}$ consumption rate.

Apart from utilizing suitable supports and promoters to formulate carbonresistant catalysts, carbonaceous deposition may be suppressed by cofeeding a small amount of oxidizing reactants, namely, $\mathrm{H}_{2} \mathrm{O}$ and $\mathrm{O}_{2}$, to the $\mathrm{CH}_{4}$ and $\mathrm{CO}_{2}$ reactant mixture. In fact, bi-reforming (or combined steam and DRM) and oxidative DRM (referring to DRM with the corresponding addition of $\mathrm{H}_{2} \mathrm{O}$ and $\mathrm{O}_{2}$ reactants) have recently been considered as alternative approaches to inhibit coke deposition. In the presence of these oxidizing agents, surface carbon can be easily gasified to gaseous products, thus keeping the catalyst surface free from carbonaceous species. Additionally, these reforming processes are capable of generating syngas with desirable and flexible $\mathrm{H}_{2} / \mathrm{CO}$ ratios for downstream processing via manipulation of reactant composition. Future investigations into bi-reforming and oxidative DRM in terms of catalyst recipe and kinetic modeling could be considered to optimize the efficiency of reforming processes for large-scale production. 


\subsection{TRI-REFORMING OF METHANE}

\subsubsection{Thermodynamic Equilibrium Aspect}

In a given landfill gas, some quantity of oxygen is usually present, possibly up to $5 \mathrm{vol} \%$. It is meaningful to be able to reform a purified landfill containing again oxygen. Fig. 4.11 shows the thermodynamic equilibrium of a mixture containing $51.3 \% \mathrm{CH}_{4}, 25.6 \% \mathrm{CO}_{2}, 20.5 \% \mathrm{H}_{2} \mathrm{O}$, and $2.6 \% \mathrm{O}_{2}$ (molar percentage, or $2 \mathrm{~mol}$ of $\mathrm{CH}_{4}, 1 \mathrm{~mol}$ of $\mathrm{H}_{2} \mathrm{O}, 1 \mathrm{~mol}$ of $\mathrm{CO}_{2}$, and $0.1 \mathrm{~mol}$ of $\mathrm{O}_{2}$ ) at atmospheric pressure. This mixture corresponds to a stoichiometric reaction of $\mathrm{CH}_{4}$ with the three oxidants, according to Eqs. (4.1), (4.5), (4.7) in Table 4.2. Oxygen is completely consumed in the temperature range studied. Methane is gradually consumed above $350^{\circ} \mathrm{C}$ and it practically disappears above $850^{\circ} \mathrm{C}(>98 \%)$. Solid carbon can be nearly eliminated above $800^{\circ} \mathrm{C}$ and it is very important for avoiding the catalyst deactivation by coke deposition. Water is permanently present as a byproduct due to the WGS. Finally, $\mathrm{H}_{2}$ and $\mathrm{CO}$ are formed as the main products, with high selectivity above $800^{\circ} \mathrm{C}$, and the molar ratio of $\mathrm{H}_{2} / \mathrm{CO}$ is close to 1.65 within $800-1000^{\circ} \mathrm{C}$, which is interesting for hydrocarbon synthesis via the Fisher-Tropsch process. Thus, it is recommended to perform tri-reforming above $800^{\circ} \mathrm{C}$.

Fig. 4.12 shows the thermodynamic equilibrium of a mixture containing $43.5 \% \mathrm{CH}_{4}, 21.7 \% \mathrm{CO}_{2}, 32.6 \% \mathrm{H}_{2} \mathrm{O}$, and $2.2 \% \mathrm{O}_{2}$ (molar percentage, or

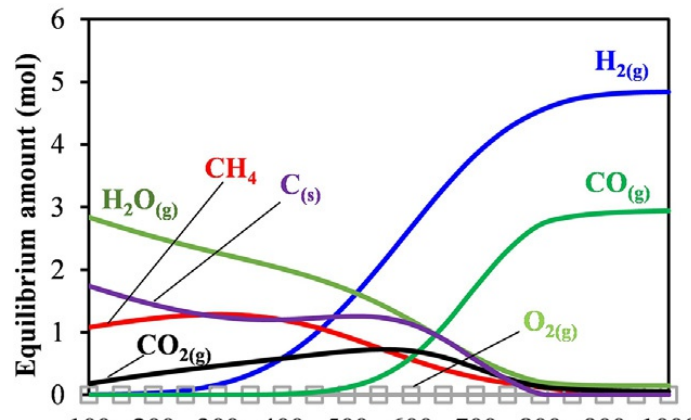

$(A)^{100}$ $\begin{array}{llllllll}100 & 200 & 300 & 400 \quad 500 \quad 600 & 700 \quad 800 & 900 & 1000\end{array}$ Temperature $\left({ }^{\circ} \mathrm{C}\right)$

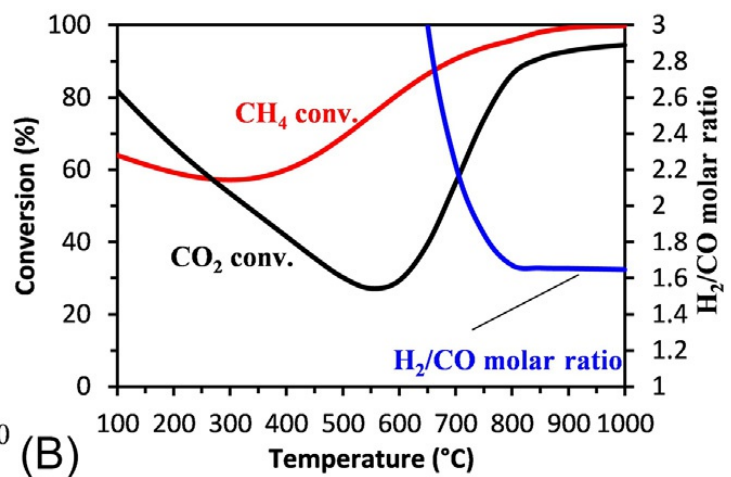

(B)

FIG. 4.11 Thermodynamic Equilibrium of the Mixture Containing 2 mol of $\mathrm{CH}_{4}, 1 \mathrm{~mol}$ of $\mathrm{H}_{2} \mathrm{O}$, $1 \mathrm{~mol}$ of $\mathrm{CO}_{2}$, and $0.1 \mathrm{~mol}$ of $\mathrm{O}_{2}$.

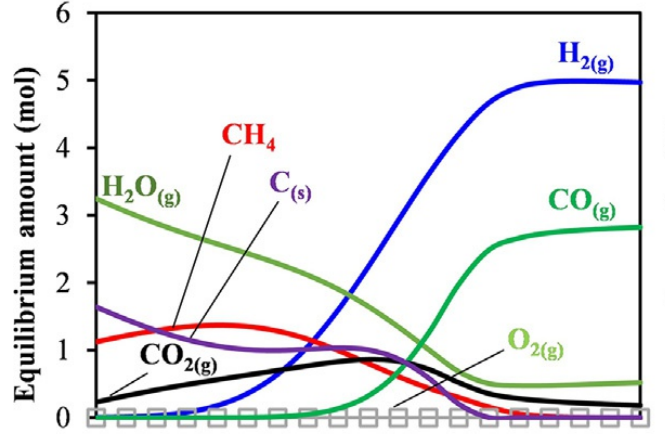

(A)
1002003004005006007008009001000 Temperature $\left({ }^{\circ} \mathrm{C}\right)$

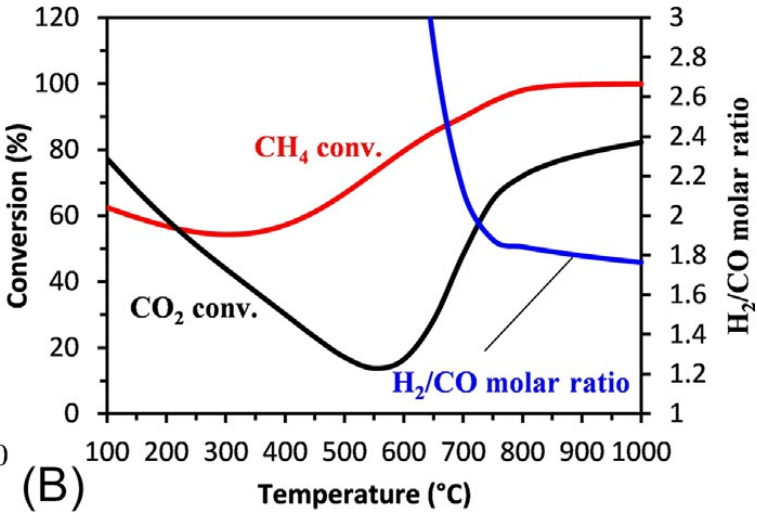

(B)
Temperature $\left({ }^{\circ} \mathrm{C}\right)$

FIG. 4.12 Thermodynamic equilibrium of the mixture containing 2 mol of $\mathrm{CH}_{4}, 1.5 \mathrm{~mol}$ of $\mathrm{H}_{2} \mathrm{O}$, $1 \mathrm{~mol}$ of $\mathrm{CO}_{2}$ and $0.1 \mathrm{~mol}$ of $\mathrm{O}_{2}$. 
$2 \mathrm{~mol}$ of $\mathrm{CH}_{4}, 1.5 \mathrm{~mol}$ of $\mathrm{H}_{2} \mathrm{O}, 1 \mathrm{~mol}$ of $\mathrm{CO}_{2}$, and $0.1 \mathrm{~mol}$ of $\mathrm{O}_{2}$ ) at atmospheric pressure. This mixture contains a slight excess of oxidants to methane, or the molar ratio of $\left(\mathrm{H}_{2} \mathrm{O}+\mathrm{CO}_{2}+\mathrm{O}_{2}\right) / \mathrm{CH}_{4}$ of this mixture is equal to $2.1 / 2$. The behavior of this system is similar to the system presented in Fig. 4.11. It is worth noting that adding more water avoids early solid carbon formation as of $750^{\circ} \mathrm{C}$. At $800^{\circ} \mathrm{C}$, the methane conversion can reach $98.1 \%$ with high selectivity in $\mathrm{H}_{2}$ and $\mathrm{CO}$, and the molar ratio of $\mathrm{H}_{2} / \mathrm{CO}$ can reach 1.87. However, both $\mathrm{H}_{2} \mathrm{O}$ and $\mathrm{CO}_{2}$ are present in large excess and can negatively impact the final energy balance of the reforming process.

\subsubsection{Catalysts for Methane Tri-Reforming}

The TRM process has been regarded as a synergetic combination technique consisting of endothermic steam reforming of methane, DRM, and exothermic partial oxidation of methane. As a heterogeneous catalytic reforming process, Ni-based catalysts are widely used in TRM due to their low cost, high availability, and capability of $\mathrm{C}-\mathrm{H}$ bond cleavage. Support and promoter are the main components of industrial Ni-based catalysts and substantially influence the catalytic performance in terms of reactant conversions, selectivity, and stability in harsh TRM reaction conditions. The effect of various supports and promoters on TRM catalysts will be discussed thoroughly in the following sections.

\subsubsection{Catalyst Supports}

As in steam reforming and dry reforming processes, the utilization of supports for dispersing active metals and providing mechanical strength for catalysts also plays a crucial role in TRM in terms of catalytic activity, product selectivity, and stability. A wide range of supports has been examined for TRM based on several main selection standards and their intrinsic nature (Song and Pan, 2004; García-Vargas et al., 2014). For instance, because $\mathrm{CO}_{2}$ is one of the reactants in TRM, supports having a basic character or high oxygen storage capacity could enhance $\mathrm{CO}_{2}$ adsorption and hence increase $\mathrm{CO}_{2}$ conversion (Song and Pan, 2004).

Song and Pan (2004) investigated the effect of both single-metal oxides, namely, $\mathrm{CeO}_{2}, \mathrm{ZrO}_{2}, \mathrm{MgO}$, and $\mathrm{Al}_{2} \mathrm{O}_{3}$, and mixed-metal oxides, including $\mathrm{CeO}_{2}-\mathrm{ZrO}_{2}$ with a $\mathrm{Ce}: \mathrm{Zr}$ atomic ratio $=3$, on the TRM catalytic performance of Ni catalysts prepared via the wet impregnation method. They observed that high $\mathrm{CH}_{4}(\geq 97 \%)$ and $\mathrm{CO}_{2}$ (about $80 \%$ ) conversions were attained on supported Ni catalysts with desirable $\mathrm{H}_{2} / \mathrm{CO}$ ratios ranging from 1.5 to 2.0 at a reaction temperature of $1073-1123 \mathrm{~K}$ and atmospheric pressure. In addition, unlike DRM reaction, TPO measurements for the deposited carbon content on the catalysts used indicate that, except for the $\mathrm{Ni} / \mathrm{ZrO}_{2}$ catalyst with a small quantity of carbonaceous carbon $(1.34 \mathrm{wt} \%)$, carbon deposition was not present on other $\mathrm{Ni}$-based catalysts. They also found that the capability of $\mathrm{CO}_{2}$ consumption over different supported catalysts was strongly reliant on the extent of 
interaction between metal and support. The order of $\mathrm{CO}_{2}$ conversion in TRM was reported as: $\mathrm{Ni} / \mathrm{MgO}>\mathrm{Ni} / \mathrm{MgO} / \mathrm{CeZrO}>\mathrm{Ni} / \mathrm{CeO}_{2} \approx \mathrm{Ni} / \mathrm{ZrO}_{2} \approx \mathrm{Ni} /$ $\mathrm{Al}_{2} \mathrm{O}_{3}>\mathrm{Ni} / \mathrm{CeZrO}$. Among the supported Ni catalysts, the greater $\mathrm{CO}_{2}$ conversion on the $\mathrm{Ni} / \mathrm{MgO}$ and $\mathrm{Ni} / \mathrm{MgO} / \mathrm{CeZrO}$ catalysts was attributed to the stronger interaction of $\mathrm{MgO}$ and $\mathrm{CO}_{2}$, as well as more $\mathrm{Ni}$ and $\mathrm{MgO}$ interface arising from the formation of $\mathrm{NiO} / \mathrm{MgO}$ solid solution.

In the study of support influence on Ni catalysts for TRM, García-Vargas et al. (2014) synthesized five different $\mathrm{Ni}$ catalysts dispersed on various supports, including $\gamma-\mathrm{Al}_{2} \mathrm{O}_{3}$, yttria-stabilized zirconia (YSZ), yttria-stabilized zirconia calcined in an oxygen-poor environment $\left(\mathrm{YSZ}_{2} \mathrm{O}_{2}\right), \mathrm{CeO}_{2}$, and silicon carbide ( $\beta$-SiC) (García-Vargas et al., 2014). Gamma-alumina was selected as a support due to its mechanical strength and thermal stability under the high reaction temperature required for TRM, while $\mathrm{ZrO}_{2}$-based supports reportedly possessed high thermal resistance and ionic conductivity for reforming processes because of their crystal surface defects in which oxygen reactant could easily be activated, and hence enhance reactivity (Bellido and Assaf, 2009). Apart from high thermal conductivity and mechanical strength, $\mathrm{SiC}$ has chemical inertness and low specific weight, which are appropriate properties for being supports of the endothermic TRM reaction (García-Vargas et al., 2014). García-Vargas et al. (2014) reported that $\mathrm{CeO}_{2}$ and $\beta$-SiC materials appeared to be the best catalytic supports for the TRM process. In fact, $\mathrm{CeO}_{2}$ - and $\beta$-SiC-supported $\mathrm{Ni}$ catalysts exhibited the highest $\mathrm{CH}_{4}$ reaction rate without considerable deactivation. $\mathrm{Ni} / \mathrm{CeO}_{2}$ catalyst yielded the lowest $\mathrm{H}_{2} / \mathrm{CO}$ ratio and this observation was attributed to the high basicity of the $\mathrm{CeO}_{2}$ support, which enhanced $\mathrm{CO}_{2}$ adsorption to initiate more of the methane dry reforming reaction. Among supported catalysts, $\mathrm{Ni} / \mathrm{Al}_{2} \mathrm{O}_{3}$ catalyst showed the lowest $\mathrm{CH}_{4}$ and $\mathrm{CO}_{2}$ conversions owing to the formation of the $\mathrm{NiAl}_{2} \mathrm{O}_{4}$ phase. In addition, the catalytic performance of $\mathrm{Ni} / \mathrm{YSZ}^{-\mathrm{O}_{2}}$ catalyst was superior to that of $\mathrm{Ni} / \mathrm{YSZ}$ catalyst because the calcination conditions of Ni/YSZ-O catalyst resulted in a better $\mathrm{NiO}$ reducibility and greater number of oxygen vacancies on the support surface.

Based on the aforementioned important characteristics of supports for TRM catalyst design, composite oxides, such as $\mathrm{MgO}^{-\mathrm{TiO}_{2}}$ (Jiang et al., 2007) and $\mathrm{MgO}-\mathrm{ZrO}_{2}$ (Walker et al., 2012), have been developed as promising supports as these materials also have high surface oxygen vacancies and great basic site concentration, which could contribute to increase carbonaceous gasification. Jiang et al. (2007) investigated $\mathrm{Mg}_{x} \mathrm{Ti}_{1-x} \mathrm{O}$ composite oxides (with $0 \leq x \leq 1$ ) as supports for impregnation of nickel nitrate. TRM longevity runs were conducted in a continuous-flow fixed-bed reactor at $1123 \mathrm{~K}$ and $1 \mathrm{MPa}$ for $50 \mathrm{~h}$. The activity of $\mathrm{Ni} / \mathrm{MgO}, \mathrm{Ni} / \mathrm{Mg}_{0.25} \mathrm{Ti}_{0.75} \mathrm{O}$ and $\mathrm{Ni} / \mathrm{TiO}_{2}$ catalysts declined within $6 \mathrm{~h}$ on-stream while high catalytic stability was observed for the $\mathrm{Ni} / \mathrm{Mg}_{0.75} \mathrm{Ti}_{0.25} \mathrm{O}$ and $\mathrm{Ni} / \mathrm{Mg}_{0.5} \mathrm{Ti}_{0.5} \mathrm{O}$ catalysts. Catalyst deactivation was reportedly induced by the re-oxidation of the $\mathrm{Ni}$ metallic phase to the inactive $\mathrm{NiO}$ phase or support 
phase transformation at high temperature. There was no graphitic carbon or carbon fiber detected in XRD and SEM measurements for $\mathrm{Ni} / \mathrm{Mg}_{0.75} \mathrm{Ti}_{0.25} \mathrm{O}$ and $\mathrm{Ni} / \mathrm{Mg}_{0.5} \mathrm{Ti}_{0.5} \mathrm{O}$ catalysts. The authors deduced that the moderate metal-support interaction and the right ability to be reduced contributed to the high stability of $\mathrm{Ni} / \mathrm{Mg}_{0.75} \mathrm{Ti}_{0.25} \mathrm{O}$ and $\mathrm{Ni} / \mathrm{Mg}_{0.5} \mathrm{Ti}_{0.5} \mathrm{O}$ catalysts.

Walker et al. (2012) studied the effect of support composition, metal loading, and preparation method on the catalytic performance of $\mathrm{Ni}-\mathrm{MgO}-(\mathrm{Ce}$, $\mathrm{Zr}) \mathrm{O}_{2}$ composite catalysts for TRM. They discovered that implementing even more Ce:Zr ratio could yield an increase in oxygen mobility and redox attributes, which in turn allow the movement of oxygen atoms to suitable sites for removing surface carbonaceous species. In addition, a greater $\mathrm{H}_{2}$ yield and production rate were observed during TRM over catalyst with a Ni:Mg ratio of 1:1. As the Ni:Mg metal ratio was about unity, a greater number of interfaces between the $\mathrm{Ni}$ and $\mathrm{Mg}$ phases were formed. Because $\mathrm{MgO}$ has a basic nature, preferably attracting $\mathrm{CO}_{2}$ adsorption, more $\mathrm{Ni}$ and $\mathrm{Mg}$ interfaces could facilitate $\mathrm{CO}_{2}$ dissociative adsorption, and consequently, the oxygen mobility could oxidize the adsorbed carbon species originating from $\mathrm{CH}_{4}$ decomposition on the $\mathrm{Ni}$ surface.

Singha et al. (2016) modified $\mathrm{CeO}_{2}-\mathrm{ZrO}_{2}$ nanoporous composite with the addition of $\mathrm{MgO}$ for synthesizing a Ni nanocluster catalyst for TRM. $\mathrm{MgO}$ addition was reportedly coke-resistant and sintering-resistant in TRM reaction conditions. The $5 \% \mathrm{Ni}-\mathrm{MgCeZr}$ composite catalyst showed a highly stable catalytic activity, with high $\mathrm{CH}_{4}$ conversion (95\%) and an ideal $\mathrm{H}_{2} / \mathrm{CO}$ ratio of about 2 for TRM, without any deactivation over $100 \mathrm{~h}$ on-stream. They attributed this outstanding catalytic performance to the synergetic effects of the various metal oxides employed. In fact, $\mathrm{ZrO}_{2}$ enhanced the thermal stability of the catalyst while the interaction between $\mathrm{MgO}$ and $\mathrm{Ce}_{x} \mathrm{Zr}_{1-x} \mathrm{O}_{2}$ metal oxides improved the dispersion of $\mathrm{Ni}$ particles. In addition, a $\mathrm{CeO}_{2}-\mathrm{ZrO}_{2}$ solid solution could increase the oxygen storage capacity, facilitating the carbon removal process due to high surface oxygen vacancies and great oxygen mobility in the lattice. Pino et al. (2014) also reported similar findings for TRM over Ni-based catalysts supported on La-Ce-O mixed oxides. In this study, a series of La-Ce-O mixed oxide-supported $\mathrm{Ni}$ catalysts with various Ni loadings was prepared using the combustion technique. The highest catalytic activity was evident for $\mathrm{Ce}_{0.7} \mathrm{La}_{0.2} \mathrm{Ni}_{0.1} \mathrm{O}_{2-\delta}$ catalyst, with no detectable carbon deposition observed in a SEM image after $150 \mathrm{~h}$ on-stream. After the prereduction step, the formation of $\mathrm{LaO}_{x}$ species increased the d-electron density of $\mathrm{Ni}$ atoms, which in turn hindered carbonaceous deposition on the catalyst surface. The authors concluded that the high catalytic activity was associated with the interaction between nickel-lanthana and surface oxygen vacancies of $\mathrm{CeO}_{2}$, which resulted in rising metal dispersion. However, at high active metal and $\mathrm{La}_{2} \mathrm{O}_{3}$ contents, the observed catalytic deterioration with TOS was attributed to re-oxidation of the $\mathrm{Ni}^{0}$ metallic phase, metal sintering, and surface coverage by excessive lanthana species. 


\subsubsection{Promoters}

Because the TRM process is a complex heterogeneous catalytic reaction involving the concomitant presence of three main catalytic reactions (including methane steam reforming, methane dry reforming, and methane partial oxidation), apart from metal oxide supports, the role of promoter addition to a TRM catalyst is essential for maximizing catalytic performance, product yield, and catalytic stability with TOS in drastic operation conditions. As a typical reforming process, rare-earth metal oxides are also employed as promoters for Ni-based catalysts in the TRM process in order to gain the benefits of their basic and redox attributes. In an investigation of La-doping on $\mathrm{Ni}-\mathrm{CeO}_{2}$ catalysts, Pino et al. (2011) reported that $\mathrm{CH}_{4}$ and $\mathrm{CO}_{2}$ conversions considerably improved with the addition of $10 \mathrm{wt} \% \mathrm{La}$, from $93 \%$ to $96 \%$ and $83 \%$ to $86.5 \%$, respectively, with the absence of carbonaceous deposition. Nevertheless, a significant decline in both $\mathrm{CO}_{2}$ and $\mathrm{CH}_{4}$ conversions was observed at excessive La loading beyond $10 \mathrm{wt} \% \mathrm{La}$ while the $\mathrm{H}_{2} / \mathrm{CO}$ ratio appeared to be unaffected at about $1.62-1.65$. The strong interaction within the $\mathrm{Ni}-\mathrm{La}_{2} \mathrm{O}_{3}$-surface oxygen vacancies of $\mathrm{CeO}_{2}$ was considered as the driving force for enhancing catalytic activity by improving the dispersion of $\mathrm{Ni}$ particles and inducing the formation of $\mathrm{Ce}^{3+}$ sites. Additionally, $\mathrm{La}_{2} \mathrm{O}_{3}$ promotion was able to create a large number of intermediate and strong basic sites, enabling a stronger binding interaction between the catalyst surface and the $\mathrm{CO}_{2}$ reactant. As a result, the increasing $\mathrm{CO}_{2}$ adsorption was able to enhance the reforming activity. The promotional effects of $\mathrm{CeO}_{2}$ and $\mathrm{La}_{2} \mathrm{O}_{3}$ addition on the catalytic performance of $\mathrm{Ni} / \mathrm{Al}_{2} \mathrm{O}_{3}$ catalyst for TRM were also examined by Solov'ev et al. (2012) at various feed compositions and with reaction temperatures of 814-1123 K. They reported that the addition of $\mathrm{CeO}_{2}$ or $\mathrm{La}_{2} \mathrm{O}_{3}$ promoter provided additional pathways for $\mathrm{CO}_{2}$ activation. Thus, the formation and decomposition of surface carbonates could yield active oxygen species reacting with surface carbon from $\mathrm{CH}_{4}$ dissociation on $\mathrm{Ni}$ metallic phase.

García-Vargas et al. (2014) examined the influence of alkaline (including $\mathrm{Na}$ and $\mathrm{K}$ ) and alkaline earth (namely, $\mathrm{Mg}$ and $\mathrm{Ca}$ ) promoters on the performance of $\mathrm{Ni} / \beta-\mathrm{SiC}$ catalyst. Although $\mathrm{Na}$ and $\mathrm{K}$ metal oxides were reported as appropriate promoters in other reforming processes, these metal oxides were not useful for TRM. This was assigned to their ability to enhance the oxidation rate of $\beta$-SiC during calcination to generate an $\alpha$-cristobalite form. A similar behavior was also observed for Ca promoter with high loading. However, the promotion of $\mathrm{Mg}$ reduced the $\mathrm{Ni}$ metal particle size and increased the basicity of the catalyst resulting in increased activity and stability of the Mg-promoted catalyst. The authors also assessed the effect of $\mathrm{Mg}$ loading and found that an increase in the $\mathrm{Mg} / \mathrm{Ni}$ ratio induced a decline in the crystallite size and in the reducibility of $\mathrm{NiO}$ particles, most likely due to $\mathrm{NiO}-\mathrm{MgO}$ solid solution formation.

In order to facilitate the comparison between catalysts and easily identify the influence of support and promoter types on the TRM catalytic performance, 
Table 4.12 summarizes the TRM reaction conditions and catalytic performance of various promoted and supported catalysts. The degree of catalyst deactivation is also estimated based on initial and final $\mathrm{CH}_{4}$ conversions. Additionally, the $\mathrm{H}_{2} / \mathrm{CO}$ ratio is given to justify the suitability of the produced syngas mixture for downstream processing.

\subsubsection{Tri-reforming of Methane: Kinetic Model}

Kinetic studies are generally conducted to determine the most appropriate reaction rate model that is fundamentally derived from mechanistic reaction pathways in order to capture the experimental reactant reaction rate and the product formation rate with the best fit. In comparison with other reforming processes (namely, methane dry reforming and methane steam reforming reactions), kinetic studies of TRM are relatively fewer and TRM kinetic investigations could become an essential focus in the near future. In kinetic studies of Ni catalysts supported on various metal oxides and mixed oxides, Song and Pan (2004) used a simplified power law model (Eq. (4.22)) to capture both the $\mathrm{CH}_{4}$ and $\mathrm{CO}_{2}$ reaction rates. In order to simplify the kinetic model for TRM, they kept the partial pressure of $\mathrm{CH}_{4}$ and $\mathrm{O}_{2}$ constant. Thus, the effect of the $\mathrm{CH}_{4}$ and $\mathrm{O}_{2}$ partial pressures could be incorporated into other associated constants.

$$
r_{i}=A \exp \left(\frac{-E_{\text {app }, i}}{R T}\right)\left(P_{\mathrm{CO}_{2}}\right)^{\alpha, i}\left(P_{\mathrm{H}_{2} \mathrm{O}}\right)^{\beta, i}
$$

where $r_{i}$ is reaction rate of $\mathrm{CH}_{4}$ or $\mathrm{CO}_{2}$ while $A$ and $E_{\text {app }}$ are the preexponential factor and apparent activation energy, respectively. Reaction orders for $\mathrm{CO}_{2}$ and $\mathrm{H}_{2} \mathrm{O}$ are $\alpha$ and $\beta$ in this order, whereas $P_{\mathrm{CO}_{2}}$ and $P_{\mathrm{H}_{2} \mathrm{O}}$ are the corresponding partial pressures of $\mathrm{CO}_{2}$ and $\mathrm{H}_{2} \mathrm{O}$. The activation energies and reaction orders for $\mathrm{CH}_{4}$ and $\mathrm{CO}_{2}$ reaction rates were estimated from Eq. (4.22) for various supported Ni catalysts and are summarized in Table 4.13.

Based on the estimated activation energies and reaction orders in Table 4.13, Song and Pan (2004) deduced that, because the reaction orders with respect to the $\mathrm{H}_{2} \mathrm{O}$ partial pressure for the $\mathrm{CO}_{2}$ consumption rate were negative for all catalysts, $\mathrm{CO}_{2}$ and $\mathrm{H}_{2} \mathrm{O}$ could compete with each other to convert $\mathrm{CH}_{4}$ to $\mathrm{CO}$ and $\mathrm{H}_{2}$. Thus, increasing $P_{\mathrm{H}_{2} \mathrm{O}}$ may result in a reduction in the $\mathrm{CO}_{2}$ reaction rate. Apart from the competition effect, the presence of the water gas shift reaction during TRM may partially contribute to the decline of the $\mathrm{CO}_{2}$ reaction rate in a $\mathrm{H}_{2} \mathrm{O}$-rich reactant mixture.

As seen in Table 4.13, the TRM kinetic investigation shows that for both the $\mathrm{CH}_{4}$ and $\mathrm{CO}_{2}$ reaction rates, the reaction orders with respect to the $\mathrm{CO}_{2}$ and $\mathrm{H}_{2} \mathrm{O}$ partial pressures were observably different for various catalyst types. Additionally, power law models do not actually comply with intrinsically mechanistic reaction pathways, although they are widely employed to sufficiently capture reactant reaction rates in reforming processes to acquire apparent activation 


\begin{tabular}{|c|c|c|c|c|c|}
\hline & & $\equiv$ & & & \\
\hline 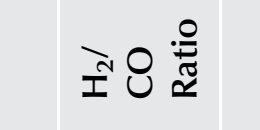 & $\stackrel{8}{\ddagger}$ & $\stackrel{g}{g}$ & & & \\
\hline 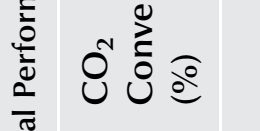 & 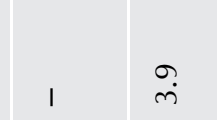 & ฐ & & & \\
\hline 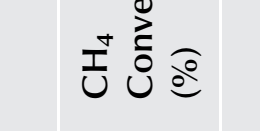 & $g$ & z & 1 & & $\underline{z}$ \\
\hline 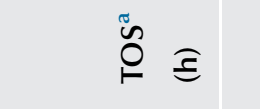 & 10 & $\approx$ & & & \\
\hline 至患 & , & 8 & , & & \\
\hline 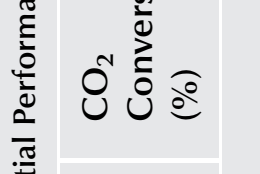 & $\cong$ & $\frac{8}{8}$ & $\frac{8}{\delta}$ & & \\
\hline 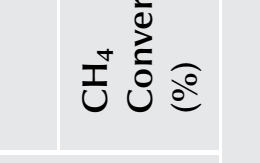 & $\stackrel{9}{9}$ & 需 & 总 & & \\
\hline 亳售 & $\approx$, & 8 & q & & \\
\hline & 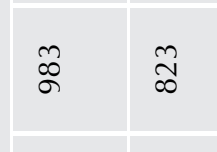 & 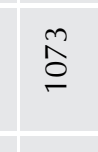 & 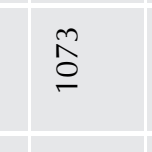 & & \\
\hline & & & 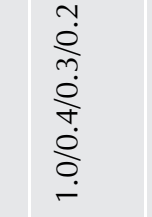 & & \\
\hline & & & & & \\
\hline
\end{tabular}




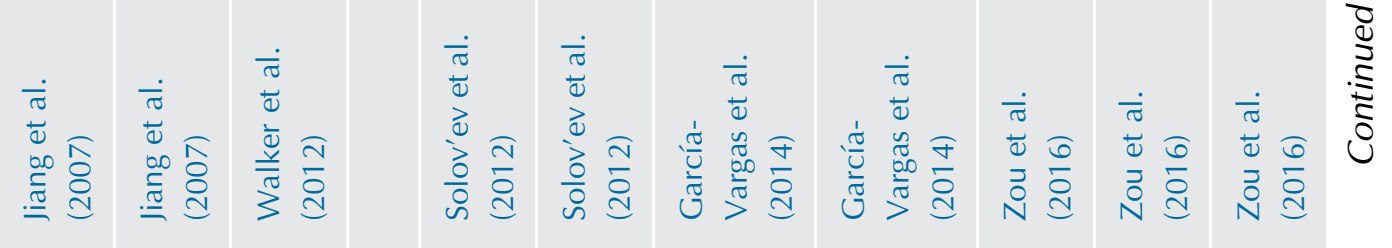
ஸे

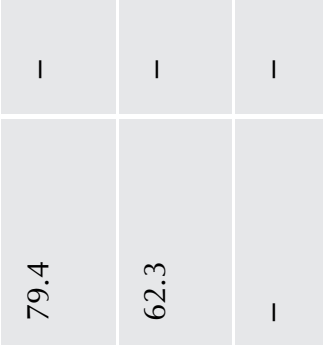

$\begin{array}{lll} & \\ \text { ñ } & \dot{0} & \\ & \infty & 1\end{array}$

\begin{tabular}{|c|c|c|}
\hline 우 & 유 & 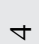 \\
\hline 1 & 1 & $\stackrel{\circ}{\stackrel{\nu}{v}}$ \\
\hline
\end{tabular}

ฐ

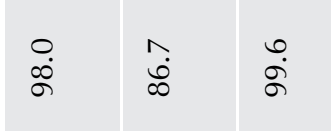

$1, \frac{1}{2}$

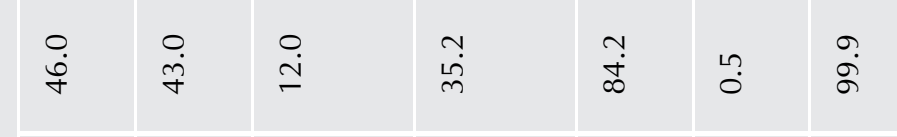

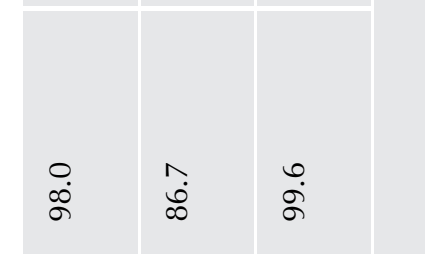

\section{$\cong \cong$}

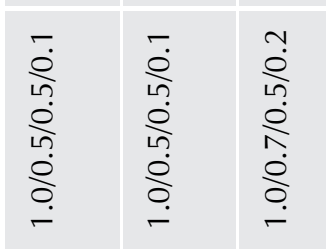

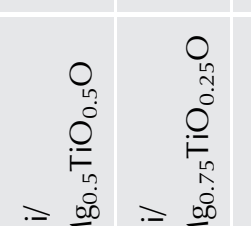

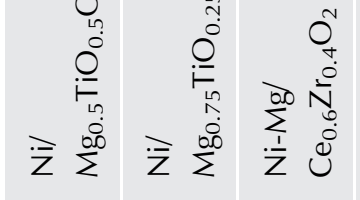

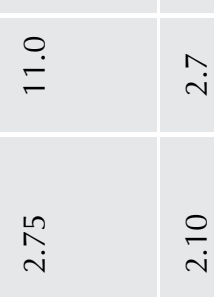

$\therefore$

$\begin{array}{ll}\infty & N \\ & \infty\end{array}$

\begin{tabular}{|c|c|c|}
\hline 1 & 1 & $\stackrel{\sim}{\sim}$ \\
\hline 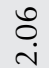 & 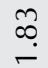 & $\begin{array}{l}\text { ஸे } \\
\sim \\
\sim\end{array}$ \\
\hline
\end{tabular}

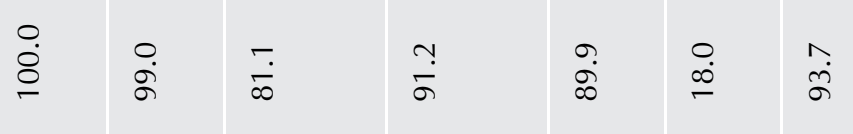

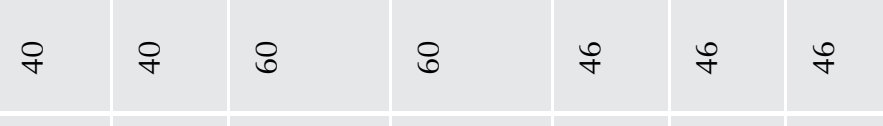

蛋

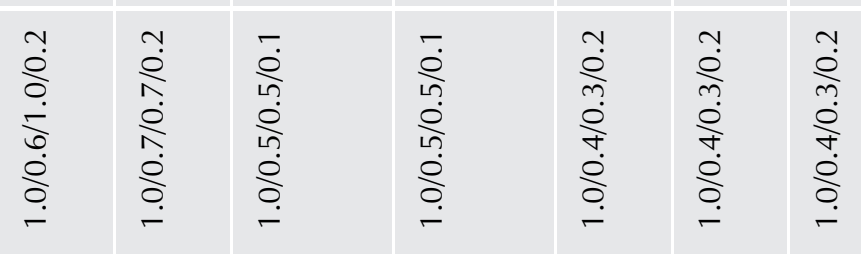

$\frac{n}{\pi}$

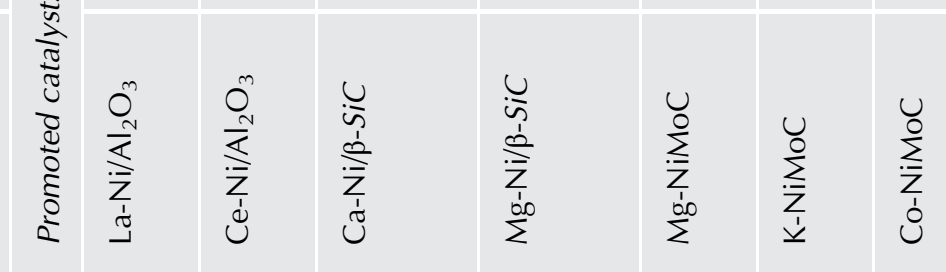




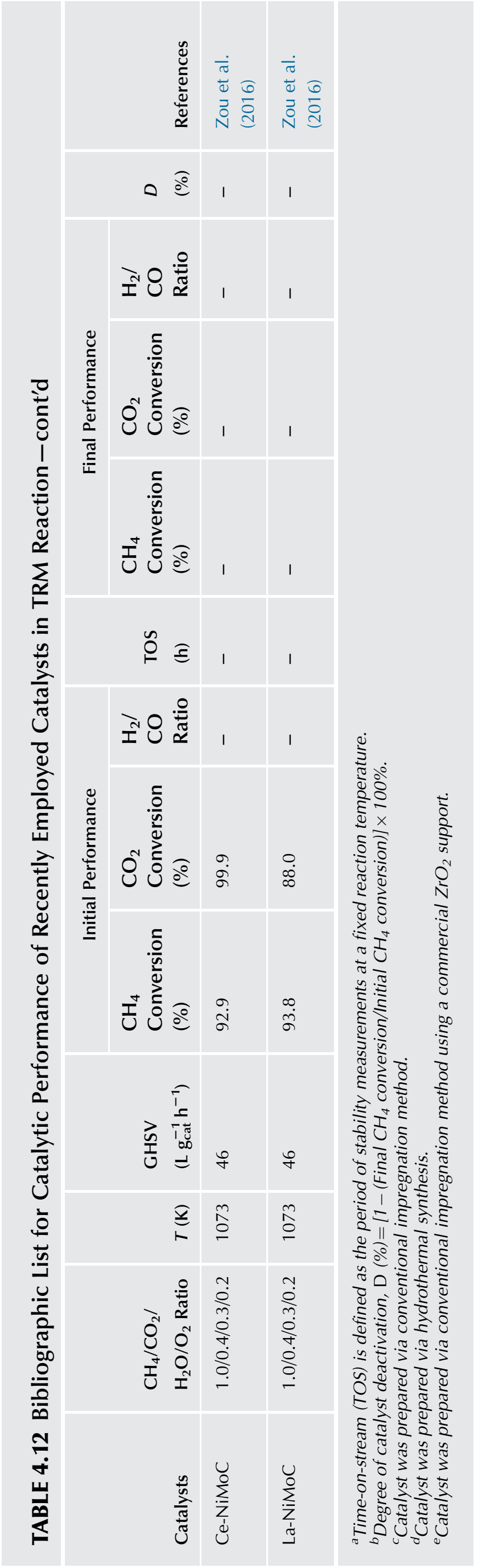




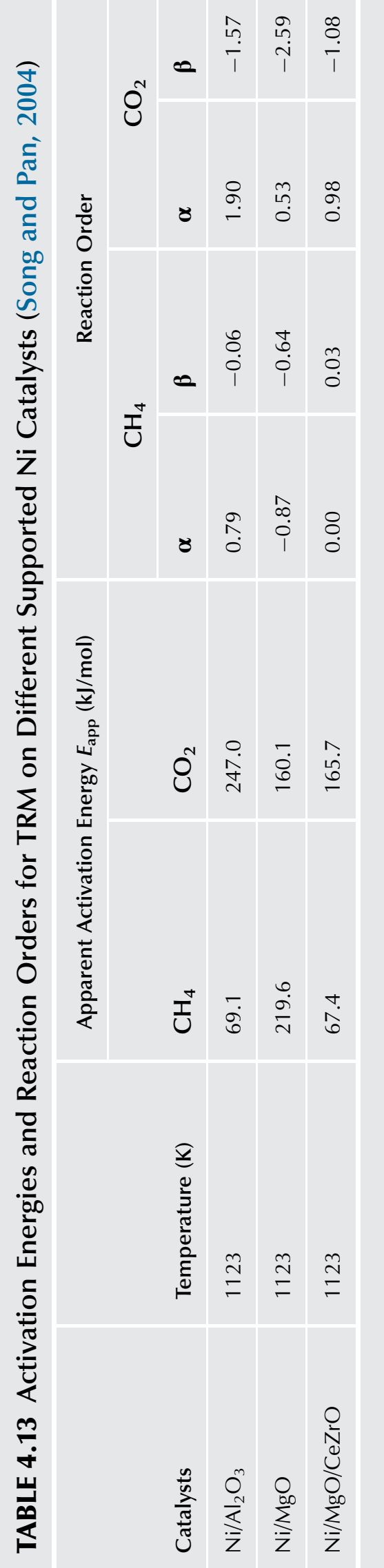


energy and reaction orders. Thus, in order to examine the interaction between $\mathrm{CO}_{2}$ and the catalyst surface, Song and Pan (2004) used a simplified LangmuirHinshelwood model based on the DRM reaction to avoid the complexity of TRM. The mechanistic steps and rate of reaction for this simplified model are summarized in Table 4.14. Based on the derived TRM kinetic model, they reported that the $\mathrm{CO}_{2}$ adsorption equilibrium constant, $K_{\mathrm{CO}_{2}}$, depended strongly on the interaction of $\mathrm{CO}_{2}$ with the catalyst surface. Because $\mathrm{CO}_{2}$ interacted strongly with the catalyst surface, molecularly adsorbed $\mathrm{CO}_{2}$ species became the most abundant reaction intermediates. Thus, most of active sites could be occupied by associatively adsorbed $\mathrm{CO}_{2}$ species at increasing $\mathrm{CO}_{2}$ partial pressure, hence leaving fewer available sites for $\mathrm{CH}_{4}$ adsorption. Therefore, a decline in the $\mathrm{CH}_{4}$ reaction rate with increased $\mathrm{CO}_{2}$ partial pressure was observed and the reaction order with respect to $\mathrm{CO}_{2}$ reactant became negative. However, in the case of weak $\mathrm{CO}_{2}$ interaction with the catalyst, the opposite results were evident and the reaction order for $\mathrm{CO}_{2}$ appeared to be positive.

Maciel et al. (2010) carried out a kinetic evaluation of $\mathrm{Ni} / \gamma-\mathrm{Al}_{2} \mathrm{O}_{3}$ catalyst for the TRM reaction and proposed a four-step reaction mechanism as summarized in Table 4.15. Step I indicates the overall combined reactions, including

\section{TABLE 4.14 Reaction Mechanism of TRM Suggested by Song and Pan (2004)}

$$
\begin{array}{l|l}
\text { Mechanistic Steps } & \mathrm{CH}_{4}+\stackrel{K_{\mathrm{CH}}}{\leftrightarrow} \mathrm{CH}_{4}^{*} \\
\hline \text { Reactant adsorption } & \mathrm{CO}_{2}+\stackrel{K_{\mathrm{CO}}}{\leftrightarrow} \mathrm{CO}_{2}^{*} \\
\hline \text { Surface reaction } & \mathrm{CH}_{4}^{*}+\mathrm{CO}_{2}^{*} \rightarrow 2 \mathrm{H}_{2}+2 \mathrm{CO}+2^{*} \\
\hline \text { Rate of } \mathrm{CH}_{4} \text { reaction } & -r_{\mathrm{CH}_{4}}=\frac{k K_{\mathrm{CH}_{4}} K_{\mathrm{CO}_{2}} P_{\mathrm{CH}_{4}} P_{\mathrm{CO}_{2}}}{\left(1+K_{\mathrm{CH}_{4}} P_{\mathrm{CH}_{4}}+K_{\mathrm{CO}_{2}} P_{\mathrm{CO}_{2}}\right)^{2}}
\end{array}
$$

Note: ${ }^{*}$ is an available active site on catalyst surface and $\mathrm{k}$ is the rate constant of rate-determining step.

TABLE 4.15 The Four-Step Reaction Mechanism for the TRM Reaction

Proposed by Maciel et al. (2010)

$$
\begin{array}{l|l}
\hline \text { Reaction Steps } & \text { Rate Models } \\
\hline \text { Step I: } \mathrm{CH}_{4}+\frac{5}{8} \mathrm{O}_{2} \leftrightarrow \mathrm{CO}+\frac{7}{4} \mathrm{H}_{2}+\frac{1}{4} \mathrm{H}_{2} \mathrm{O} & r_{\mathrm{I}}=\frac{k_{1} K_{\mathrm{CH}_{4}} P_{\mathrm{CH}_{4}} K_{\mathrm{O}_{2}} P_{\mathrm{O}_{2}}}{\left(1+K_{\mathrm{CH}_{4}} P_{\mathrm{CH}_{4}}+K_{\mathrm{O}_{2}} P_{\mathrm{O}_{2}}\right)^{2}} \\
\hline \text { Step II: } \mathrm{CH}_{4} \text { cracking } \mathrm{CH}_{4} \rightarrow \mathrm{C}+2 \mathrm{H}_{2} & r_{\mathrm{II}}=\frac{k_{2} K_{\mathrm{CH}_{4}} P_{\mathrm{CH}_{4}}}{1+K_{\mathrm{CH}_{4}} P_{\mathrm{CH}_{4}}} \\
\hline \begin{array}{l}
\text { Step III: Boudouard reaction } \\
\text { 2CO } \rightarrow \mathrm{C}+\mathrm{CO}_{2}
\end{array} & r_{\mathrm{III}}=k_{3} P_{\mathrm{CO}}^{2} \\
\hline \begin{array}{l}
\text { Step IV: Reverse water gas-shift reaction } \\
\mathrm{CO}_{2}+\mathrm{H}_{2} \rightarrow \mathrm{CO}+\mathrm{H}_{2} \mathrm{O}
\end{array} & r_{\mathrm{IV}}=k_{4}\left(P_{\mathrm{H}_{2}} P_{\mathrm{CO}_{2}}-\frac{P_{\mathrm{CO}} P_{\mathrm{H}_{2} \mathrm{O}}}{K_{\mathrm{eq}}}\right)
\end{array}
$$


methane dry reforming, methane steam reforming, methane partial oxidation, and methane oxidation, whereas step II is the methane cracking reaction to form solid carbon and $\mathrm{H}_{2}$. Besides these main reactions, the Boudouard reaction and the reverse water gas-shift reaction were also considered in the corresponding steps III and IV. Based on the rate laws of the four-step TRM reaction mechanism, the reactant consumption rate $\left(-r_{\mathrm{CH}_{4}}\right.$ and $\left.-r_{\mathrm{CO}_{2}}\right)$ and the product formation rate $\left(r_{\mathrm{H} 2}\right.$ and $\left.r_{\mathrm{CO}}\right)$ were expressed as follows: $-r_{\mathrm{CH} 4}=-r_{\mathrm{I}}-r_{\mathrm{II}}$; $-r_{\mathrm{CO} 2}=r_{\mathrm{III}}-r_{\mathrm{IV}} ; r_{\mathrm{H} 2}=\left(7 r_{\mathrm{I}} / 4\right)+2 r_{\mathrm{II}}-r_{\mathrm{IV}} ;$ and $r_{\mathrm{CO}}=r_{\mathrm{I}}-2 r_{\mathrm{III}}+r_{\mathrm{IV}}$. By evaluating the TRM kinetic model, the authors deduced that methane decomposition yielded carbon deposition and hydrogen during the TRM reaction while the high $\mathrm{CO}$ production rate was attributed to the concomitant presence of the reverse water gas-shift reaction and carbon gasification by carbon dioxide and oxygen reactants.

Garcia-Vargas et al. (2015) examined the effect of temperature and feed composition on the catalytic behavior of $\mathrm{Ni}-\mathrm{Mg} / \beta-\mathrm{SiC}$ catalyst for the TRM reaction. They observed that oxygen was not virtually detected in the effluent stream from the outlet of the reactor, indicating that methane partial oxidation rapidly achieved full conversion during the TRM process. Thus, experimental data were simply fitted to kinetic expressions for individual reactions, including methane steam reforming, methane dry reforming, and water gas-shift reaction. In fact, kinetic equations proposed by Wei and Iglesia (2004a, b) and De la Osa et al. (2011) for the corresponding reforming reactions (namely, steam and DRM) and water gas-shift reaction were employed for assessing the fitness of the experimental reaction rates of the TRM reaction.

Table 4.16 summarizes the reaction rates and associated kinetic parameters involved in the TRM reaction from the findings of Garcia-Vargas et al. (2015). In that study, the kinetic parameters were estimated using the Arrhenius' equation, $k_{i}=k_{i}^{0} e^{\left(-E_{a i} / R T\right)}$ with $k_{i}^{0}, E_{a_{i}}, R$, and $T$ being the corresponding preexponential factor for reaction $i$, activation energy, the universal gas constant, and the reaction temperature. A good agreement was obtained between the modeled results and the experimental data, with average errors of $10.8 \%$ and $19.4 \%$ for $\mathrm{CH}_{4}$ and $\mathrm{CO}_{2}$ molar flows, respectively. Additionally, the estimated activation energies (see Table 4.16) for each main reaction during the TRM process were consistent with the range of values reported in the literature for steam reforming and DRM (Garcia-Vargas et al., 2015).

\subsubsection{Conclusions and Outlook}

The catalytic TRM process appears to be a promising substitution for other conventional reforming processes for syngas production at an industrial scale as it is a synergistic combination of methane steam reforming, methane dry reforming, and methane partial oxidation. Particularly, coupling methane dry reforming and methane steam reforming can provide the flexible tuning of $\mathrm{H}_{2} / \mathrm{CO}$ ratios by adjusting the reactant feed composition, while the simultaneous presence of 
TABLE 4.16 Kinetic Expressions and Associated Parameters for Each Reaction Involved in the TRM Process (Garcia-Vargas et al., 2015)

\section{Rate Models}

For methane steam reforming:

$r_{\mathrm{SR}}=k_{1} P_{\mathrm{CH}_{4}}\left(1-\frac{P_{\mathrm{CO}} P_{\mathrm{H}_{2}}^{3}}{P_{\mathrm{CH}_{4}} P_{\mathrm{H}_{2}} \mathrm{O} K_{\mathrm{SR}}}\right)$

$K_{\mathrm{SR}}=1.198 \times 10^{17} e^{\left(\frac{-26830}{T}\right)}$

For methane dry reforming:

$r_{\mathrm{DR}}=k_{2} P_{\mathrm{CH}_{4}}\left(1-\frac{P_{\mathrm{CO}}^{2} P_{\mathrm{H}_{2}}^{2}}{P_{\mathrm{CH}_{4}} P_{\mathrm{CO}_{2}} K_{\mathrm{DR}}}\right)$

$K_{\mathrm{DR}}=6.780 \times 10^{18} e^{\left(\frac{-31230}{T}\right)}$

For water gas-shift reaction:

$r_{\mathrm{WGS}}=k_{3}\left(\frac{P_{\mathrm{CO}} P_{\mathrm{H}_{2} \mathrm{O}}}{P_{\mathrm{H}_{2}}}-\frac{P_{\mathrm{CO}_{2}}}{K_{\mathrm{WGS}}}\right)$

$K_{\text {WGS }}=10^{\left(\frac{2078}{T}-2.029\right)}$

\section{Associated Kinetic} Parameters

$$
k_{1}^{0}=85.77 \mathrm{~mol} \mathrm{~s}^{-1} \mathrm{kPa}^{-1}
$$

$E_{\mathrm{a}_{1}}=74.72 \mathrm{~kJ} \mathrm{~mol}^{-1}$

$$
k_{2}^{0}=70.99 \mathrm{~mol} \mathrm{~s}^{-1} \mathrm{kPa}^{-1}
$$

$E_{\mathrm{a}_{2}}=77.82 \mathrm{~kJ} \mathrm{~mol}^{-1}$ $k_{3}^{0}=149.92 \mathrm{~mol} \mathrm{~s}^{-1} \mathrm{kPa}^{-1}$

$E_{\mathrm{a}_{3}}=54.26 \mathrm{~kJ} \mathrm{~mol}^{-1}$

$\mathrm{H}_{2} \mathrm{O}, \mathrm{CO}_{2}$, and $\mathrm{O}_{2}$ oxidizing agents in the TRM reaction substantially reduce coke formation, and hence enhance the catalytic activity and prolong the catalytic lifespan.

However, bibliographic knowledge about the TRM reaction is still littleknown in both academic and industrial realms due to the complexity of this reaction. Additionally, catalyst deactivation caused by carbonaceous deposition as well as thermal sintering is always an unavoidable problem of reforming processes. Hence, studies related to carbon-resistant catalyst development have been extensively conducted by employing different groups of metals and supports to examine their synergetic effect on catalytic performance and stability over the TRM reaction.

Additionally, the use of advanced catalyst preparation approaches in order to maximize the combined benefits of promoters and supports could substantially affect the physicochemical attributes of catalysts, namely, the extent of interaction between metal and support, as well as surface metal dispersion. In order to effectively design a functional catalyst and optimize reactor design, the best-fit kinetic modeling derived from the intrinsic TRM mechanistic steps is crucial. Hence, future research on adequate catalyst synthesis methods and TRM kinetics should be considered to improve catalytic performance and stability for the industrial application of the TRM process. 


\subsection{GENERAL CONCLUSIONS}

At the present time, SMR is still the predominant process for hydrogen production from fossil resources. However, green hydrogen can be obtained from biogas as a renewable resource using not only SMR but also dry, dual, and tri-reforming processes. These alternative solutions have the advantages of employing carbon dioxide, a major component of biogas, as an oxidant in the reforming reaction, and also minimizing the steam to carbon $(\mathrm{S} / \mathrm{C})$ ratio compared to actual SMR processes. However, catalyst deactivation is still identified as the main drawback for the deployment of these reforming technologies. Among numerous studies on the cataysts for dry, dual, and tri-reforming of methane, some of them showed very promising catalytic performance. The thermodynamic equilibrium, reaction pathway and kinetic of these reforming processes are discussed in this chapter. Significant progress has been made recently but effort is still needed to determine most kinetic and mechanistic aspects of these processes.

\section{ACKNOWLEDGMENTS}

This work is a part of the VABHYOGAZ3 project supported by the French "Programme d'Investissements d'Avenir" under the supervision of ADEME, the French Energy and Environment Agency. The authors are grateful to the ADEME for its support for this project. This work is also the result of the collaboration between "Université de Toulouse, IMT Mines Albi, UMR CNRS 5302, Centre RAPSODEE," "Faculty of Chemical and Natural Resources Engineering, University Malaysia Pahang," and HERA-ALBHYON enterprise.

\section{REFERENCES}

Abbas, S.Z., Dupont, V., Mahmud, T., 2017. Kinetics study and modelling of steam methane reforming process over a NiO/ $\mathrm{Al}_{2} \mathrm{O}_{3}$ catalyst in an adiabatic packed bed reactor. Int. J. Hydrog. Energy 42, 2889-2903.

Abdollahifar, M., Haghighi, M., Babaluo, A.A., Talkhoncheh, S.K., 2016. Sono-synthesis and characterization of bimetallic $\mathrm{Ni}-\mathrm{Co} / \mathrm{Al}_{2} \mathrm{O}_{3}-\mathrm{MgO}$ nanocatalyst: effects of metal content on catalytic properties and activity for hydrogen production via $\mathrm{CO}_{2}$ reforming of $\mathrm{CH}_{4}$. Ultrason. Sonochem. 31, 173-183.

Abdullah, B., Ghani, N.A.A., Vo, D.-V.N., 2017. Recent advances in dry reforming of methane over Ni-based catalysts. J. Clean. Prod. 162, 170-185.

ADEME (2014a) Climat, Air, Energie.

ADEME (2014b) Alléger l'empreinte environnementale de la consommation des Français en 2030. Rapport de synthèse.

Air Liquide, n.d. https://www.engineering-airliquide.com/fr/reformage-du-methane-vapeur-productiondhydrogene (Accessed on May 16, 2018).

Akbari, E., Alavi, S.M., Rezaei, M., 2017. Synthesis gas production over highly active and stable nanostructured $\mathrm{Ni}-\mathrm{MgO}-\mathrm{Al}_{2} \mathrm{O}_{3}$ catalysts in dry reforming of methane: effects of $\mathrm{Ni}$ contents. Fuel 194, 171-179. 
Albarazi, A., Beaunier, P., Da Costa, P., 2013. Hydrogen and syngas production by methane dry reforming on SBA-15 supported nickel catalysts: on the effect of promotion by $\mathrm{Ce}_{0.75} \mathrm{Zr}_{0.25} \mathrm{O}_{2}$ mixed oxide. Int. J. Hydrog. Energy 38 (1), 127-139.

Al-Fatesh, A.S., 2017. Promotional effect of $\mathrm{Gd}$ over $\mathrm{Ni} / \mathrm{Y}_{2} \mathrm{O}_{3}$ catalyst used in dry reforming of $\mathrm{CH}_{4}$ for $\mathrm{H}_{2}$ production. Int. J. Hydrog. Energy 42 (30), 18805-18816.

Angeli, S.D., Monteleone, G., Giaconia, A., Lemonidou, A.A., 2014. State-of-the-art catalysts for $\mathrm{CH}_{4}$ steam reforming at low temperature. Int. J. Hydrog. Energy 39, 1979-1997.

Arandiyan, H., Peng, Y., Liu, C., Chang, H., Li, J., 2014. Effects of noble metals doped on mesoporous LaAlNi mixed oxide catalyst and identification of carbon deposit for reforming $\mathrm{CH}_{4}$ with $\mathrm{CO}_{2}$. J. Chem. Technol. Biotechnol. 89 (3), 372-381.

Argyle, M.D., Bartholomew, C.H., 2015. Heterogeneous catalyst deactivation and regeneration: a review. Catalysts 5 (1), 145-269.

Ay, H., Üner, D., 2015. Dry reforming of methane over $\mathrm{CeO}_{2}$ supported $\mathrm{Ni}$, $\mathrm{Co}$ and $\mathrm{Ni}$-Co catalysts. Appl. Catal. B Environ. 179, 128-138.

Ayodele, B.V., Khan, M.R., Lam, S.S., Cheng, C.K., 2016. Production of CO-rich hydrogen from methane dry reforming over lanthania-supported cobalt catalyst: kinetic and mechanistic studies. Int. J. Hydrog. Energy 41 (8), 4603-4615.

Ayodele, B.V., Khan, M.R., Cheng, C.K., 2017. Greenhouse gases abatement by catalytic dry reforming of methane to syngas over samarium oxide-supported cobalt catalyst. Int. J. Environ. Sci. Technol. 14 (12), 2769-2782.

Barroso-Quiroga, M.M., Castro-Luna, A.E., 2007. Kinetic analysis of rate data for dry reforming of methane. Ind. Eng. Chem. Res. 46, 5265-5270.

Barroso-Quiroga, M.M., Castro-Luna, A.E., 2010. Catalytic activity and effect of modifiers on Ni-based catalysts for the dry reforming of methane. Int. J. Hydrog. Energy 35 (11), 6052-6056.

Baysal, M., Gunay, M.E., Yildirim, R., 2017. Decision tree analysis of past publications on catalytic steam reforming to develop heuristics for high performance: a statistical review. Int. J. Hydrog. Energy 42, 243-254.

Bellido, J.D.A., Assaf, E.M., 2009. Effect of the $\mathrm{Y}_{2} \mathrm{O}_{3}-\mathrm{ZrO}_{2}$ support composition on nickel catalyst evaluated in dry reforming of methane. Appl. Catal. A Gen. 352, 179-187.

Cai, W., Ye, L., Zhang, L., Ren, Y., Yue, B., Chen, X., He, H., 2014. Highly dispersed nickelcontaining mesoporous silica with superior stability in carbon dioxide reforming of methane: the effect of anchoring. Mater. 7 (3), 2340-2355.

Cao, Y., Li, H., Zhang, J., Shi, L., Zhang, D., 2016. Promotional effects of rare earth elements (Sc, Y, $\mathrm{Ce}$, and $\mathrm{Pr}$ ) on $\mathrm{NiMgAl}$ catalysts for dry reforming of methane. RSC Adv. 6 (113), $112215-112225$.

Charisiou, N.D., Siakavelas, G., Papageridis, K.N., Baklavaridis, A., Tzounis, L., Avraam, D.G., Goula, M.A., 2016. Syngas production via the biogas dry reforming reaction over nickel supported on modified with $\mathrm{CeO}_{2}$ and/or $\mathrm{La}_{2} \mathrm{O}_{3}$ alumina catalysts. J. Nat. Gas Sci. Eng. 31, 164-183.

Chen, W.H., Lin, M.R., Jiang, T.L., Chen, M.H., 2008. Modeling and simulation of hydrogen generation from high-temperature and low-temperature water gas shift reactions. Int. J. Hydrog. Energy 33, 6644-6656.

De la Osa, A.R., De Lucas, A., Romero, A., Valverde, J.L., Sánchez, P., 2011. Kinetic models discrimination for the high pressure WGS reaction over a commercial CoMo catalyst. Int. J. Hydrog. Energy 36 (16), 9673-9684.

Djinović, P., Pintar, A., 2017. Stable and selective syngas production from dry $\mathrm{CH}_{4}-\mathrm{CO}_{2}$ streams over supported bimetallic transition metal catalysts. Appl. Catal. B Environ. 206, 675-682.

Factsage, n.d., http://www.factsage.com/ (Accessed on May 16, 2018). 
Ferreira-Aparicio, P., Benito, M.J., 2005. New trends in reforming technologies: from hydrogen industrial plants to multifuel microreformers. Catal. Rev. 47, 491-588.

Foo, S.Y., Cheng, C.K., Nguyen, T.H., Adesina, A.A., 2011. Kinetic study of methane $\mathrm{CO}_{2}$ reforming on Co-Ni/ $/ \mathrm{Al}_{2} \mathrm{O}_{3}$ and Ce-Co-Ni/ $/ \mathrm{Al}_{2} \mathrm{O}_{3}$ catalysts. Catal. Today 164 (1), 221-226.

Fouskas, A., Kollia, M., Kambolis, A., Papadopoulou, C., Matralis, H., 2014. Boron-modified Ni/ $\mathrm{Al}_{2} \mathrm{O}_{3}$ catalysts for reduced carbon deposition during dry reforming of methane. Appl. Catal. A Gen. 474, 125-134.

$\mathrm{Fu}, \mathrm{X}$., Su, H., Yin, W., Huang, Y., Gu, X., 2017. Bimetallic molybdenum nitride $\mathrm{Co}_{3} \mathrm{Mo}_{3} \mathrm{~N}$ : a new promising catalyst for $\mathrm{CO}_{2}$ reforming of methane. Cat. Sci. Technol. 7 (8), 1671-1678.

García-Vargas, J.M., Valverde, J.L., Dorado, F., Sánchez, P., 2014. Influence of the support on the catalytic behaviour of $\mathrm{Ni}$ catalysts for the dry reforming reaction and the tri-reforming process. J. Mol. Catal. A Chem. 395, 108-116.

Garcia-Vargas, J.M., Valverde, J.L., Diez, J., Dorado, F., Sanchez, P., 2015. Catalytic and kinetic analysis of the methane tri-reforming over a $\mathrm{Ni}-\mathrm{Mg} / \beta-\mathrm{SiC}$ catalyst. Int. J. Hydrog. Energy 40, 8677-8687.

Gould, T.D., Montemore, M.M., Lubers, A.M., Ellis, L.D., Weimer, A.W., Falconer, J.L., Medlin, J.W., 2015. Enhanced dry reforming of methane on Ni and Ni-Pt catalysts synthesized by atomic layer deposition. Appl. Catal. A Gen. 492, 107-116.

Habibi, N., Wang, Y., Arandiyan, H., Rezaei, M., 2016. Biogas reforming for hydrogen production: a new path to high-performance of $\mathrm{Ni} / \mathrm{MgAl}_{2} \mathrm{O}_{4}$ spinel catalysts. ChemCatChem 8 (23), $3600-3610$.

Habibi, N., Wang, Y., Arandiyan, H., Rezaei, M., 2017. Effect of substitution by Ni in $\mathrm{MgAl}_{2} \mathrm{O}_{4}$ spinel for biogas dry reforming. Int. J. Hydrog. Energy 42 (38), 24159-24168.

IEA, 2009. IEA bioenergy, task 37-energy from biogas and landfill gas. 2009.

IEA, 2017. IEA, renewables 2017, analysis and forecasts to 2022. 2017.

Jabbour, K., El Hassan, N., Casale, S., Estephane, J., El Zakhem, H., 2014. Promotional effect of Ru on the activity and stability of Co/SBA-15 catalysts in dry reforming of methane. Int. J. Hydrog. Energy 39 (15), 7780-7787.

Jiang, H., Li, H., Xu, H., Zhang, Y., 2007. Preparation of Ni/Mg $\mathrm{Mi}_{x}{ }_{1-x} \mathrm{O}$ catalysts and investigation on their stability in tri-reforming of methane. Fuel Process. Technol. 88 (10), 988-995.

Jones, G., Jakobsen, J.G., Shim, S.S., Kleis, J., Andersson, M.P., Rossmeisl, J., Abild-Pedersen, F., Bligaard, T., Helveg, S., Hinnemann, B., Rostrup-Nielsen, J.R., 2008. First principles calculations and experimental insight into methane steam reforming over transition metal catalysts. J. Catal. 259 (1), 147-160.

Kathiraser, Y., Oemar, U., Saw, E.T., Li, Z., Kawi, S., 2015. Kinetic and mechanistic aspects for $\mathrm{CO}_{2}$ reforming of methane over $\mathrm{Ni}$ based catalysts. Chem. Eng. J. 278, 62-78.

LeValley, T.L., Richard, A.R., Fan, M., 2014. The progress in water gas shift and steam reforming hydrogen production technologies—a review. Int. J. Hydrog. Energy 39, 16983-17000.

Li, X., Li, D., Tian, H., Zeng, L., Zhao, Z.J., Gong, J., 2017. Dry reforming of methane over $\mathrm{Ni} / \mathrm{La}_{2} \mathrm{O}_{3}$ nanorod catalysts with stabilized Ni nanoparticles. Appl. Catal. B Environ. 202, 683-694.

Lide, D.R., 2003-2004. Handbook of Chemistry and Physics, 84th ed. CRC Press, Boca Raton, FL.

Linde. n.d. http://www.lindeengineering.in/en/process_plants/hydrogen_and_synthesis_gas_plants/ gas_products/hydrogen/index.html (Accessed on May 16, 2018).

Liu, K., Song, C., Subramani, V., 2010. Hydrogen and Syngas Production and Purification Technologies. John Wiley \& Sons, Inc., Hoboken, New Jersey.

Lou, Y., Steib, M., Zhang, Q., Tiefenbacher, K., Horváth, A., Jentys, A., Liu, Y., Lercher, J.A., 2017. Design of stable $\mathrm{Ni} / \mathrm{ZrO}_{2}$ catalysts for dry reforming of methane. J. Catal. 356, 147-156. 
Ma, Q., Sun, J., Gao, X., Zhang, J., Zhao, T., Yoneyama, Y., Tsubaki, N., 2016. Ordered mesoporous alumina-supported bimetallic Pd-Ni catalysts for methane dry reforming reaction. Cat. Sci. Technol. 6 (17), 6542-6550.

Maciel, L.J., de Souza, A.E., Cavalcanti-Filho, V.O., Knoechelmann, A., de Abreu, C.A., 2010. Kinetic evaluation of the tri-reforming process of methane for syngas production. React. Kinet. Mech. Catal. 101 (2), 407-416.

Mahoney, E.G., Pusel, J.M., Stagg-Williams, S.M., Faraji, S., 2014. The effects of Pt addition to supported $\mathrm{Ni}$ catalysts on dry $\left(\mathrm{CO}_{2}\right)$ reforming of methane to syngas. J. $\mathrm{CO}_{2}$ Util. 6, 40-44.

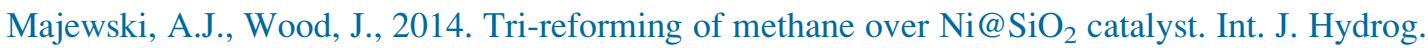
Energy 39 (24), 12578-12585.

Nguyen, V.N., Blum, L., Peters, R., 2014. Operational behavior and reforming kinetics over Ni/YSZ of a planar type pre-reformer for SOFC systems. Int. J. Hydrog. Energy 39, 7131-7141.

Nguyen, V.N., Deja, R., Peters, R., Blum, L., 2016. Methane/steam global reforming kinetics over the Ni/YSZ of planar pre-reformers for SOFC systems. Chem. Eng. J. 292, 113-122.

Omoregbe, O., Danh, H.T., Abidin, S.Z., Setiabudi, H.D., Abdullah, B., Vu, K.B., Vo, D.-V.N., 2016. Influence of lanthanide promoters on Ni/SBA-15 catalysts for syngas production by methane dry reforming. Procedia Eng. 148, 1388-1395.

Omoregbe, O., Danh, H., Nguyen-Huy, C., Setiabudi, H., Abidin, S., Truong, Q., Vo, D.-V.N., 2017. Syngas production from methane dry reforming over Ni/SBA-15 catalyst: effect of operating parameters. Int. J. Hydrog. Energy 42 (16), 11283-11294.

Osazuwa, O.U., Setiabudi, H.D., Abdullah, S., Cheng, C.K., 2017. Syngas production from methane dry reforming over $\mathrm{SmCoO}_{3}$ perovskite catalyst: kinetics and mechanistic studies. Int. J. Hydrog. Energy 42 (15), 9707-9721.

Özkara-Aydınoğlu, Ş., Aksoylu, A.E., 2013. A comparative study on the kinetics of carbon dioxide reforming of methane over $\mathrm{Pt}-\mathrm{Ni} / \mathrm{Al}_{2} \mathrm{O}_{3}$ catalyst: effect of $\mathrm{Pt} / \mathrm{Ni}$ ratio. Chem. Eng. J. $215,542-549$.

Pakhare, D., Spivey, J., 2014. A review of dry $\left(\mathrm{CO}_{2}\right)$ reforming of methane over noble metal catalysts. Chem. Soc. Rev. 43 (22), 7813-7837.

Pechimuthu, N.A., Pant, K.K., Dhingra, S.C., Bhalla, R., 2006. Characterization and activity of K, $\mathrm{CeO}_{2}$, and $\mathrm{Mn}$ promoted $\mathrm{Ni} / \mathrm{Al}_{2} \mathrm{O}_{3}$ catalysts for carbon dioxide reforming of methane. Ind. Eng. Chem. Res. 45 (22), 7435-7443.

Pichas, C., Pomonis, P., Petrakis, D., Ladavos, A., 2010. Kinetic study of the catalytic dry reforming of $\mathrm{CH}_{4}$ with $\mathrm{CO}_{2}$ over $\mathrm{La}_{2-x} \mathrm{Sr}_{x} \mathrm{NiO}_{4}$ perovskite-type oxides. Appl. Catal. A Gen. 386 (1), $116-123$.

Pino, L., Vita, A., Cipitì, F., Laganà, M., Recupero, V., 2011. Hydrogen production by methane trireforming process over Ni-ceria catalysts: effect of La-doping. Appl. Catal. B Environ. 104, 64-73.

Pino, L., Vita, A., Laganà, M., Recupero, V., 2014. Hydrogen from biogas: catalytic tri-reforming process with $\mathrm{Ni} / \mathrm{LaCeO}$ mixed oxides. Appl. Catal. B Environ. 148, 91-105.

Qian, L., Ma, Z., Ren, Y., Shi, H., Yue, B., Feng, S., Xie, S., 2014. Investigation of La promotion mechanism on Ni/SBA-15 catalysts in $\mathrm{CH}_{4}$ reforming with $\mathrm{CO}_{2}$. Fuel 122, 47-53.31.

Ray, K., Sengupta, S., Deo, G., 2017. Reforming and cracking of $\mathrm{CH}_{4}$ over $\mathrm{Al}_{2} \mathrm{O}_{3}$ supported $\mathrm{Ni}$, Ni-Fe and Ni-Co catalysts. Fuel Process. Technol. 156, 195-203.

Rong-jun, Z., Guo-fu, X., Ming-feng, L., Yu, W., Hong, N., Da-dong, L., 2015. Effect of support on the performance of Ni-based catalyst in methane dry reforming. J. Fuel Chem. Technol. 43 (11), 1359-1365.

Rostrup-Nielsen, J.R., 2002. Syngas in perspective. Catal. Today 71, 243-247. 
Sarkar, B., Goyal, R., Pendem, C., Sasaki, T., Bal, R., 2016. Highly nanodispersed Gd-doped Ni/ZSM-5 catalyst for enhanced carbon-resistant dry reforming of methane. J. Mol. Catal. A Chem. 424, 17-26.

Selvarajah, K., Phuc, N.H.H., Abdullah, B., Alenazey, F., Vo, D.-V.N., 2016. Syngas production from methane dry reforming over $\mathrm{Ni} / \mathrm{Al}_{2} \mathrm{O}_{3}$ catalyst. Res. Chem. Intermed. 42 (1), 269-288.

Shah, Y.T., 2017. Chemical Energy from Natural and Synthetic Gas. CRC Press, Boca Raton, FL.

Shamskar, F.R., Meshkani, F., Rezaei, M., 2017. Preparation and characterization of ultrasound-

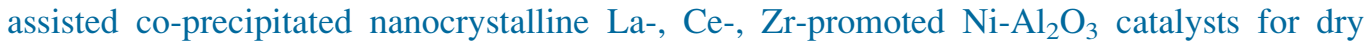
reforming reaction. J. $\mathrm{CO}_{2}$ Util. 22, 124-134.

Singh, S.A., Madras, G., 2016. Sonochemical synthesis of $\mathrm{Pt}, \mathrm{Ru}$ doped $\mathrm{TiO}_{2}$ for methane reforming. Appl. Catal. A Gen. 518, 102-114.

Singha, R.K., Das, S., Pandey, M., Kumar, S., Bal, R., Bordoloi, A., 2016. Ni nanocluster on modified $\mathrm{CeO}_{2}-\mathrm{ZrO}_{2}$ nanoporous composite for tri-reforming of methane. Cat. Sci. Technol. 6 (19), 7122-7136.

Solov'ev, S.A., Gubareni, Y.V., Kurilets, Y.P., Orlik, S.N., 2012. Tri-reforming of methane on structured Ni-containing catalysts. Theor. Exp. Chem. 48 (3), 199-205.

Song, C., Pan, W., 2004. Tri-reforming of methane: a novel concept for catalytic production of industrially useful synthesis gas with desired $\mathrm{H}_{2} / \mathrm{CO}$ ratios. Catal. Today 98 (4), 463-484.

Soria, M.A., Mateos-Pedrero, C., Marín, P., Ordonez, S., Guerrero-Ruiz, A., Rodríguez-Ramos, I., 2012. Kinetic analysis of the $\mathrm{Ru} / \mathrm{SiO}_{2}$-catalyzed low temperature methane steam reforming. Appl. Catal. A Gen. 413-414, 366-374.

Temkin, M.I., 1979. Eley, H.P.D.D., Paul, B.W. (Eds.), Advances in Catalysis. Academic Press, New York, pp. 173-291.

Usman, M., Daud, W.W., Abbas, H.F., 2015. Dry reforming of methane: influence of process parameters-a review. Renew. Sust. Energ. Rev. 45, 710-744.

Walker, D.M., Pettit, S.L., Wolan, J.T., Kuhn, J.N., 2012. Synthesis gas production to desired hydrogen to carbon monoxide ratios by tri-reforming of methane using Ni-MgO-(Ce, $\mathrm{Zr}) \mathrm{O}_{2}$ catalysts. Appl. Catal. A Gen. 445, 61-68.

Wang, C., Zhang, Y., Wang, Y., Zhao, Y., 2017. Comparative studies of non-noble metal modified mesoporous $\mathrm{M}-\mathrm{Ni}-\mathrm{CaO}-\mathrm{ZrO}_{2}(\mathrm{M}=\mathrm{Fe}, \mathrm{Co}, \mathrm{Cu})$ catalysts for simulated biogas dry reforming. Chin. J. Chem. 35 (1), 113-120.

Wang, N., Yu, X., Wang, Y., Chu, W., Liu, M., 2013. A comparison study on methane dry reforming with carbon dioxide over $\mathrm{LaNiO}_{3}$ perovskite catalysts supported on mesoporous SBA-15, MCM-41 and silica carrier. Catal. Today 212, 98-107.

Wang, N., Xu, Z., Deng, J., Shen, K., Yu, X., Qian, W., Wei, F., 2014. One-pot synthesis of ordered mesoporous $\mathrm{NiCeAl}$ oxide catalysts and a study of their performance in methane dry reforming. ChemCatChem 6 (5), 1470-1480.

Wang, Y., Yao, L., Wang, S., Mao, D., Hu, C., 2018. Low-temperature catalytic $\mathrm{CO}_{2}$ dry reforming of methane on Ni-based catalysts: a review. Fuel Process. Technol. 169, 199-206.

Wei, J., Iglesia, E., 2004a. Reaction pathways and site requirements for the activation and chemical conversion of methane on Ru-based catalysts. J. Phys. Chem. B 108, 7253-7262.

Wei, J., Iglesia, E., 2004b. Isotopic and kinetic assessment of the mechanism of reactions of $\mathrm{CH}_{4}$ with $\mathrm{CO}_{2}$ or $\mathrm{H}_{2} \mathrm{O}$ to form synthesis gas and carbon on nickel catalysts. J. Catal. 224 (2), $370-383$.

Xie, T., Zhao, X., Zhang, J., Shi, L., Zhang, D., 2015. Ni nanoparticles immobilized Ce-modified mesoporous silica via a novel sublimation-deposition strategy for catalytic reforming of methane with carbon dioxide. Int. J. Hydrog. Energy 40 (31), 9685-9695. 
Xu, J., Froment, G., 1989. Methane steam reforming, methanation and water-gas shift. 1. Intrinsic kinetics. AICHE J. 35, 88-96.

Xu, J., Saeys, M., 2007. First principles study of the coking resistance and the activity of a boron promoted Ni catalyst. Chem. Eng. Sci. 62 (18), 5039-5041.

Yao, L., Galvez, M.E., Hu, C., Da Costa, P., 2017. Mo-promoted Ni/ $\mathrm{Al}_{2} \mathrm{O}_{3}$ catalyst for dry reforming of methane. Int. J. Hydrog. Energy 42 (37), 23500-23507.

Zarei, M., Meshkani, F., Rezaei, M., 2016. Preparation of mesoporous nanocrystalline Ni- $\mathrm{MgAl}_{2} \mathrm{O}_{4}$ catalysts by sol-gel combustion method and its applications in dry reforming reaction. Adv. Powder Technol. 27 (5), 1963-1970.

Zeppieri, M., Villa, P.L., Verdone, N., Scarsella, M., De Filippis, P., 2010. Kinetic of methane steam reforming reaction over nickel- and rhodium-based catalysts. Appl. Catal. A Gen. 387, 147-154.

Zhang, L., Zhang, Q., Liu, Y., Zhang, Y., 2016. Dry reforming of methane over Ni/MgO- $\mathrm{Al}_{2} \mathrm{O}_{3}$ catalysts prepared by two-step hydrothermal method. Appl. Surf. Sci. 389, 25-33.

Zhang, S., Muratsugu, S., Ishiguro, N., Tada, M., 2013. Ceria-doped Ni/SBA-16 catalysts for dry reforming of methane. ACS Catal. 3 (8), 1855-1864.

Zhang, S., Shi, C., Chen, B., Zhang, Y., Zhu, Y., Qiu, J., Au, C., 2015. Catalytic role of $\beta-\mathrm{Mo}_{2} \mathrm{C}$ in DRM catalysts that contain Ni and Mo. Catal. Today 258, 676-683.

Zou, H., Chen, S., Huang, J., Zhao, Z., 2016. Effect of additives on the properties of nickel molybdenum carbides for the tri-reforming of methane. Int. J. Hydrog. Energy 41 (38), 16842-16850. 